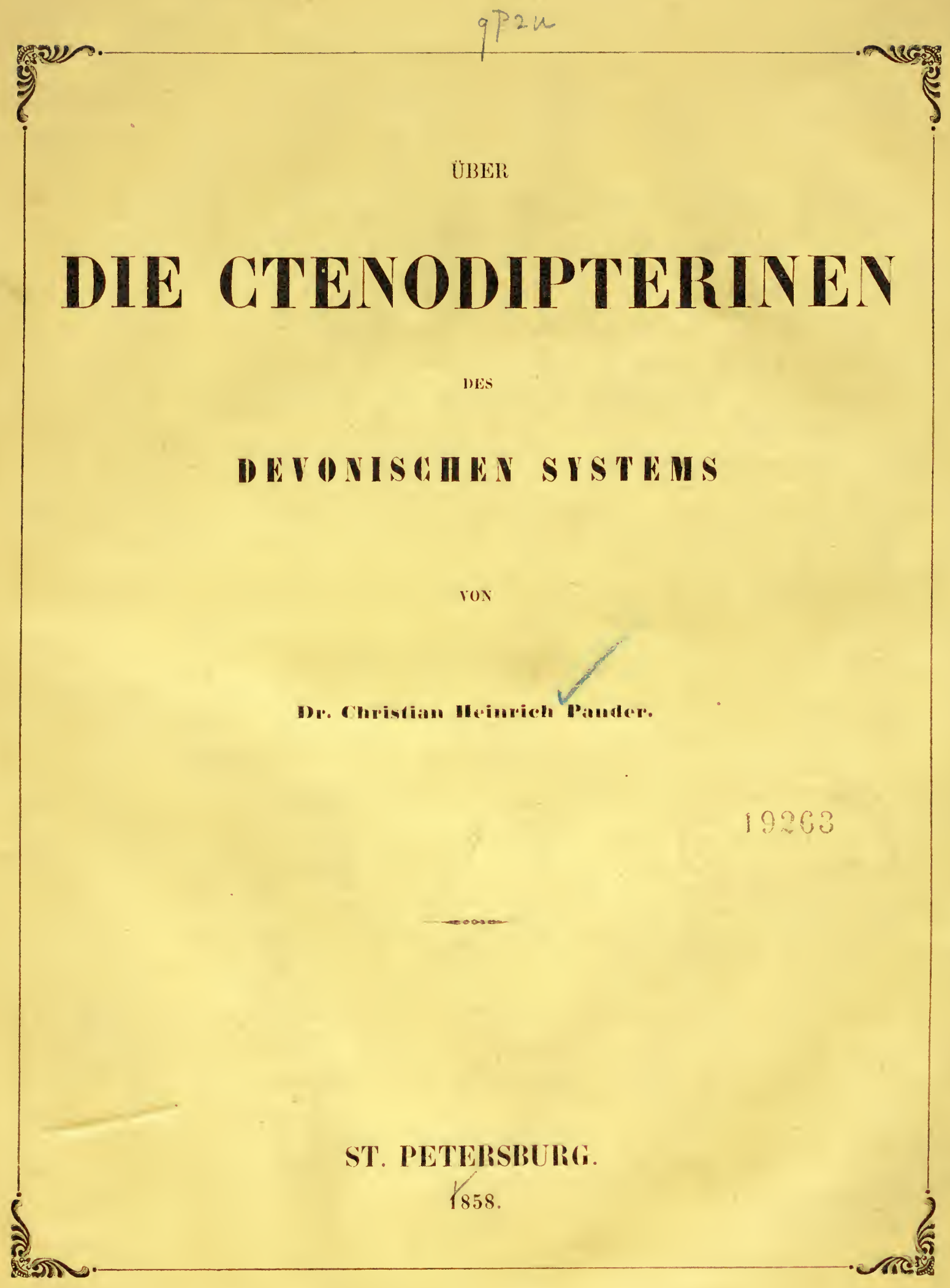



ÜBER

\section{DIE CTENODIPTERINEN}

DES

\section{DEVONISCHEN S I S T E M S}

VON

Dr. Christian Heinrich Pander.

19263

ST. PETERSBURG.

BCCHDRLCKEREI DFR KAISERLICHEN AKADEMIE DER WISSENSCHAFTEN.

K 858. 
Zum Druck erlaub t

unter der Bedingung, dass nach beendiglem Drucke die gesetzliche Auzabl ron Exemplaren an das Censur-Comité eingesandt werde. St. Petersburg, den 10. Juni 1858.

A. Freigang. Censor. 


\section{E I N L E I T U N G.}

Die Subklasse der Ganoiden, zuerst von Agassiz nach ausgestorbenen Geschlechtern errichtet, von allen Palaeontologen als richtig anerkannt und von J. Müller durch Untersuchungen an jetzt noch lebenden Fischen bekräftigt, hat in der Systematick so festen Fuss gefasst, dass sie wol schwerlich erschïttert werden konnte. Wenn eine Classification, hauptsächlich auf äussere Characktere gegrïndet, auf der Gestalt und Beschaffenheit der harten Theile, der Schuppen, Knochen und Zähne, die einzigen Ueberresten einer Fauna der frïheren Periode der Erde, gestïtzt, durch die Anatomie lebender verwandter Geschopfe in Uebereinstimmnng gebracht wird, so kann wol kein Zweifel gegen die Richtigkeit derselben aufkommen. Es frägt sich nun aber, genügt die Errichtung dieser Subklasse, sie mag als solche den übrigen coordinirt oder untergeordnet sein, um alle die verschiedenen Formen ausgestorbener Fische, die jetzt unter ein Haupt vereinigt werden, zu umfassen und das ist es, was wir wol bezweifeln möchten.

Wir haben schon unter den Placodermen Thiere kennen gelernt, die wol schwerlich nur eine Familie der Ganoiden bilden dürfen, da sie auch nicht das Geringste mit ihnen gemein haben. Die Verbindung zwischen Kopf und Körper erinnert sehr an eine ähnliche bei den Inseckten vorkommende, an den Gliedern, die zur Bewegung des Thieres dienten, ist eine gewisse Aehnlichkeit mit denen der Crustacien nicht zu verkennen und es möchte jetzt noch mancher Zweifel 
über ihre Stellung im Systeme entstehen, wenn nicht ihre fest zusammenhängenden Panzer aus wirklicher, nur den Wirbelthieren zukommender Knochensubstanz beständen.

Wenn J. Müller') die vielfachen Klappen des Arterienstieles, Muskelbele'g desselben, Mangel der Kreuzung der Sehnerven, freie Kiemen und Kiemendeckel, abdominale Bauchflossen, die Spiralklappe im Darm, Verzweigung der Kiemenarterie zum Kiemendeckel und den Bau des Auges als absolute Characktere der Ganoiden betrachtet, so bleiben dem Palaeontologen von diesen Kennzeichen nur der Kiemendeckel und die Stellung der Bauchflossen als sichere übrig, die aber beide nicht hinreichend sind, um einen Ganoiden von einem anderen Fische der Subklasse der Teleostei zu unterscheiden. Was dic Spiralklappe des Darmes anbelangt, so bezeugen die so häufig in Gemeinschaft mit anderen Ueberresten ausgestorbener Fische vorkommenden Coprolithen hinlänglich die Anwesenheit derselben und namentlich im A. R. Sandsteine Russlands. Beide Formen, sowol die in schraubenformigen Windungen, als die der Länge nach segelartig angewachsenen und dabei spiralförmig gerollten, sind nicht selten. Es ist aber ein höchst seltener Fall diese Coprolithen, mit Gewissheit den Thieren zuzutheilen, von denen sie herstammten und da in denselben Schichten auch Fragmente von Elasmobranchii vorkommen, so wird die Stütze, die die Coprolithen geben könnten, sehr schwankend.

Die Characktere welche Herrn Agas siz hauptsächlich bewogen, die Ganoiden als eine eigene Unterklasse der Fische aufzustellen, liegen in iliren harten Hautbedeckungen, in der Gestalt, der Structur, in dem durch eine obere Schicht Ganoins veranlassten, glänzenden emaillartigen glatten Ansehen und der Aneinanderfügung der Schuppen. Unter den lebenden Fischen giebt es nur zwei Geschlechter, deren Schuppen in vieler Hinsicht eine gewisse Aelnnlichkeit mit denen der ausgestorbenen besitzen und diese beiden Genera, Polypterus und Le-

1) Ueber den Bau und die Grenzen der Ganoiden pag. 142 und pag. 207 in der Abhandlung der königl. Akad. der Wiss. zu Berlin 1844. 
pidosteus wurden deswegen als die analogen Ueberreste der ausgestorbenen Ganoiden und namentlich aller Knochenfische der älteren Formationen, bis zur Kreide betrachtet. Ihre Organisation diente hauptsächlich dazu, durch anatomische Characktere diese Unterklasse fest zu begründen.

Nun ist es aber wol merkwürdig, dass im ganzen devonischen Systeme Russlands auch nicht ein einżiger Fisch vorkömmt, dessen Schuppen mit denen der beiden noch lebenden oben erwähnten Geschlechtern völlig gleich sind, denn wo Glanz, Glätte, Verbindung und Gestalt der Schuppen ähnlich ist, ist die mikroskopische Structur eine ganz andere und wo letztere übereinstimmt, eine Uebereinstimmung die nur darin besteht, dass die Schuppen eine wahre knöcherne Structur haben, ist die Gestalt verschieden, die Verbindung eine ganz andere und die Oberfläche mit Tuberkeln und erhabenen Rippen geschmückt.

Schliessen wir die gepanzerten Placodermen, die doch wol von den Ganoiden getrennt werden müssen aus, so finden wir am häufigsten runde, sich dachziegelartig deckende, mit erhabenen Hockern und rippenartigen Streifen gezierte Schuppen, wie die von Glyptolepis, Holoptychius u. s. w. rhomboidale, auf gleiche Weise geschmiickte und endlich glatte, die ihrer äusseren Gestalt nach am meisten denen von Polypterus und Lepidosteus sich nähern, die aber durch ihre mikroskopische Structur von ihnen ganz verschieden sind. Die Schuppen der beiden lebenden Geschlechter, dem äusseren Ansehen nach einander schr ähnlich, unterscheiden sich bedeutend in ihrem Baue von einander.

Bei Lepidosteus ${ }^{1}$ ) besteht die ganze Schuppe aus Isopedin, bei Polypte-

1) Leider war es uns nicht möglich die Schuppen von Lepidosteus selbst zu untersuchen, wir bezichen uns daher auf die Abbildungen, die Ag. Tom. 2 Tab. H Fig. 8 und 9, Williamson Philos. Trans. 1849 pars 2 Tab. 11 Fig. 1 und 2, und Huxley: Descriptive and Illustrated Catalogue of the Histological Series contained in the Museum of the Royal College of Surgeons of England. Prepared for the Microscope. Volume II 1855 pag. 75 Tab. 6 Fig. 16-22. gegeben haben. Nach diesen zu urtheilen besteht die ganze Schuppe aus Isopedin, d. h. aus horizontalen und parallel über einander liegenden Knochenlamellen, durch welche die Gefässkanäle in geringer Anzalll vertical von der unteren Fläche gegen die obere hinaufsteigen, bei Polypterus hingegen aus der wahren Knochensubstanz, in welcher die Markkanäle geschlängelt, häufig mit ein- 
rus aus wahrer Knochensubstanz; ersteres bildet bei der grössten Anzahl devonischer Schuppen Russlands die Basis, letztere häufig die obere Schicht, gewohnlich aber nur die mittlere, da bei allen glatten Schuppen, wie bei Osteolepis, Diplopterus u. s. w. und also namentlich bei denen, die scheinbar eine so grosse Aehnlichkeit mit den jetzt noch lebenden haben, ihr noch eine dritte Schicht mit Kosmin oder Dentine mit feinen ausstrahlenden Röhrchen aufgelagert ist. Eine ähnliche Bildung findet bei den Ctenodipterini Statt $\left.{ }^{\mathbf{1}}\right)$. Die vollständigste Ausbildung der Schuppen und Kopfknochen, die wir kennen, zeigt sich bei Osteolepis, Diplopterus und Megalichthys. Diese Schuppen besitzen nicht nur als Basis das Isopedin, bestehen in der Mitte aus wahrer Knochensubstanz, welchen das Kosmin, von Ganoin bedeckt, aufgelagert ist, sondern ruhen ausserdem noch auf einer Basis von wahren Knochen. Am Kopfe bildet dieser Knochen die Unterlage der Schuppen, an den Schuppen des Körpers ragt er als Kiel auf der unteren Fläche hervor, dessen hervorstehender Fortsatz zur Gelenkverbindung mit der benachbarten Schuppe dient.

Es ist, wie man schon aus dem Vorigen ersehen wird, durchaus nicht unsere Absicht, weder gegen die Subklasse der Ganoiden etwas einzuwenden, noch die Verwandtschaft der Lepidosteini, Polypterini und Amiae, so wie der Accipenserini und Spatulariae mit ausgestorbenen Familien der alten Formationen zu bestreiten, wir glauben im Gegentheil, dass die Gründe, die so meisterhaft aus einandergesetzt sind, vollkommen genügen die Errichtung der Unterklasse zu rechtfertigen und die Verwandtschaft deutlich darzustellen. Wir werden selbst in Zukunft eine grosse Uebereinstimmung zwischen den lebenden und mehreren ausgestorbenen Geschlechtern, denen ein gemeinschaftlicher Typus zu Grunde lag, nachweisen, wir glauben nur, dass der Umfang, der der Unterklasse der Ganoiden jetzt gegeben wird, zu gross ist, wenn sie alle die Fische, abgesehen von den Placoiden, die vor der Kreideperiode erschie-

ander anastomosirend, netzartige Maschen bilden und die Knochenzellen die Windungen der Gefässe concentrisch umgeben.

1) Tab. 5 Fig. 17. 
nen, umfasst, und dass gewiss eben so starke Gründe, als die, die Trennung der Leptocardii von den Marsipobranchii veranlasste, vorhanden sind, um die, jetzt unter der gemeinschaftlichen Benennung der Ganoiden vereinigten Fische von einander zu sondern.

Herr J. Müller betrachtet die Ganoiden als eine Abtheilung, die den Gyclostomen, den übrigen Knochenfischen und den Selachiern coordinirt ist ${ }^{1}$ ) und scharf geschieden zwischen den beiden letzteren steht ${ }^{2}$ ), indem sie Characktere in einer dritten eigenthümlichen Form combinirt. Schwerlich wird man eine Familie, denn zu einer solchen glauben wir das bisher als Dipterus bekannte Geschlecht zu erheben, finden, die diese Combinationen so vollständig besitzt, als die, die wir jetzt als Cteno dipterini zu beschreiben beabsichtigen. Als Malocopterygii abdominales schon von Cuvier, Valenciennes und Pentland richtig erkannt, als Heterocerci den Lepidosteinen, Accipenserinen und Plogiostomen sich anschliessend, durch das Vorhandensein eines vollständigen Kiemendeckelapparates den Teleostei verwandt, in der Structur des unteren und mittleren Theiles der glatten und glänzenden Schuppen des Korpers und der Koplknochen, mit denen von Polyterus und Accipenser, in der oberen Schicht dieser harten Theile mit dem schagrin lebender und ausgestorbener Placoiden übereinstimmend, sind ihre Gaumen und Unterkiefer mit Zähnen besetzt, die von den meisten Forschern als den Cestracionten angehörig betrachtet wurden. Sind unsere Vermuthungen gegründet, dass diejenigen Wirbelkorper oder wenigstens ein Theil von denen, die in grosser Menge in devonischen Mergeln vorkommen, diesem Genus angehoren, so schliessen sich an die oben erwähnten Angaben noch harte Wirbelkörper an, die die Structur der Plagiostomen wirbel besitzen, und von welchen aus, wenn auch nicht mit ihnen zusammengewachsen, processus spinosi ausgingen. Ausser den Geschlechtern, die wir glauben den Ctenodipterini zurechnen zu konnen, haben wir hier noch einige andere angeschlossen, deren Zähne in Rücksicht ihrer mikrokopischen Structur viele

1) Ueber den Bau und die Grenzen der Ganoiden pag. 122.

2) Ueber den Bau und die Grenzen der Ganoiden pag. 124. 
Uebereinstimmung mit ihnen zeigen, obgleich in anderer Hinsicht doch eine grosse Abweichung Statt findet. Was das Genus Holodus anbelangt, so deutet der merkwürdige Bau des Kopfes, der so auffallend verschieden von allem bis jetzt aus den älteren Formationen Bekanntem ist, auf eine neue Familie, deren Hautbedeckungen, wie bei den Ctenodipterini aus einer knöchernen Substanz bestand, die nach aussen durch eine Kosminschicht geschützt wurde. Das Wenige, das wir unseren Lesern von dieser noch unbekannten Familie mittheilen können, wird hoffentlich hinreichen spätere Forscher auf dasselbe aufmerksam zu machen und die Härte der Zähne und Knochen verspricht noch eine reiche Ausbeute derselben in den Umgebungen von Orel. Von dem Genus Ptyctodus haben wir leider keine Hoffnung mehr noch andere gut erhaltene Ueberreste, als die hier beschriebenen Zähne anzutreffen, da diese wahrscheinlich die einzigen Nachbleibsel eines ausgestorbenen Knorpelfisches waren. Ein gleiches Schicksal steht wol auch denjenigen Zähnen bevor, welche auf der 7-ten Tafel Fig. 12 abgebildet sind. Aus den obersten Schichten devonischen Systemes herstammend, der Form und Structur nach mit dem Genus Helodus aus dem Bergkalke übereinstimmend, haben wir sie hier nur mit aufgenommen, um alle die einander in der Structur so ähnlich gebildeten, einer Formation angehorigen Zähne, zu vereinigen. 


\section{Teber die Familie der Grenodipterini.}

Die für die Wissenschaft so fruchtbaren, schon vor lïnger als dreissig Jahren in Gross-Britannien begonnenen und seit dieser Zeit forlgesetzten geognostischen Untersuchungen der Herren Sedgwick und Murchison, denen wir so viel Licht über das Uebergangsgebirge verdankien, hatten auch auf die Kenntniss der ichthyologischen Fauna der ältesten sedinentären Schichten der Erde einen grossen Einfluss. Durch sie wurden, die in den Steinbrüchen von Banniskirk aufgefundenen Fischüberreste zuerst bekannt ') und ihr Vorkommen, durch spätere weiter fortgesetzte Nachforschungen, in allen dunkeln Schiefern von Cadithness bis auf die gegenüberliegenden Orkney-Inseln nachgewiesen. Die Untersuchung und Yergleichung der ersten, damals einzigen Exemplaren wurde von den Herren Sedgwick und Nurchison Herrn Baron Cuvier, der höchsten Autoritit jener Zeit, überlassen. Cuvier's richtiger Scharfblick erkannte, ungeachtet des schlechten Zustindes der ihm ïbergegebenen Fischabdriicke, an der Gestalt des zugespitzten Schwanzes, dessen Strahlen sich alle an der unteren Seite befinden, die Verwandischaft dieser:deronischen Ueberreste mit zweien jetzt noch lebenden Fischen dem Accipenser und Lepidosteus und neigte sich mehr dafür sie dem letzteren, wegen der Aehlnlichkeil im Schuppenbalu anzuschliessen; er vermuthete schon damals, obgleich er die paarigen Flossen, namentlich die des Bauches nicht auffinden lionnte, dass sie wie diese zu den malacopterygii abdominales gehören mïssten. Durch vollstindigere, in spïterer Zeit, aufgefundene Exemplare, welche die Herren Valenciennes und Pentland untersuchten, wurden die Ansichten von Curier nicht nur bestitigt, sondern noch genauere Beobachtungen hilızugefiigt, diese Fische wegen ilırer doppelten Rückenflosse Dipteri benannt, ihre Schuppen als runde sich dachziegelartig deckende beschrieben und nach der Grösse, Stellung und Gestalt der Flossen mehrerer Species wie Dipt.brachypygopterus, Dipt. macropygopterus, Dipt. Valenciennesii und Dipt. macrolepidohs festgestellt.

1) Geol. Trans, 2 Ser. Tom. 3. On the Structure and Relations of the Depusits contained between the Primary Rocks and the Oclitic Series in the North of Scolland. By the Rew. Adam Sedgwick and Roderick Impey llurchison. Esq. 
Herr Agassiz dem anfangs nur unvollständige Exemplare zu Gebote standen, konnte sich nicht von dem Vorhandensein zweier Rückenflossen überzeugen, er vermuthete, dass die französischen Gelehrten durch mehrere abgebrochene Strahlen vom vorderen Theile der einzigen Dorsalflosse zu einer irrigen Annahme veranlasst seien und nannte dieses Gesclilecht, wegen der so sehr nach hinten gerückten Flossen, Catopterus ${ }^{1}$ ). Er beschreibt die Schuppen dieses Fisches als rhomboidale und rechnet denselben zu seinen Lepidoiden, deren Faniliencharackter hauptsïchlich darin besteht, dass ihre Kiefer mit bürstenförmigen Zähnen, ihr Körper mit rhomboidalen Schuppen besetzt sind. Als Herr Agassiz später Gelegenheit hatte die Originalexemplare, die den Herren Cuvier, Valenciennes und Pentland zu ihrer Beschreibung gedient hatten, in der Sammlung der geologischen Gesellschaft in London, selbst zu betrachten, überzeugte er sich an diesen von der wirklichen Anwesenheit zweier Dorsalflossen und nahm dìher die frühere vorgeschlagene Benennung Dipterus ${ }^{2}$ ) für dieses Genus an.

Herr Agassiz ging aber noch einen Schritt weiter, er hatte auf seiner Reise durch Gross-Britannien in Edinburg, in der auf der Insel Pumona, einer der Orkney-Inseln, von Herrn Trail gemachten Sammlung devonischer Fische, sehr wol erhaltene Exemplare gefunden, die von Dipterus verschieden waren, aber darin mit diesem Geschlechte übercinstimmten, dass sie gleichfalls zwei Dorsilllossen besassen, aber ausserdem doch zwei anale haben sollten. Die verschiedene Stellung dieser doppelten Flossen, sowol des Ruickens wie des Afters, zu einander, veranlassten Herrn Agassiz aus diesen, zwei neue Genera Diplopterus und Pleiopterus ${ }^{3}$ ) zu bilden. Nach seiner Rückkehr in London nahm er die Exemplare von Dipterus von neuem zum Vergleich ror und da er an ihnen gleichfalls zwei Analflossen zu entdecken glaubte, so setzte er, zum Unterschiede von den beiden obengenannten Geschlechtern den Charackter des Genus Dipterus folgendermassen fest: Zwei dorsale, zwei ïhnlichen analen entgegengesetzt, nit einem Schwanze wie bei Palaeoniscus $\left.{ }^{*}\right)$.

Die Anwesenheit zweier Analflossen, welche von Herrn Agassiz den Geschlechtern Dipterus, Diplopterus, Osteolepis (Pleiopterus Ag.) und späier auch Glyptolepis zugeschrieben wurde, ist in der Ichthyologie etwas so Befremdendes, dass wir es für unsere Pflicht hielten, dieser Angabe unsere besondere Aufnerksamkeit zu schenken. Wir überzeugten uns bald, dass bei Dipterus eine Verwechselung mit der Ventralflosse zu diesem Irrthume Veranlassung gegeben hatte und können nach genaueren Untersuchungen an Exemplaren der übrigen genannten Geschlechtern versichern, dass kein einziger von ihnen eine doppelte anale besitzt.

Herr Agassiz citirt zum Beweise des Vorhandenseins der vorderen analen, die in der Abhand-

1) Recherches sur les poiss. foss. Tom. 2 pag. 23.

2) ibidem pag. 112.

3) Procced. Brit. Ass. pag. 75 recherches Tom. 2 pars 1 pag. 113.

4) Recherches etc. Tom. 2 pars 1 pag. 113. 
lung der Herren Sedgwick und Murchison gegebene Albildung aut Tab. 15 Fig. 3 \%). In dieser Zeichnung soll die anale über die Schuppen des Körpers zurïckgeschlagen sein. Ein Blick auf die Tifel wird aber wol Jeden davon überzeugen, dass eine unpaarige Flosse, die mit ihrem oberen Rande an deın unteren des Körpers zum Theil hätte angewachsen sein müssen, unmöglich eine solche Lage annehmen kann und dass von ihr die Endigungen aller Flossenstrahlen nach oben, hinten und unten unmöglich so deutlich und unverletzt hätten hervortreten können. Nur eine parige Flosse kann in dieser Lage auf die Seite des Körpers zurückgeschlagen sein. Sowol in der Skizze, die Cuvier, in der schon mehrere Ilale erwähnten Abhandlung in den Transactions der geologischen Gesellschift, als in denen, die Agassiz in seinen recherches Tom. 1, Tab. A. Fig. 2 und 0ld Red Tab. E, Fig. 1 gegeben hat, sind die Ventralflossen viel zu weit nach vorn gerückt. Diese ihnen fälschlich gegebene Stellung ist vielleicht mit eine. Ursache weshalb man einen grossen Theil der ausgestorbenen Fische der älteren Formationen eher mit dem Lepidosteus, als dem Polypterus verwandt, betrachtet, wälırend bei Ihpterus und mehreren anderen gleichzeitigen Geschlechtern die Ventralflosse durch ihre Lage sich doch weit mehr dem letzteren Genus anschliesst. Ueberhaupt ist es inerkwürdig zu sehen, wie Polypterus so ganz in den Hintergrund gestellt wird, Herr J. Müller ${ }^{2}$ ) sagt ausdrücklich: aFür den Polypterus kenne ich unter allen fossilen Ganoiden keine Analogie» und Herr Pictet ${ }^{3}$ ) wiederholt dasselbe gleichfalls: đducun fossile n’a été rapproché de ce genre remarquable». Wir werden in Zukunft sehen, dass, wenn man überhaupt ein Recht hat, wie es doch höchst wahrscheinlich ist, die ausgestorbenen Geschlechter der devonischen Formation jetzt noch lebenden Fischen an die Seite zu stellen, mehrere, durch ihren Zahmbau, durch die grossen Knochenplatten an der Stelle der Kiemenhautstrahlen, durch den Bau der Kopfknochen u s. w. eine grössere Analogie mit dem Polyplerus, als seinem amerikanischen Zeitgenossen besitzen.

Die durch Herrn Agassiz angestellten, wiederholten Untersuclungen der Exemplare von Dipterus in der geologischen Gesellschaft zu London, in welcher die Herren Sedgwick und Murchison vier Species zu finden glaubten, hatten zu Folge, dass diese in eine einzige vereinigt wurden, inden es sich zeigte, dass die angegebenen Verschiedenheiten zu einer solchen Annalme nicht hinreichten und nur auf eine bessere oder schlechtere Erhaltung der Fische, ihrer Flossen u. s. w. beruhten. Herr Agassiz vereinigte daher diese vier Species unter einem gemeinschaftlichen Namen Dipt. macrolepidotus, der von den französischen Gelehrten für eine der angeführten Species vorgeschligen war. Berücksichtigen wir nun aber die kurze Beschreibung der letzteren Form, so sehen wir aus den sie begleitenden Abbildungen, dass der Name Dipt.macrolepidotus einer Species gegeben wurde, die ganz verschieden ron den übrigen ist, dass die geringen Fragmente die von ihr angegeben werden, sich

1) Geolng. Transactions 2 Ser. Tom. 3 .

2) Ueber den Bau und die Grenzen des Ganoiden pag. 1307.

3) Traité de Palaeontologie sec. edit. pag. 153. 
nur auf eine Platte') beziehren, auf welcher mehrere Stücke des Kiemendeckelapparats und einzelne zerstreute Schuppen herumliegen, die ilırer Grösse und Gestalt nacls zu urtlreilen, eirenn gan z arderen Genus, nämlich Diplopterus angehören und selbst vorr $\mathrm{Agassiz}$ an einer anderen Stelle seines grossen Werkes ${ }^{2}$ ), diesem zugeschrieben werden. Dasjenige Exemplar, das in Fig. 7 dargestellt und vou Agass. ${ }^{3}$ ) gleichfalls wiedergegeben ist und als ein junges Individuun von derselben Art betrachtet wird, entspricht, dem Bau seiner Kopfknochen mach zu urtheilen, nicht in Geringsten denen von Dipterus, sordern ist ein Osteolepis.

Wir haben schon früher erwähnt, dass in der Abhandlung der Herren Sedgwick und Murchison die Schuppen als runde, von Agassiz dagegen als rhomboidale beschrieben wurden und glauben diese verschiedenen Angaben darauf zurückführen zu liönnen, dass A gassiz, welcher die Untersuchung der Schuppen an dem vermeintlichen Dipterus macrolepidotus (Diplopterus und Osteolepis) machte, diese als rhomboidal finden musste, während die eigentlichen Dipleri immer abgerundete Sclruppen besitzen. Indem wir jetzt Dipterus macrolepidotus Ag. von den Dipteri, mit denen er bis jetzt vereinigt warr, trennen, müssen wir für diese einen inderen, früher sclon festgesetzten Namen aussuchen und glauben an besten derjenigen auszuwählen, der dem Andenken des berühmten Gelehrten gewidmet ist, dem die Iclrthyologie so viel zu verdanken hat, indeın wir sie unter deın gemeinschaftlichlen Nanen Dipterus Valenciennesii vereinigen. In Tableau général des Poissons fossiles ${ }^{4}$ ) hat Herr Agassiz das Genus Dipterus von den Lepidoiden getrennt und in Verbindung mit Osleolepıs eine eigene Familie unter dem Namen der diptériens gebildet; in der Monographie der Poissons fossiles ${ }^{5}$ ) schliesst er diesen beiden Geschlechtern noch Diplopterus und Glyplopomus, von welchen letzteren bis jetzt die Flossen noch unbekannt sind, ản und führt diese vier Genera unter dem Familiennamen der Sauroides diptériens auf. Diese Familie ist mit geringen Abänderungen von alten Sctrriftstellern beibehalten worden und wahrscheinlich nur deswegen, weil alle die hierher gerechneten Geschlechter zwei Anal- und zwei Dorsalflossen besitzen sollten. Alle übrigen Charaktere, wie der Bau des Kopfes, der Schuppen, der Zähne, selbst des Schwanzes weichen bei Dipterus so sehr von, denen der übrigen $a b$, dass an eine Vereinigung derselben schon bei oberflächlicher Betrachtung nicht zu denken ist.

Unter allen, der Familie der Ctenodipterini eigenthümlichen Charackteren, nehmen die Zälme den ersten Platz ein, sie weichen von denen, in Rücksicht der Schuppen und anderen äusseren Kennzeichen ihnen verwandt scheinenden Fischen so sehr ab, dass ihre, bîs jetzt gewölınlich nur vereinzelt, aufgefundenen Ueberreste einer ganz anderen Unterklasse der Fisclie und namentliclı den Cesira-

1) Geolg. Transact. loc. vis. Tab. 16. Fig. 4.

2) Recherches Tom 2 pars 1, pag. 113

3) Recherches Tom 2 Tab. 2 Fig. 4.

4) Recherches Tom 1 pag. XXIV.

5) Recherches pag. 47 . 
cionten unter den Placoiden zugeschrieben und unter dem Namen Ctenodus im Systeme aufgenommen wurden. Der einzige Schriftsteller, welcher den Zusammenhang der Zithne von Ctenodus mit den knöchernen Köpfen des Dipterus deutlich beschrieb und durch Abbildungen klar anseinandersetzte war Hugh Miller ${ }^{2}$ ). Von Thurso demselben Fundorte, von welchem Herr Akademiker Ham el seine Exemplare gesammelt hatte, an denen wir schon vor zwölf Jahren die Identität der Geschlechter Dipterus, Placothorox und Ctenodus erkannt hatten, stammten auch dic Fischüberreste her, die Herr Hugh Niller beschrieb und es ist ganz unbegreiflich, dass Niemand hievon Notiz genommen hat und dass, in allen später erschienenen Werken, noch immer Ctenodus unter den Placoiden, Polyphractus unter den Cephalospiden und Dipterus unter der Familie der Dipterini aufgefuihrt wird.

Das Geschlecht Dipterus erhielt vor dreisssig Jahren seine bis jetzt beibehaltene Benennung, weil man in der doppelten Rückenflosse einen, ihm ganz eigenthümlichen Charackter aufgefunden zu haben glaubte und auch bis dahin nur in ihm, unter den ausgestorbenen Fischen, gefunden hatte; als sich aber bei mehreren Geschlechtern aus derselben Formation wie bei Osteolepis und Diplopterus eine gleiche Zahl der Dorsalflossen zeigte, verlor dieser Charackter seinen Werth, das Genus behielt aber denselben Namen und die scheinbar durch gleiche Zahl der Flossen, sich anschliessenden Geschlechter wurden unter dem Familiennamen Dipterini vereinigt.

Eine solche Vereinigung ganz heterogener Geschlechter, kann jetzt, nachdem wir genauer mit der Organisation von Dipterus bekannt sind, nicht mehr Statt finden und da demiselben Fische, nach dessen zerstreut aufgefundenen Zïhnen, der Name Ctenodus beigelegt wurde, so vereinigen wir, un hiedurch die Combination verschiedener Characktere anzugeben, die beiden bis jetzt gebräuchlichen Beziehungen mit einander, indem wir der Familie die Benennung der Ctenodipterimi beilegen.

Leider haben wir von den übrigen Geschlechtern, die, nach der Gestalt und mikroskopischen Structur ihrer Zähne zu urtheilen, dieser Familie angehören, keine anderen Ueberreste als diese und wir müssen es daher späteren Nachforschungen überlassen, ob Ceratodus, Cheirodus (Chirodus II' Coy Conchodus II' Coy), wie wir es jetzt thun, mit Recht unter den Ctenodipterini aufzunehmen sind oder nicht.

1) Footprints of the Creator or the Asterolepis of Stromness by Hugh Miller. 3te Ausg. 


\title{
DIPTERUS Sedgw. und Murch.
}

Diplerus Sedgw. und Murch. et ceter. auctorum.

\author{
Caloplerus Agass. \\ Diplerus Agass. \\ Polyphrachus Agass. et auct. \\ Ctenodus Agass. et auct.
}

Die Dipteren haben einen schlanken Körper, der mit runden dachziegelartig sich deckenden Schuppen besetzt ist, mit stark entwickelten unpaurigen Flossen, von denen zwei auf dein Rücken und eine Aftarflosse weit nach hinten in die Nähe des Schwanzes gerückt sind, und, sowol durch ihre Stellung, als Grösse, diese Fische als tüchtige Schwinmer charakterisiren. Die parigen Flossen, besonders die der Brust, sind gleichfalls ron bedeutender Grösse, und werden mit kleinen Schuppen, die denen des Körpers an Gestalt gleichkomnen, bekieidet. Der Schwanz, obgleich in hohen Grade heterocere, besitzt auf seinem Rückenrande kurze Strahlen, die nur bei sehr wol erhaltenen Exemplaren zum Vorschein kommen. Der Kopf ist breit und flach, stark deprimirt, vorn sehr abgestumpf, mit grossen vieleckigen knöchernen schuppenförinigen Platten bedeckt. Der Kiemendeckel-Apparat und die Knochen der Schulter besitzen einen hohen Grad der Ausbildung. Der knöcherne Gaumenapparat, ist aus mehreren an einander gefügten Knochen zusammengesetzt, ist mit zwei, in der Mittellinie des Rachens sich berührenden gezähnten oder tuberculirten, flachen oder concaven; der Unterkiefer mit zwei correspondirenden convexen, seinen Seitenästen aufsitzenden Zahnplatten, besezt. Ober- und Zwischenkiefer sind mit den vorderen Knochen des Kopfes in eine zusammengewachsene Schnautze, einem Entenschnabel gleich, rereinigt.

\section{Der Kopf:}

Ohngeachtet der grossen Anzahl ron Excmplaren die uns aus den Banniskirken Schiefern, in denen die von den Herren Sedg. und Murch. aufgeführten drei Species Dipt. macropygopterus, Dipt. brachypygopterus und Dipt. Valenicennesii, die wir unter der letzteren Benennung vereinigen möchten, nachzuweisen waren, zu Gebote standen, war doch bei sehr wenigen der Kopf so gut erhalten, dass wir die Gestalt und die Grenzen der einzelnen Schuppen desselben genau beobachten konnten, 
Wir mussten daher unsere Zullucht zu den besser erhaltenen Köpfen der grösseren Art die Agass. als Polyphrachs platycephalus beschrieben hat, nachdem wir uns von der Uebereinstimmung in Bau der Kopfknochen überzeugt hatten. Von letzteren Species, dein Dipterus platycephalus, haben wir aus einer grossen Reihe von Exemplaren die vollständigsten ausgesucht, diese auf der dritten Tafel in den Figuren 2-12 abgebildet und nach thnen eime ideelle Zeichnung in Fig. 1 angefertigt, welche die einzelnen Schuppen, so viel als möglich, in Zusammenhange darstellt und ihre Grenzen angiebt. Vergleicht man diese Abbildung mit der auf,Tab. 1 Fig. 2 von der kleineren Species gegebenen, so wird man leicht die Aehnlichkeit im Bau der einzelnen Schuppen erkennen; eine rollkommene Uebereinstimnnung in der Gestatt, Grösse, Zahl und den Grenzen der einzelnen Kopfschuppen zeigt sich nicht einmal bei den verschiedenen Exemplaren einer und derselben Species, und die Teränderlichkeit in diesen ist grade ein Beweis, dass wir hier nicht wirkliche Knochen, sondern nur Schuppen vor uns haben. Wir finden häufig, dass die knöchernen Bedeckungen des Kopfes der rechten Seite, von denen der linken in vieler Hinsicht abweichen, dass dieselbe Schuppe, die auf der einen Seite doppelt ist, auf der anderen einfach erscheint, nnd wir beinerken nicht selten Verschiedenheiten in den äusseren Umrissen, die sogar in den Schuppen der Mittellinie sich zeigen und daher die Synnetrie, die wir sonst an den Knochen des Kopfes zu sehen gewohnt sind, häufig verschwunden ist.

Der grösste Theil der Schuppen des Schïdels ist mit Poren besetzt, die wahrscheinlich die nach aussen sich öffnenden Canäle des Seitenporensystems darstellen. Am stärksten ist dieses System an den Seitenplatten des Kopfes entwickelt, während die in der Mittellinie liegenden, gewöhnlich glatt und eben sind. Man könnte hierdurch versucht werden einen Unterschied zwischen Knochen des Scliädels und der Haut aufzufinden, allein diese Ansicht kinn nicht gerechtfertigt werden, denn selbst die Schuppen in der Mittellinie sind sehr häufig mit einer grossen Anzahl Poren versehen, wie die in Fig. 10 abgebildete Squama occipitalis media beweist.

Wenn gleich die Köpfe von Dipterus platycephalus im Allgemeinen gut erhalten sind, so sind sie doch alle an hinteren Rande mehr oder weniger verlegt und dieser, so wie die sich demselben an schliessenden Theile können wir im Zusammenhange nur da auffinden, wo Kopf und Körper nicht von einander getrennt sind. Hier werden wir dann wieder unsere Zuflucht zu der kleineren Banniskirken Species nehmen müssen Tab. 1 Fig. 1 und 2.

Der hintere Rand des Schädeldaches ist am vollständigsten in dem auf Tab. 3 Fig̀ 3 abgebildeten Exemplare erhalten, eine mittlere gewöhnlich siebeneckige Platte wird von zwei Seitenplatten eingefasst, deren geineinschaftliche hintere Ränder einen concaren Bugen bilden. Es wird nicht schwer sein diese drei Platten an dem, auf Tab. 1 Fig. 2 abgebildeten Exemplare der kleineren Species wieder aufzufinden. An diesem zeigte sich hinter dem Schädel und diesen begrenzend eine Reihe anderer Schuppen, die durch ihre Grösse sich von denen des Körpers auszeichnen. Sie liegen in der Quere, bald drei, bald vier an Zahl, je nachdem die mittlere einfach oder doppelt ist und gleichen, ihrer Lage 
nach zu urtheilen, kleinen Hautschildern, wie sie bei Polypterus und Amia in derselben Gegend vorkommen. Aehnliche Schuppen, gleichfalls in Reihen geordnet, ziehen sich an Aussenrande des Schädeldaches Tab. 3 Fig. 1 Nr. 7 bis zur orbila hin, von deren hinterem Rande eine doppelte Reihe dieser ossa intercalaria bis zur Schnautze verläuft. Man könnte diese inneren Schilder die mit Mr. $\$$ bezeichnet sind, als ossa supraorbilaha ansehen, da älnnliche Gebilde, wie wir spiiter sehen werden, unter der Augenhöhle als ossa (oder squamae) infraorbitalia zu betrachten sind. Alle diese Schilder sind durch eine bedeutende Anzahl der Poren des Seitencanal-Systems, die nach vorn gegen die Schnautze und besonders auf dieser an Ilenge zunehmen, ausgezeichnet. Nach Abzug dieser, an Gestalt und Zahll häufig wechselnden Knochenschilder, bleiben, zwischen ihmen in der Mitte des Schädels grössere Platten iibrig, welche im Allgemeinen eine regelmässigere, wenn auch nicht ganz constante Form beibehalten. Einige von ihnen gehören gewöhnlich gan\% der Mittellinie an, sind bald einfach, bald paarig, andere zu beiden Seiten sich ilnen anfügend. Die Deutung dieser Knochen ist sehr schwierig und vielleicht ganz fruchtlos, denn wenn auch, wie dies namentlich am hinteren Theile des Schiidels der Fall ist, an mehreren von ihnen, sowohl ihrer Gestalt als Lage nach, eine gewisse Annäherung an bekannte Formen der Kopfknochen nicht zu rerkennen ist, so wird diese Deutung nach roine selır unsicher. Wir haben es hier ja nur mit Schuppen zu thun.

Die constanteste Form unter den Schuppen des Schiidels behialt diejenige die Tab. 3 Fig. 1 mit Nr. 1 bezeichnet ist, bei; sie kann, ihrer Lage nach, als Squama occipitalis media bezeichnet werden, nach hinten endigt sie mit einem graden Rande, zu beiden Seiten legen sich ihr zwei paarige, vor einander liegende Platten an, Nr. ̈̈ und Nr. 6, nach vorn dräingt sie sich mit einer hervorragenden Spitze zwischen die beiden sich in der Mittellinie berührenden Platten Nr. 2 und trennt dieselben hinten von einander. Aber auch selist diese Squama occipitalis media, obgleich, ilırer Lage nach, immer constint, ist, ihrer Gestalt nach, vielfachen Verïnderungen unterworfen, bald vorn mehr abgestumpft Tab. 3 Fig. 2, bald spitzer zulaufend Fig. 3 und 7, bald schmäler bald breiter, sind ihre vorderen seitlichen Ränder bald einfach, bald mehr gezackt Fïg, 10. An beide Seiten der Squama occipilalis media legen sich die beiden Schuppen Nr. 5 und Nr. 6 an. Die ersteren bilden mit ilıren hiuteren concaven Rändern in Verbindung mit dem der mittleren Sehuppe einen Kreisalssclunitt Tab. 3 Fig. 3, in welchen sich die Hautplatten des Nackens, die wir frïher kennen gelernt haben, einlïgen, nach aussen legen sich ähnliche Hautschuppen Mr. 7 an und nach vorn stossen sie an die mit Mr. 2 bezeichneten. Mlan kann die hinteren Nr. $\ddot{3}$ als squamae occipilales laterales oder externae, die vorderen Nr. 6 als squamae occ. anteriores oder als Squamae parielales anselien, doch möchten wir lieber die beiden folgenden, sich in der Mittellinie rereinigenden, fiir letztere gelten lassen. Ihre Lage ist in Fig. 1 deutlich angegeben, ihre hintere Grenze an die Schuppen Nr. 1 und Nr. 6 ist ziemlich regelulïssig und constant, nach vorne hingegen sind ilıre Umrisse vielen Unregelmässigkeiten unterworfen, da der ror ihnen liegende Knochen $\mathrm{Nr}$, 3, dem wir aus Nangel eines besseren charakteristi- 
schen den Namen Squama mediana capitis geben wollen, an Grösse und Gestalt sehr variirt. Er ist oft sehr klein, scheint zuweilen gar nicht rorhanden und dann mit den Schuppen Nr. 2 verwachsen zu sein, so dass diese dann unmittelbar mit den Nr. 4 bezeiehmeten Platten, die Squamae frontales, in Beriihrung kommen. Diese letzteren, gewöhnlich in der llittellinie ron einander getrennt, scheinen in Fig. 2 zu einem einzigen verwachsen zu sein; an ihren äusseren Rändern legen sich die, die innere Reilıe der über der Orbita, liegenden Hautplatten an, und rorn stossen sie an den hinteren Rand der Schnautze. Der vordere Theil des Kopfes ist stumpf abgerundet und scheint gleichsam aus einem Gusse gebildet zu sein, und wenn wir in der Zeichnung Tab. 3 Fig. 1 einen miltleren Theil von zwei seitlichen durch Näthe abgesondert dargestellt taben, so sind duch die Trennungslinien, die uns in den plattgedriickten Exemplaren zur Richtschnur dienten und in denen wir die Spuren von Suturen zu erblicken glaubten, so vielen Veränderungen unterworfen, dass hier leicht eine Täuschung Statt finden karin. Die Bildung des vorderen Theils des Kopfes erinnert sehr an Acpredo (Cuv. Yergl. Anatonie pag. 612).

Vergleicht man die so eben beschriebenen Schuppen des Kopfes von Diplerus platycephahs, deren äusserer Glanz beweist, dass die emailartige obere Schicht vollkommen erhalten war, mit denen von Dipterus Valenciennesii, an denen diese fast inmer fehlt, und Kopf und Körperbedeckunger ein mattes Ansehen bekommen haben, so sieht man bei letzteren die Suturen zwischen den einzelnen Platten sehr deutlich bis in die Tiefe dringen, erkennt dieselhen Formen nur mit dem Unterschiede,

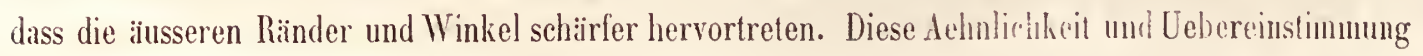
in der Gestilt der Schuppen des Schädels bei beilen Species giebt uns die Zuversicht, dass wir keinen grossen Fehler begehen werden, wenn wir das Fehlende bei der einen, durch das Vorhandenc bei der anderen ersetzen und uns auf diese Weise ein deutliches Bild von der Organisation des ganzen Genus rerschalfen. So wie wir bei Dipterus Valenciennesii nie den vorderen Theil des Kopfes, nie die Schnautze zu sehen bekommen haben, so haben wir auch nie einen grossen Theil der Gesichtsknochen mit den übrigen des Kopfes in Zusammenhange bei Dipterus platycephahs angetroflen und entlehnen diese daher zur Ergänzung der ersteren Species. In den Fig. 1 und 2 der ersten Talel, nach welcher hauptsächlich die Kopfgegend in der auf Tab. 2 Fig. 1 gegehenen ideellen Zeichnung angefertigt ist, sieht man die die Augen umgebenden Schuppen und den Unterkiefer sehr deutlich und in ihrem naliirlichen Zusamınenhange. Eine grosse Anzahl kleiner Schilder neben und hinter einanciergestellt, nehmen den Raum zwischen der órbita und dem Kiemendeckelapparat ein und können als squamae in/raorbitales und temporales betrachtet werden: erstere bilden mit den schon fiüher als squamae supraorbitales beschriebenen einen vollstïndigen Kreis un die Augenhöhle. Nach vorn scheint eine grössere Platte zu liegen, deren unterer vorderer Rand wahrscheinlich mit dem auf Tab. 3 Fig. 1 angegebenen fliigelförmigen Fortsetzung der Schmautze in Berülırung tritt, oder mit ihm verwachsen ist, hinten sind diese Hautkmochen in zwei neben einander liegende vertical absteigende Reihen geordnet, sie erreiclien hier das praeoperculum und bedecken die Wangen panzerartig wie bei Lepidosteus. Am unteren 
Rande der orbila kann man deutlich vier, durch tiefe verticale Suturen getrennte Platten, die der Länge nach durch eine tiefe Rinne eingefurcht sind, erkennen. Voin Ober- und Zwischenkiefer ist keine Andeutung vorhanden.

Der Apparat der Kiemendeckelknochen ist krifftig entwickelt. Das operculum von viereckiger Gestalt mit abgerundeten Ecken ist Tab. 1 Fig. 1 in seimer natiurlichen Lage bei Dipt. Valenc.zu sehen, von Dipt. platyceph. Tab. 3 Fig. 7 Nr. 19 und isolirt Tab. 4 Fig. 23 dargestellt. Was die übrigen zu diesem Apparat gehörigen Theile anbelingt, so kann man sich leicht von ihrem Vorhandensein überzeugen, leider aber ihre Aneinanderfügung nicht genau erkennen. In Fig. 26 Tab. 4 legt sich an das opercuhum eine andere Platte, die isolirt in Fig. $2: 3$ dargestellt ist, an und vielleicht das interoperculum ist, während eine dritte Platte Fig. 24 wol dem Suboperkel entsprechen dürfte.

Die Schiidelbasis und der Gaumenapparat Tab. 3 Fig. 11-1:3 werden aus mehreren dicken, flạchen, neben einander liegenden, durch deutliche Suturen verbundene Knochen gebildet. In der Mittellinie der Basis des Schädels liegt eine einfache rhomboidale Knochenplatte Nr. 12 deren hintere Spitze sich bis in die Gegend erstreckt, die auf der oberen Fläche des Kopfes vom hinteren Rande der Squama occipilalis media eingenonnnen wird und deren seitliche Ecken den Knoclren Nr. 13 iufliegen. Die vordere Spitze schiebt sich zwischen diese beiden letztgenanuten Knochen in dem Vereinigungswinkel derselben himein. Die hinteren divergirenden Ränder seheinen mit keinen anderen harteı Theilen in unmittelbarer Berïlırung gestanden zu haben, sondern sind wahrseheinlich nur von Knorpelnasse umgeben worden; die vorderen convergirenden Ränder werden von den inneren der Knochen Nr. 13 eingefasst. Die untere Fläche dieser Platte, die wir als dis os sphenoideum basilare anselren, ist mit schwachen Furchen und Rippen versehen, die grösstentheils von hinten nach vorn, parallel nit den vorderen Seitenrändern verlaufen. Sehr häufig findet man yollstiindig erhaltene Abdrücke dieses Knochens in den Schiefern und wir vermuthen daher, dass seine Verbindung mit den benachbarten Theilen sehr schwach gewesen sein muss, entweder nun durch Harmonie oder schuppenartig.

Zu beiden Seiten des os sphenondeum fügen sich an dessen vordere Seitenı̈̈nder zwei nebeneinander liegende durelr eine schwache Sutur von einander geschiedene Knochenplatten Nr. 13 und $\mathrm{Nr}$. 14 an. Vor der vorderen Spitze des as sphenoideum vereinigen sich die gleichnamigen in der Mittellinie mit einander und bleiben bis zum vorderen Ende des Rachens in unmittelbarer Beriuhrung. Ihre ganze vordere Hälfte ist mit den grossen dreieckigen Zahnplatten besetzt; leider konnten wir diese an den vorlıandenen Exemplaren nicht unverletzt ablösen und sind daher nicht in Stande den Verlauf der Knochen nach rorn genau anzugebelı. Es erleidet wol keinen Zweitel, dass diese beiden Knochen Nr. 13 und Nr. 14 das os palatinum und das os pterygoideum internum darstellen, ob aber letzterer sich gegen die vordere Spitze mit dem der entgegengesetzten Seite durch Nath vereinigt und dann sowol durch seine Lage, als Verbindung dem os palatinum wie bei Polypterus entspricht, rode ob, wie bei Amia und bei melireren anderen Fischen, derselbe das os pterygoideum internum 
und also dann der Knochen Nr. 13 dem os palatinum gleichkommt, können wir bis jetzt noch nicht entscheiden. Wir halten jedoch das Letztere für wahrscheinlicher, indem die beiden ossa (Nr. 13) palatina sich in der Mittellinie zu verbinden scheinen. Hinter diesen beiden an einander liegenden und verbundenen ossa palatina und pterygoidea interna sieht man nach tinten und aussen in Nr. 15 eine andere, von den rorigen getrennte Knochenplatte hervorragen, deren äussere Ränder ganz unverletzt sind, deren genauer Zusammenhang aher mit den vorher beschriebenen nicht gut zu ermitteln ist. Wir halten diese Platte für das os pte ygoideum externum. Zwischen diesem os pteryg. ext. und der vorderen Hälfte des os pteryg. int. ragt in Fig. 16 ein anderer abgerundeter knochen hervor, gleichfalls mit unverletzter Oberflïche, der seiner Lage und Verrichtung nach, nur für das os quadrato-jugale angesehen werden kann und dessen convexe Oberlläche zur Gelenkverbindung mif dem Unterkiefer bestimmt ist. Obgleich dieser Knochen in allen uns vorgekommenen Exemplaren, mit den übrigen des Gaumenapparates, in einer Flïche liegt, so ist es doch augenscheinhch, dass er in diese Lage nur durch Druck und Quetschung gekommen ist und wir miissen, weun wir ihn in seine natïrliche, ursprüngliche Lage zurïckbringen wollen, ihn vertical stellen, so dass dessen fast senkrechter Condylus in die tiefe Grube hineinpasst, die wir am Lnterkiefer zwischen dem proc. posticus und proc. anticus oder coronoideus nach weisen werden.

Der Unterkiefer, Tab. 3 Fig. 16 nach der Natur im vergrösserten Maassstabe Tab. 2 Fig. 9 im Prufil dargestellte, aus den stärksten und dicksten Kınochen des ganzen Thieres gebildet, besteht aus zwei Seitenästen die sich vorn vereinigen und durch ihre Verbindung eine breite, . vorn stumpf abgerundete Platte bilden, die ihrer Gestalt nach der, der breiten Schnautze des Kopfes entspricht. Am hinteren Ende treten zwei Fortsitze hervor von denen der vordere, in unserem Excmplare niedergedriickt und zum Theil zerbrochen, der hintere dagegen gut erhatten ist. Letzterer Nr. I ragt mit gewölbter Oberfliche stark hervor, entspricht seiner Lage nach, am hinteren Ende des Unterkiefers, dem processus condyloideus, kann aber schwerlich als solcher betrachtet werden, da wir bis jetzt nicht in Stande sind, die ihm entsprechende Gelenkgrube am Schädel nachzuweisen, vielmehr an letzterem, wie wir frïher gesehen haben ein hervorragender Tuberkel vorhanden ist, der in die Gelenkgrube am Unterkiefer Nr. II hineinpasst. Diese fovea glenoidalis, zur Aufnahme des os quadrato-jugale bestimmt, ist sehr tief und wird vorn durch einen vertical hervortretenden langen Fortsatz begrenzt, den wir wol processus coronoideus nennen können. Die vorderen Enden der Seitenïste des Unterkiefers werden grösstentheils von den beiden Zahnplatten bedeckt und die vordere breite Fläche ist stumpf abgerundet und zahnlos.

Zwischen beiden Aesten des Unterkiefers liegen zwei Knochenplatten Tab. 3 Fig. 17 Nr. 22 , welche die Stelle der Kiemenhautstrahlen bei den gewöhnlichen Knochenfischen einnelımen und wie bei Polypterus, Osteolepis, Megalichthys aus zwei von einander getrennten, bei Amia aus einer unparigen Medianen gebildet werden. 
Die Zahnplatten des Gaumens Tab. 3 Fig. 11, 13 und 14 von Dipterus platycephalus bilden jede ein rechtwinkliges Dreieck, dessen Hypothenuse den äusseren und dessen beide Catheten den inneren und hinteren Rand darstellen. Man kann an ihnen drei verschiedene Abtheilungen unterscheiden 1) die eigentliche Kaufläche die mit erhabenen Spitzen, Tuberkeln oder Zähnehen besetzt ist, 2) eine innere glatte Fläche und 3) ein hinterer inannigfach gestaltetur Rand. Die ebene oder grösstentheils mehr oder weniger concav ausgehöhlte Kaufläche behält die dreieckige Gestalt des Zahnes bei, und aus ihrem inneren, hinteren, dem rechten des Dreiecks entsprechenden Winkel gehen, von einem Punkte aus, schwach erhabene mit kleinen Zähnchen besetzte Rippen strahlenförmig nach vorn und aussen ab. Die inneren Rippen laufen in grader Linie nach vorn, die hintersten rechtwinklig von diesen nach aussen. Diese, an ihrem Ursprunge dicht an einander gedrängt stelıenden Zahınreihen, nehmen in ihrem Verlaufe nach vorn und aussen, in gleichem Naasse wie die sie trennenden Vertiefungen an Ausdehnung zu, und erreichen am Aussenrande der Platten, besonders nach vorn, ihre grösste Höhte und Tiefe.

Die innere glatte Fläche, ein bis zwei Linien breit, verläuft parallel mit dem inneren Rande der Zahnnippen, legt sich in der Mittellinie des Rachens der gleichnamigen ron der entgegengesetzten Seile an und ist emailartig überzogen und stark glänzend. Der hintere liand, den Agassiz als charakteristisch für eine besondere Species, die er aus diesem Grunde Ctenodus marginalis nannte, ansall, bildet am hinteren Rande der Kaulläche eine älınliche Begrensung der Kaufläche, wie die innere, hat aber keinen glänzenden Ueberzug, sundern ein ganz mattes Ansehen.

Die Zahnplatten des Unterkiefers weichen von denen des Gaumens in ihrer Gestalt bedeutend ab. Sie bilden ein stumpfwinkliges Dreieck, dessen lïngste Seite einen inehr oder weniger convexen Bogen nach aussen bildet, nach hinten sind sie schräg abgestuzt und die beiden Flächen, die an den Zähnen des Gaumens dieselben von innen und hinten begrenzen, fehlen gänzlich. Wegen des Mangels der ersteren berühren sie sich nicht in der Mittellinie, sondern ruhen mit ihren stark concaven unteren Flächen, weit von einander entfernt, auf den Seitenästen des Unterkiefers. Die mit Zahnreihen besetzten Rippen, der mehr oder weniger convexen Kaufläche, divergiren rom inneren hinteren stumpfen Winkel nicht wie bei den Gaumenzähnen nur nach vorn und aussen, sondern auch nach hinten. Betrachten wir die beiden Kaullächen, sowol die der Gaumenplatten, wie die des Unterkiefers in ihrer Thätigkeit, so werden wir finden dass die Zahnrippen und die sie trennenden Vertiefungen, wegen der verschiedenen Richtung ihrer Ausstrahlung von innen nach aussen unmöglich in einander eingreifen können, sondern dasss nur die, scharf gezähnten Rippen mit ihren Spitzen das Zerreiben und Verkleinern der Nahrungsmittel bewirken konnten. 


\section{$-13$}

\section{Die SeInuppen.}

Die stark entwickelte Ausbildung der Schuppen auf der Oberfläche des Schädels lässt schon vermuthen dass die Hautbedeckung des Körpers gleichfalls sehr ausgebildet sein wird. Die Untersuchung zeigt, dass die Entwickelung der Schuppen des Körpers bei den Ctenodipteren in jeder Hinsicht den höchsten Grad der Vollendung erreicht hat, sowol in flinsicht der inikruskopischen Structur, als der Ausdehnung über alle, dem Körper angehörigen Theile, den Flossenträgern und Flossenstrahlen. Im Allgemeinen von kreisrunder Gestalt Tab. 4 Fig. 22 erscheinen die Schuppen, wie aus einzelnen in den Schiefern zerstreut herumliegenden Ueberresten zu sehen ist, oft oval, symmetrisch und unsymmetrisch je nach ihrer Stellung, aber immer mit abgerundeten Ecken und Kanten. Auf den Flossenträgern behalten sie dieselbe Gestalt bei, wie am Körper, sind aber bedeutend kleiner und nehmen, je näher der Insertion der Strahlen, desto mehr an Grösse ab Tab. 1 Fig. 3. Auf den Flossenstrahlen verändern sie gänzlich ihre runde Gestalt und die dachziegelartig sich deckende Verbindung; sie nehmen hier eine längliehe stabförmige Form an, die der, von ilmen bedeckt werdenden Glieder derselben entspricht, und verbinden sich mit einander durch Iuxtaposition. Tab, 4 Fig. $2 S$ a.

Die Oberflïche der Schuppin ist, wie die der Kopfplatten, glatt, gläzend und mit kleinen Poren, den äusseren Oeffnungen der heraufsteigenden Markkanäle besetzt. Bei Dipterus Valenciennesii ist diese obere Schiclit selten gut erhalten, die Schuppen bekommen diher, durcli das Verwittern derselben, ein mattes Ansehen, die härteren nicht zerstörten, zwischen den Reihen der Porenıüudungen sich befindenden Theile treten auf der Oberfläche hervor und geben dem, frei nach hinten hervorstelienden Abschnitte der Schuppen eine gestreifte oder gerippte Oberflïche Tab. 4 Fig. 22, 2S, 29 und 30. Die untere Fläche Tab. 2 Fig. $\$$ ist wie bei allen Cycloidschuppen der devonischen Fische, Glyptolepis, Holoptychius u. s. w. aus über einander geschichteten Lanellen gebildet, deren äussere Ränder durch kreisförnige, concentrische Ringe angedeutet sind. Wird die untere Schicht zerstört und die mittlere tritt zum Vorschein so erhält diese das Ansehen wie in Tab. 1 Fig. 11 gezeigt ist. Wir haben den verschiedenen Zuständen der Schuppen nur deswegen mehrere Abbildungen gewidmet, weil Agassiz gegen die Annahme von Cuvier, Valenciennes und Pentland, nach welcher dieselben kreisförmig sein sollten, seine frühere. Ansicht von ihrer rhomboidalen Gestalt ') selbst noch in Old Red ${ }^{2}$ ) nicht aufgiebt. Gegen diese Ansicht reichen unsere Abbildungen vollkommen hin.

Die Herren Sedgwick und Murchis on ${ }^{3}$ ) geben von den Veränderungen, dic die Farbe und Beschaffenheit der Fischversteinerungen und besonders der Schuppen in den Banniskirker Schiefern erlitten, durch welche diese ein mattes Ansehen und blaue Färbung bekommen haben, eine genaue Be-
1) Recherches Vol. 2 pars 1 pag. 115.
2) Monographie etc. pap. 58 .
3) Geological Transactions 2 ser. pag. 141. 
schreibung und theilen diese der Phosplırsäure und ihrer Verbindung mit Eisen unter dem Einfluss der Athmosphärilien zu.

Die mikroskopische Structur derSchuppen des Schïdels und Körpers von Dipterus konnte leider an keinem der schottischen Exemplare genügend untersucht werden, wir haben uns daher zu diesem Zwecke zweier Kupfschuppen, die eine Tab. „ै Fig. 16 aus den Mergeln von Kokenhusen, die andere von den Ufern des Wolchow herstammend, bedienen müss'n. Eiı verticaler Schliff durch die ganze Schuppe, wie er in Fig. 17 dargestellt ist, giebt genauen Aufschluss über ibren Batu; die unterste Schircht besteht aus Isopedin, sie ist sehr dick, voller stralliger Knochenhöhlen, von einer geringen Anzalıl vertical aufsteigender Markkanäle durchschnitten, die mittlere Schichı, mil netzlörmig anastomosirmnden Gefïsscanälen durchzogen, ist in einem horizontalen Durchschnitt in Fig. 18 sichıbar. Aus diesem Gefässnetz treten vertical gegen die Oberflïche hinaufsteigende grosse Canäle, un sich auf dieser nach aussen zu öffnen, Fig. 19. In den Zwischenrüumen zwischen diesen Poren begeben sich feinere, gleichfalls aus demselben Gefässnetze entspringinde Stämmchen himein, die sich nach allen Seiten in feinere Aeste zertheilen und deren feimsten Zweige gegen de obere Fläche ausstrahtlen, un auf diese Weise das Kosmin zu bilden.

\section{Die Flossen.}

Ein Blick auf unsere ideelle Zeichnung Tab. 2 Fig. 1 zeigt die kriiftige Ent wickelung der Flossen; die Stellung der unpaarigen, des Riückens und Afters, die ganz an den hinteren Theil des Körpers gerückt sind, deutet auf kräflige Schwimmer und wenn auch ihre Grösse nicht besonders auffallend ist, so zeigt ihre Ausbildung von der bedeutenden Gewalt, die sie auszuüben im Stande waren. Die Flossenstrahlen die bei vielen Fischen von weicher Beschaffenheit sind, oder, wie bei Polypterus, Accipenser und anderen, aus wirklichen Knochen bestehen, haben hier nicht nur len letzteren Bau, sondern sind noch äusserlich mit knöchernen Platten bedeckt, die die kräftigste mikroskopisehe Structur besitzen, eine wahre Dentine. Die Flossenträger der unpaarigen Flossen sind so dicht an einander gedrängt, dass mehrere von ihnen die Zwischenräume zwischen den processus spinosi und den ihnen angehörig'n Wirbelkörpern einnehmen. Aehnliche knöcherne Stäbe finden sich in den paarigen Flussen, wie bei Polypterus wieder, und auch ihre äussere Bekleidung besteht aus Schuppen, denen des Körpers in ihrer Structur gleich.

Zur genaueren Beschreibung der Flossen bedienen wir uns des auf Tab. 1 Fig. 4 abgeblldeten ausgezeichnet schönen Exemplares von Dipterus Valenciennesii aus Banniskirk. Druck und Quetschung haben so vortheilhaft auf das Original eingewirkt, dass alle in Rede stehenden Theile eine sehr günstige Lage erhalten haben und klar und deutlich fast ganz in ihrer natürlichen Lage erscheinen. Die an mehreren Stellen unterbrochene Seitenlinie des Korpers zeigt an der vorderen Hälfte, dass hier ein Theil des Bauches hinaufgeschoben ist und daher die rechte Brustllosse höher zu liegen kommt, als sonst in einer Seitenansicht möglich wäre. Dieses Hinaufschieben des Bauches hat sich bis zu. den 
Bauchflossen erstreckt, denn sonst köınten unmöglich beide zu gleicher Zeit sichtbar sein. Ueber diesen Ventralflossen ist dagegen der Rücken ein wenig hinunter gedrückt worden, so dass die vordere Dorsalflosse gänzlich und die hintere zum Theil auf die rechte Seite geschoben sind, wälhrend die anale und der Sclıwanz ilıre natürliche Richtung und ursprüngliche Lage beibehalten haben. Die vordere Dorsalllusse ist von geringem Umfange, die Flossenträger bilden Tab. 4 Fig. 29 nach hinten einen convexen Bogen, an den sich die Strahlen so ansetzen, dass die vorderen oberen kürzer sind, als die nächstfolgenden, die rasch an Länge bis zumı oberen Rande zunchmen und dann stufenweise vom hintersten abgerundeten Rande sich verklenern. Die zweite dorsale ist fast vier Male grösser als die vordere, von ganz gleichem Bau, unterscheidet sich aher von ihr durch andere Contouren, indem zwischen den oberen und unteren Strahlen kein so bedeutender Unterschied in der Abnahme ilırer Grösse Statt findet und sie daher gemeinschaftlich einen anmuthigen Bogen nach hinten bilden.

Die Schwanzflosse gehört zu denen, die unter allen Fischen des devonischen Systems sich der vollkommenen Heterocercie an meisten nähert, aber dennoch am oberen oder Riickenrande mit kurzen, nach hinten sich verlängernden Strahlen besetzt ist Tab. 1 Fig. 引े.

Die parrigen Flossen stehen sehr weit von einander, die der Brust sind an der Clavicula, gleich hinter demn Operkel, befestigt; die des Bauches liegen unten, etwas hinter der vorderen Rückenflosse.

Das Vorhandensein des Schultergürtels erkennt man in der ersten und seclssten Figur der ersten Tufel. Seime Verbindung mit den Knochen des Kopfes und den Flossen haben wir nicht genau beobachten können, glauben indessen, dass das auf Tab. 4 Fig. 27 abgebildete Stiick diesem Knochen von Dipterus plalycephalus entspricht, wenn es nicht der Präoperkel ist. In Tab. 1 Fig. 1, 3, 6 und 7 sind die Brustllossen, ein spitziges Dreieck bildend, von denen die Strahlen nach allen Seiten divergiren, abgebildet. Die Bauchflossen sind an deutlichsten in der vierten Figur der ersten Tafel zu sehen, in der ersten Figur derselben Tafel ist, die der linken Seite, gegen den Rücken hinaufgeschlagen und liegt den Schuppen des Körpers auf, aber ihre Gestalt ist deutlich zu erkennen.

An den paarigen Flossen haben wir leider nie wie an den unparigen, die Flossenträger erkannt, da sie in allen Exemplaren noch mit Schuppen bedeckt waren Tab. 4 Fig. $2 S$ a und $2 S$ b. Es leidet aber wol keinen Zweifel, dass diese bald ossa metacarpi und ossa metatarsi, oder als Anfänge der Flossenstrahlen nach J. Müller ${ }^{\dagger}$ ) betrachteten einfachen Knoclienstäbchen, ganz ebenso gebaut waren, wie bei Polypterus.

\section{Die Wirbel.}

Es ist cine sehr auffallende Erscheinung, dass, ohngeachtet der mühsamsten Untersuchungen in den Schiefern Schotllands und im A. R. Sandstein Englands, bei der zahllosen Mlenge wol erhaltener vollstïndiger Exemplare von Ichtyolithen keine Spur des Axensystems der Wirbelsäule aufgefunden

1) Müller, Ueber den Bau und die Grenzen der Ganoiden, pag. 210. 
wurde, während deutliche-Ueberreste, des zu demselben gehörigen Bogensystems, wie wir sie namentlich Tab. 2, Fig. 4 und ว̆ dargestellt haben, und wegen der mit ihnen in Gemeinschaft vorkommenden Cycloidschuppen zu Diplerus zu rechnen glauben, nicht so gar selten erseheinen. Der Schiidel, und die mit diesem verbundenen Skeletheile, die Schuppen und Flossen haben indessen bei den Ctenodipterini eine so vollendete Knochenbildung erreicht, dass man wol auch eine feste, harte Wirbelsäule erwarten könnte. Agassiz äussert sich öfter nnd namentlich iu zweiten Bande seiner recherches sur les poissons fossiles pag. 00 bei der Beschreibung des Palaeoniscus Blainvillei sehr verwundert über den Hangel aller Spuren einer Wirbelsäule. Er fand viele Exemplare so vollkommen gut erhalten, dass an eine Verletzung der Wirbel, selbst wenu diese einen geringen Zusammenhang unter einander gehabt hätten. nicht zu denken war und es diaher ummöglich zu erklären sei, wie sie zwischen der Hautbedeckung hiitten entweichen können. Es scheint, so schliesst H. Ag., dass irgend eine physische, noch unbekannte Thätigkeit sie zerstört haben muss, da durch eine mechanische ihre Abwesenheit unerklärlich bleibt. Bei der Beschreibung der Wirbelsäule des Polypterus ${ }^{1}$ ) bei welehem, wie bei Salmo Esox, einigen Cyprinen u. s. w. die Dornfortsitze nicht immer mit dem Körper zusammengewachsen sind, kommt er wieder auf diesen Gegenstand zurïck und sucht in der Trennung dieser Theile vou einander die Möglichleit des välligen Verschwindeus der Writbelkörper bei den Ganoiden des dev. Syst. zu erklären, deren weniger knöcheine Subslanz lẹichter zerrieben, zerstört oder wenigstens unkenntlich wurde. Eine solche Annahme, nur auf Vermuthung beruhend, hat, glaube ich, wenig Eingang gefunden und es blieb wahrscheiulicher den devenischen Fischen, statt einer knörhernen Wirbelsäule eine knorpelige Chorda verlebralis, wie Lepidosiren und Accipenser sie besitzen und wie sie auch wol bei Coccosteus stittfand, zuzutheilen.

Indessen hatte Herr General Hehmersen schou im Jahre 1840 in den devonischen Schichten des Nowgorodschen Gouvernements zwei deutliche Wirbel aufgefunden, an dene'l keine Apophysen angeheftet, aber die Gruben zur Aufnahme derselben leicht zu erkemen waren. In Jahre 184. fand ich an den Ufern des Scias cinen Wirbel ${ }^{2}$ ) mit concaven Flächen und oberen und unteren Grübchen für die Apophysen, den vorigen ähnlich, oben viel kleiner. Durch diese zwei, in verschiedenen Gegenden gemachten Beobachtungen, war das Vorhandenscin ron Fischen mit kü̈chernen Wirbeln im der. System erwiesen und es kan jetzt nur darauf an, die arngedeuteten Spuren weiter zu verfolgen. Nach vielen vergeblichen Bemühungen gelang das Auffinden eimer grösseren Anzahlı Wirłelkörper, leider aber immer ohne Zusammenhang init dem Körper; und die Ansicht von Agassiz, dass die Wirbel-

1) Recherches Vol. 2 pars 2 pag. 64 .

2) Die Auflagerung der devonischen blawen und rothen Nergel auf den unteren silur. Schichten ist nirgends so sehïn zu beobachten als an den Ufer! des Scias. Als ich einen rothen Kalkstein, in welchem ein sehr schön erhaltenes Exemplar von Illaemus crassicauda sass, behauen wollte, sprang dieser Wirbel von Gesteine ab, ich konute aber die Stelle die er im Gesteine eingenommen hatte, nichtit auffinden. Es ist daher mügiich, diss er ron oben aus den dev. Mergetthonen heruntergefallen und diesem Stücke aufsass. 
körper durch chemische Agentien, nach dem Absterben der.Thiere, in den Schichten, in denen sie begraben liegen, zerstört wurden, erhielt hiedurch eine gewisse Bestätigung. An den steiten Ufern der Prickschi, an welcher die Auflagerung der unteren Sandschicliten des Bergkalks auf den oberen Mergeln des dev. Syst. so klar vor Augen liegt, wechseln blaue, grünliche, röthliche und violettgefärbte plastische Thone mit einander ab; und eine Schicht dieser blauen Thone schliesst eine grosse Anzahl Fiscluüberreste ein. Wir fanden in einem Stück, das gegen 2 Kubikzoll betrug, zerbrochene Zähne von Dendrodus, von Diplerus, Schuppen von Osteolepis und mit ihnen iu Gemeinschaft drei und dreissig rollstïndig erhaltene Wirbel von den verschiedensten Formen.

Es ist unmöglich mit Gewissheit zu bestimmen, welchen Thiren diese Wirbel angehören, es ist sogar wahrscheinlich, dass so versclieden gestaltete Wirbelkörper nicht einem Genus allein zuzutheilen sind; um aber doch irgend einen IIatlungspunkt zu haben, suchten wir in den schollischen Exemplaren, die uns zu Gebote standen, nach, ob sich nicht irgendwo eine Andeutung einer Wirbelsiüle auffinden liess und wir glauben uns nicht im Nachsuchen derselben zu irren.

In dein von Agassiz Vol. 2 Tab. 2 a Fig. 1 abgebildeten und gut erhaltenen Exemplare von Diplerus Vulenciennesii (Dipt.macrolepidotus Agas.) ist auf der vorderen Hälfte die Schuppenbekleidung der linken Seite unversehrt sichtbar, auf der hinteren nur der Abdruck, den die Schuppen der rechten Seite des Körpers im Gestein zurïckgelassen haben, zu erkennen. Man sieht deutlich eimen schon in der vorderen Hülfte anfangenden, fast durch die Nitte des Körpers rerlaufenden, dem Rücken mehr ats dem Bauche genillerten und erst an Ende des Schwanzes endigenden, schnurartigen, aber eingekerbten Streifen sich hinziehen. Diesen Streifen halten wir für die Wirbelsïule, wir gliuuben die. selbe in dem Exemplare, das wir auf Tab. 1 Fig. 1 abgebildet haben, gleichfalls wieder zu erkennen, wo sie unter den Schuppen des Körpers, über der Seitenlinie gelegen ist; endlich ist auf unserer Tab. 2 Fig. 6 ein Bruchstück vom Körper abgebildet, an welchem die hintere Dorsalflosse, ein grosser Theil der Schwanzflosse und die anale noch zienlich vollständig erhalten sind und zwisthen ihmen, eine gleichsam aus aneinander gereihten Perlen bestehenden Schnur, bis gegen das Ende des Schwanzes, zu verfolgen ist. Man könnt!, selbst durch unsere eigune Abbildung verleitet, diese angegebene Wirbelsäule, sowol ihrer Richtung, als ihres Verlaufes nach, mit der Seitenlinie verwechseln, allein abgesehen davon, dass diese unter der Wirbelsïule und mit ihr an einem und demselben Exemplare zıgleich vorhanden ist Tab. 1 Fig. 1, so hat sie gegen das Ende des Schwanzes einen ganz anderen Verlauf, als letztere.

Da wir keinem anderen Fische des devonischen Sxystems eine Andeutung von Vorhandensein einer Wirbelsüule ausfindig machen konnten, so haben wir alle Wirbel, die wir bis jetzt in den devonischen Schichten angetroffen haben, ungeachtet der grossen Verschiedenheit in illrer Gestalt, hier aneinander gereiht. Es bleibt künftigen Untersuchungen die Bestimmung übrig, welchem Genus oder Species dieselben angehörun. Für diesen Augenblick werden wir uns mit der allgemeinen Beschreibung der Form und Structur dieser Wirbel begnügen; was erstere betrifli, so soll diese bei der Beschreibung 
der Tafeln genauer angegeben werden; was letztere anbelangt, so bleibt das Speciellere für eine spätere Arbeit vorbehalten, die nur über Structur der Zähne, Schuppen u. s. w. der devonischen Fische handeln wird.

Von allen denen auf Tab. 4 abgebildeten Wirbeln zeichnen sich die beiden ersten Fig. 1 und 2 durch das Vorhandensein der Grübchen aus, die für die Aufnahme des Bogensystems der Wirbelsäule bestimnt waren, ihre beiden Flächen sind schwach concav; die übrigen Figuren $3-18$ besitzen keine solche Griibchen und wir vermuthen, dass die Höhlen für die Apophysen, wenn diese vorhanden waren, sich in einer knorpligen, den Körper umgebenden aber zerstürten Hiille befanden. Man crkennt an mehreren ausser einem flachen Längskanal Tab. 4 Fig. 4b, dem wahrscheinlich das Rückenmark auflag, häufig nur an ihrem peripherischen äusseren Rande, eine mehr oder weniger bedeutende, bald in der Mitte, bald dem vorderen oder hinteren Rande genäherte Einschnürung. Fig. 6, 7, 8, 9, 11, 17. In den vorderen und hinteren Flächen der Wirbel zeigen sich bedeutende Verschiedenheiten, es giebt concav-concave und zwar in bedeutender Menge und concav-convexe, letztere in allen möglichen Graden der Convexität, so dass, wie Fig. 16 zeigt, diese fast keilförming sich gestaltet. Einen anderen Unterschied finden wir in der Verbindung der Wirbelkörper unter einander, indem näimlich bei vielen, zwischen den beiden entgegengesetzten Flächen eine Communication Statt findet oder nicht, d. h. ob eine Chorda verlebralis durch die ganze Säule verlief und diese äusserlich von cinem knöchernen Ringe umgeben wurde, oder ob die Wirbelkörper gesehlossen sind und nur der Rest der Chorda die Verbindung unter ihnen vermittelte. Die Perforation der Wirhel sehen wir in allen möglichen Graden, von der Grösse einer Nadelspitze Fig. 11, 13 bis so weit entwickelt, dass die knöcherne Substanz nur wie ein schmaler Ring die mittlere 0effnung einfasst, Fig. 17. Noch auffallender ist es, dass diese Perforation zuweilen excentrisch ist Fig. 8. In Rücksicht ihrer Gestalt wechscln dic Verlältnisse zwischen den drei Dimensionen sehr bedeutend, im Allgemeinen sind aber die Unrisse kreisförmig und nur mit wenigen Ausnahmen finden Abweichungen von dieser Form Statt. Fig. $S$ und Fig. 11.

Eine eilfache Loupe, unter welche unsere Abbildungen gegeben sind, zeigt schon, dass unsere Wirhelkörper in ihrer Structur keine Aehnlichkeit weder mit denen der Teleostei, noch der lebenden Ganoiden besitzen. Die kleinen Poren deuten auf eine spongiöse, zellige Masse. Fcine Schliffe zeigen unter dem Mikroskop horizontale, anastomosirende, grosse, dunkele, nach aussen sich öffnende Röhren, die eine homogene weisse durchscheinende Grundsubstanz mit durchsichtigen länglichen Zellen, ohne alle Verästelungen, gleich den Knorpelzellen be den Wirbeln von Lamna und Otodus ') durchziehen. Herr Agassiz hat vollkommen Recht, wenn er sagt ${ }^{2}$ ), dass die Ganoiden der Vorwelt eine

1) Ag. Tom. 3. pag. 364 .

2) Tom. III pag. 368 . D'un autre coté, le fait que les Ganoides anciens, dont les vertèbrés s'ossifient, offrent dans les caractères de leur colonne vertébrale la plus grande analogie avec celle des Placoides, acquiert 
knöcherne Wirbelsäule der höheren Placoiden unserer Epoche ähnlich, besessen haben. Die ersten Wirbel, welche Agassiz fand, und anfangs als den Placoiden angehörig betrachtete, später aber dem Lepidotus minor') zuschrieb, stammen aus dem Jura, den Purbeckschichten, seine Beschreibung passt in Riicksicht des faserigen Anscheins der flachen Gruben auf der oberen und unteren Fläelie zur Insertion der proc.spin. und der konischen Vertiefungen so ziemlich auch auf unsere Exemplare, und wenn bei der Species, die er vor Augen hatte, die Körper sehr hoch in Verhältniss zur Länge waren, so zeigt Quenstedt ${ }^{2}$ ) bei einer anderen Species, dass dieselben sehr deprimirt waren.

Wir können nicht umhin zum Schlusse unsere Leser noch einmal darauf aufmerksan zu machen, dass wol keine Familie der ausgestorbenen ichthyologischen Fauna Agassiz's und Miiller's Ansichterl, dass eine Unterklasse von Fischen existirt hat, welche zwischen der Elasmobranchii und den Teleostei in der Mitte steht, mehr bekräftigt, als die der Ctenodipterini.

Die Wirbel und Zähne sind dem äusseren Ansehen und ihrer inneren Structur nach, denen der Selachier :ahnlich, die Schuppen schliessen sich nach ihrer knöchernei Beschaffenheit, den Schildern von Callichthys und den Ostracionten an, ihre Gestalt und dachziegelartige Auflagerung nähert sie den Cycloidschuppen, die knöchernen Flossenstrahlen der Teleostei und der heterocerce Schwanz den Accipenserinen und Selachiern.

\section{Die Tiilnne.}

Als diese Arbeit, deren Gegenstand die Familie der Ctenodipterini sein sollte, vor mehreren Jahren begann, kannte ich ausser den schottischen Exemplaren, nur ein paar Zähne aus den Ostseeprovinzen Russtands und aus den Umgebungen von Zarskoje Zelo, welche letztere von Eichwald ${ }^{3}$ ) und $A$ gassiz ${ }^{4}$ ) schon früher beschriebèn waren. Beide Gelehrte hatten diese Zähne, nach der Achnlichkeit ilırer äusseren Gestalt, dem im Bergkalke vorkommenden Geschlechte Ctenodus zugerechn't, und ich folgte in so fern ihrem Beispiele, als ich diese devonischen Ueberreste mit jenem gleichfalls in eine Fanilie und Genus rereinigte. Als sich aber später die Materialien häuften und es hiedurch möglich geworden war, von melireren Exemplaren die inikroskopische Structur zu untersuchen, zeigten sich in dieser bedeutende Verschiedenheiten, mit der von Agassiz aus der juingeren Formation untersuchten, und weun ich jetzt noch den vor mehreren Jahren schon gegebenen, nach dieser Aehnlichkeit gebildeten Faniliennamen beibehalte, so geschieht es nur wegen der grossen Achnlichkeit in dem äusseren Ansehen.

maintenant une haute importance pour l'histoire du développement des animaux vertèbrés des leur apparition sur la terre.

1) Ag. Tom. 2 pars 1 pag. 269.

2) Ueber Lepidotus im Lias Würtembergs von Dr. Fr. Aug. Quenstedt, Tübingen 1847.

3) Ueber die Fische des devonischen Systems in den Umgebungen von Pawlowsk pag. 4.

4) Old Red pag. 122. 
aDans un domaine aussi noureau que celui de l'étude des poissons fossiles, il n'est pas surprenant de voir les linites des familles subir de fréquentes modifications, surtout lorsque les faits acquis se multiplient dans une proportion rapide" $\left.{ }^{\prime}\right)$, sagt Agassiz bei der allgemeinen Beschreibung der Familie der Sauroides diptériens, zu welcher er gleichfalls das Geschlecht Dipterus rechnete, aus welchem wir jetzl gezwungen sind eine eigene Familie zu bilden.

Es ist höchst wahrscheinlich dass unsere eben aufgestellte Familie in Kurzem ein ähnliches Schicksal, wie das der Sauroides dipteriens erleiden und in mehrere zerfallen wird, wenn in Zukunft vollstïndigere Exemplare aufgefunden werden. Die folgenden Beschreibungen beruhen nur auf einzelnen Fragmenten, auf Zïhnen die grösstentheils isolirt im Gesteine lagen und an denen nur selten der Zusammenhang mit den sie tragenden Knochen zu beobachten war. Ohngeachtet schon an diesen eine grosse Verschiedenheit in der mikroskopischen Structur nicht zu verkennen war, wie z. B. zwischen den Zähnen von Dipterus tuberculatus ${ }^{2}$ ) und Dipterus Keyserlingii ${ }^{3}$ ), so haben wir es doch vorgezogen, sie wegen der Aehnlichkeit in der äusseren Gestalt fürs erste in einem Geschlecht zu vereinigen.

Bei Ueberresten ausgestorbener Organismen, deren zu einander gehörigen Theile häufig in be deutenden Entfernungen gefunden werden, ist es oft sehr schwierig, diejenigen nit einander zu verbinden, die iu lebenden Zustande zusammenhängend waren oder wenigstens einer Species angehörten. Die Zähne, oft nur die einzigen nachgebliebenen Fraginente einer ausgestorbenen Fauna, bieten sowol durch Uebereinstimınng in ihrer Gestalt, als ihrer inneren Structur die bessten Mittel dar, Gleiches aneinander zu fügen und Ungleiches zu scheiden. Bei denjenigen Thieren, bei welchen Ober-und Unterkiefer mit gleichen und ähnlichen Zähnen besetzt sind, wird die Vergleichung leicht, bei solchen hingegen, wie die Ctenodipterini, deren Zähne in dem Unterkiefer den Seitenästen desselben aufruhen, im Oberkiefer keine entsprechende ihnen entgegenstehen, sondern diese sich in der Mittellinie des Gaunens befinden, ist eine grosse Uebereinstimınung in der äusseren Gestalt nicht zu erwarten. Es ist daher ganz unmöglich mit völliger Sicherheit zu bestimmen, dass isolirt aufgefundene Zälıne dieser Thiere des Gaumens und des Unterkiefers einer Species angehören und wenn wir es versucht haben die concaven dem Schlunde angehörigen, und die ilinen, unserer Ansicht nach entgegengesetzten, convexen der unteren Kinnlade zu einander zu passen, so berult das nur auf einer Annahme, zu welcher wir uns durch vielfältige Beobachtungen berechtigt glauben. Zu dieser Annahme bielen die verschiedenen Formen der Zabnplatten und der kleinen hinter einander gereihten Zähnchen auf letzteren ziemlich sichere Kennzeichen dar. Was letztere anbelangt, so beruht der Unterschied auf ihre stïrkere oder schwächere Hervorragung über dic Fläehe, auf ihre bald abgerundete oder zugespitzte, bald inchr oder weniger comprimirte Gestalt, auf ihre Stellung in grösserer oder geringerer Entfernung von ein-

1) Recherches sur les poiss. foss. Tom 3 pag. 137.

2) Old Red pag. 47.

3) Tab. 5 Fig. 21. 
ander. An den Zahnplatten selbst zeigen sich bedeutende Verschiedenheiten in Rücksicht ihrer Grösse und Ausdelınung. Die vorderen Hälften der Platten, und namentlich ihr vorderer und innerer Rand, sind bei allen Species fast gleıch gestaltet, die hintere Hälfte hingegen erleidet grosse Abweichungen, indem der äussere und hintere Rand und in Folge dessin, die dieselben besetzenden zahntragenden Rippen, sich mehr oder weniger nach hinten erstrecken.

Ohngeachtel der grossen Verschiedenheit in der Gestalt und den Umrissen, die zwischen den Gaumen- und Unterkieferzähnen Statt findet, stimmen sie doch darin überein, dass die Erweiterung nach hinten verhältnissmässig bei beiden gleichen Schritt hält, so dass, wenn bei eineın Zahne die Rippen oder Kiele sich bedeut'nd nach hinten erstrecken, an entgegengesetzten gleichfalls eine älınliche Verlängerung der Zahnplatte Statt findet und ungekehrt.

Wir kö̉nnen nach der Grösse der Zahnplatten und nach der Richtung der zahntragenden Rippen, zwei verschiedene Typen unterseheiden. Bei der einen, für wetche Dipterus platycephahus ') als Beispiel dienen kann, divergiren suf den Gaumenplatten die Rippen vom hinteren inneren Winkel, nach vorn und aussen, so dass die innerste und hinterste mit einander einen rechten Winkel bilden, wïlnrend die des Unterkiefers unter einem stumpfen Winkel, nach vorn und hinten von demselben Punkte ausstrahlen. Bei dem anderen ist die Ausdehnung der Zahnplatte un die Hälfte kleiner, an der des Gaumens strahlen die Rippen fast nur nach vorn, und die innerste und hinterste bilden mit einander einen spitzen Winkel, die des Unterkiefers sind nur nach rorn und aussen gewandt und die hintere Hälfte fehlt ihnen gänzlich. Zu dieser Abtheilung dient als Beispiel Dipterus Murchisoni.

\section{DIPTERUS VERNEUILLII.}

Tab. 5 Fig. 1-9.

Eine sehr ausgezeichnete ziemlich flache Gaumenplatte, welche durch ihre rechtwinkelige Gestalt, den Zähnen von Dipt.platycephalus sehr ähnlich ist, aber durch die geringe Anzihl der rom hinteren inneren Winkel nach vorn, und der äusseren Seite verliufenden Rippen hinlïnglich von ilnnen verschieden ist. Nicht nur die Rippen selbst, sondern auch die dieselben bildenden Zälne nehmen von innen nach aussen und hinten an Höhe und Breite ab und die 弓̈-te oder hinterste Rippe erreicht kaum die Hälfte der ersten oder inneren. Die innere Lamelle, welche mit der der anderen Scite in der Mittellinie zusammenstösst, ist nicht wie bei den übrigen Arten eine cinfache emailartig überzogene, sondern besteht aus in inehreren Reihen neben und hinter einander liegenden flacher glïnzender Täfelchen; die hintere Lamelle, die den hinteren Rand der Platte bildet, ist glatt und durch schräge, von hinten nach vorn verlaufende Einkerbungen gefurcht. Die Zähnchen sind sowol in den verschiedenen Gegenden derselben Rippe, wie an den rerschiedenen Rippen von ungleicher Form und Grösse, bei den inneren kielartigen Rippen sind die hinteren Zühnchen melır mit einander verschınolzen, während

1) Tab. 3 Fig. 12, 13 und 14. 2) Fig. 16. 
die vorderen mehr von einander getrennt, init ihren Spitzen nach vorn hervorragen. An den hinteren Rippen, und zwar je weiter nach hinten, desto inehr werden die eimzelnen Zähnchen durch grössere Zwischenräume von einander geschieden. Die obere Platte ist schwarz gefïrbt und ruht auf einer helleren, dünnen, knöchernen, deren untere Flïche glatt ist.

\section{DIPTERUS TUBERCULATUS.}

Tab. 5 Fig. $20-22$.

Ctenod. parvulus? Ag. Old Red pag. 124.

Wir bilden hier einen kleinen Zahın vom Unterkiefer, aus den blïulichen Mergeln von Kokenhusen ab, der von den jetzt beschriebenen Arten durch die abgerundete Gestalt der kleinen Zähnchen und durch ihr Getrenntsein von einander selbst bis zum hinteren Winkel, so wie durch seine mikroskopische Structur abweicht. Es wäre möglich, dass er mit dem von Agassiz als parvulus besehriebenen identisch wäre, doch fehlen uns zu gehörigen Vergleichungen die Materialien.

\section{DIPTERUS RADIATUS Eichw.}

Tab. 7 Fig. 8, 9 .

Obgleich es jetzt nicht unsere Absicht ist alle bekaunnten Species des devonischen Systems Russlands hier aufzuführen, so können wir doch nicht umbin eine Art, von welcher wir Gatunen-und Kieferzähne besitzen, die in ihrer äusseren Gestalt an meisten denen von Dipterus platycephalus entsprechen und daher zu unserer ersten Abtheilung gehören, hier mit aufzunehınen. Herr Ag. beschreibt, in seiner im Jahre 1844 erschienenen Honographie zwei Arten, unter dem Namen Ctenod. Keyserlingï und Wörthii ${ }^{\prime}$ ) aus den Ungebungen von Zarskoje Zelo. Herr Eich wald, welcher schon in Juli desselben Jalıres die von Herrn von Simachko in anstehenden devonischen Schriften gefundenen Fischüberreste an den Ufern der Slavïnka, in den vater!ändischen Blättern, in russischer Sprache ${ }^{2}$ ), beschrieben hatte, nimmt für diese beiden Arten seine früher gegebenen Bestimmungen in Anspruch und nainentlich für die erstere Species den Namen serraus für die zweiteradiatus, welche Benennung wir ihrer Prioritit wegen beibehalten müssen. Was die erstere Art betrifft, so haben wir bis jetzt noch kein vollständiges Exemplar zu sehen bekomınen, sondern nur einzelne Zähnchen, die hinreichten die mikroskopische Structur zu untersuchen, die letztere Species glauben wir in der Agassiz'schen Abbildung Fig. 36 wieder zu erkenıen, in welcher die Divergenz der Rippen nach hinten deutlich ist, so wie auch die übrigen angegebenen Kennzeichen, die Zahl der kielförmigen im Verhïltniss sehwach comprimirten Erhabenheiten und die abgestumpften Zähnchen, passen. Offenbar hat Herr Agassiz nur einen Zahn des linken Unterkiefers vor sich gehabt und nach Herrn Eichwald's Angabe, dass

1) Old Red 1844 pag. 122 Tab. 33 Fig. $32-36$.

2) Otetscheswennaja Zapisky, 8-te und 9 -te Heft, St. Petersburg 1844. 


\section{$-23-$}

der seinige, etwas gewölbt und die eine Seite umgebogen war, ist es einleuchtend, dass er gleichfalls nicht eine Unterkieferplatte, wie er angiebt, sondern einen Gaumenzahn besass.

Die Zahuplatte des Gaumens bildet wie bei Dipterus platycephalus einen Quadranten eines Zirkels. Aus dem inneren, hinteren Winkel strahlen gegen zwölf gezälnte Rippen nach vorn und aussen, so dass die innere und hintere unter einander einen rechten Winkel bilden. Die innere Zahnlamelle, deren innerer Rand sich mit dem gleichnamigen der entgegengesetzten Seite verbindet, ist glatt, glänzend, etwas concav und durch eine schwache Längsfurche in zwei ungleiche Theile getrennt, die hintere abgeflachte Lamelle ist ohne emailartigen Ueberzug und hat ein poröses knöchernes Ansehen. Die kleinen Zähnchen, deren Spitze nach vorn gerichtet ist, bilden ein Dreieck mit scharf abgestutzten vorderen Rande.

Die Zahnplatten des Unterkiefers gleichen in Allgemeinen gleichfalls denen ron Dipt. platycephahus, ihre, gegen einander gekehrten inneren Ränder, fallen fast vertical hinunter, der hintere innere Winkel ist sehr stumpf, der äussere Rind aber, der bei der letzten Species einen nach aussen convexen gleichförmigen Bogen bildet, wird bei unserer Species in zwei ungleiche Hïlften, die fast unter einen rechten Winkel zusammenstossen, getheilt; einen hinteren, schräg nach rorn rerlaufenden und einen vorderen äusseren. Zwei Exemplare liegen vor uns, das eine kleinere entspricht nach der geringeren Zahll der Rippen, dem oben beschriebenen Gaumenzahn und dem Eichwald'schen, das grössere dem Agassiz'schén; bei ersterem sind die kleinen Zähnchen, über die Fläche der zwölf Rippen stark hervorragend und ihrer Gestalt nach, denen der Gaumenzïhne gleich, bei letzterem stumpfer und bilden gleichsam nur wellenförmige Erhabenheiten auf den fünfzehn Rippen.

\section{DIPTERUS MURCHISONI.}

Tab. 7 Fig. 2, 3, 4 .

Wir kennen von dieser Species nicht nur die Gaumenzähne, sondern auch ilıre Verbindung mit den sie tragenden Knochen und es zeigen sich noch hinter diesen, andere harte Theile des Kopfes, die ähnlichen, den schottischen Exemplaren von Dipterus platycephalus aufgefundenen, entsprechen. Es ist das vollständigste Exemplar, das bis jetzt in Russland aufgefunden ist. Die Zahnplatten bilden durelı die geringe Zahl, der voin hinteren inneren Winkel ausstrahlenden, inneren scharfkantigen, äusseren mehr abgerundeten Rippen, welche auf der etwas concaven Flïche fast bis zun iusseren Rande einfach verlaufen und erst gegen diesen zwei kleine hervorstehende Zïhnchen besitzen, den Uebergang von Cheirodus zu Dipterus. Die ossa pterygoidea und palatina sind durch tiefe Furchen von einander getrennt und die Sutur zwischen der, in der Mitte sich berührenden Knochen sehr deutlich. Hinter dieser finden sich in der Mittellinie der unteren Fläche des Kopfes zwei parallel neben einander liegende vertical stehende Knochenplatten, ihrer Lage nach dem einfachen os sphenoideum basilare des Dipt. plalycephalus zu vergleichen. Höchst wahrscheinlich gehören die auf Tab. 7 Fig. 2 und 3 
abgebildeten convexen Zahnplatten deın Unterkiefer derselben Species an. Gleiche Zahl und Einfachheit der vorderen schärferen und der hinteren stumpferen, voun hinteren inneren Winkel bis gegen den' vorderen Rand verlaufenden Rippen, an welchen kleine Zahnhö̈cker, je melır nach aussen desto grösser werden, sprechien dafür. In der Anzilhl der Zähnchen an den äusseren Endigungen der Rippen herrscht freilich eine grosse Verschiedeulıeit, denn wälıend bei dem Gaumenzahn eine jede nur zwei besitzt, von denen die hintere noch dazu sehr unbedeutend ist, haben die der Unterkieferplatte zwei, drei, und auf der lintersten gegen sechs herrorragende Spitzen. Wir schreiben eine solche Verseliedenheit nur der Altersversehiedenheit zu, und betrachten sogar noch die in Fig. 2 abgebildete convexe Unterkieferplitte, welche noch inelır Zähnchen auf der vorderen äusseren Hällte besitzt, als der jüngere Zustand der vorigen. Die Zilhuplatle Tab. 7 Fig. 3 ist vollkommen erhalten, der unterliegende Knochen nach hinten und vorn hervorragend, nach innen vertical herabsteigend, Fig $3 \mathrm{c}$ mit concaver Unterfläche.

\section{DIPTERUS MARGINALIS.}

Tab. 7 Fig. $6,7$.

Ctenodus marginalis Ag. Old Red. pag. 123 Tab. 28 a Fig. 21 und 22.

Diese schon von Agassiz beschricbene Species ist deswegen hier aufgenommen worden, weil wir an ihr die mikroskopische Struetur genau beobachten konnten und weil wir durch sie genau erfahren, welche Stellung Agassiz den Cienoduszähnen in Hunde gab, indem er sagt: ๙ a l'angle antérieur on remarque en outre des arrèts concentriques d'acraisseinent.o Dieser vordere Winkel ist aber der innere hintere. Agassiz hatte schon bei der Beschreibung des Clenodus cristatus ') richtig angegeben, dass der glatte Theil der Krone, der Lünge nach in der Nittellinie des Rachens gelegen war, irrte aber darin, dass er die kleineren Rippen die unit kleineren Zähnchen beselzt waren, für die vorderen inneren, die grösseren für die äusseren linteren hielt und da der von ihm abgebildete und beschriebene Zahn, wie aus seiner Convexifät zu sehen ist, dem Unterliefer und nicht dem Gaumen angehörte, so fehlte bei ihm die innere glatte Lamelle; es ist daher nicht die Linie von c bis b, sondern von a bis b 3 , welche dem entgegengesetzten Zahne zugewandt ist.

Wir liaben Tab 7 Fig. 7 einen Gaumenzahn abgebildet, aus dem hinteren inneren abgerundeten Winkel strahlen sieben schwach divergirende geradlinigte gezähnte Rippen nach rorn. Diesæ zahntragende Platte wird innen, hinten und aussen von drei schmalen concentrischen hinter einander liegenden Lamellen eingefisst, welche erstere in ihrem Verlaufe sich einander nähern und vereinigen, un die glänzende Platte zu bilden, deren innerer Rand sich an die, der entgegengesetzlen Seite anschliesst. Diese Lamellen, welche Ag. Veranlassung gaben dieser Species den Nanen marginalis heizulegen, da er sie als etwas Eigenthümliches derselben betrachtete, hielt er für Anwachsringe. Die kleinen dreieckigen Zähnchen stehen in den vorderen Reihen getrennt von einander, ragen wit ihren

1) Poiss. foss. Tom. 3 pag. 137, Tab. 19, Fig. 16. 
scharfen, ein wenig nach vorn geneigten Spitzen hervor, nach hinten nïhern sie sich einander und werden mit der Abnahme der Grösse zugleich stumpfer. Am hinteren äussiren Winkd ragt ein kleiner knöcherner vierkantiger Höcker nach aussen hervor, dem os pterygoideum entsprechend. Diesen Höcker finden wir rollständig erhalten in dem in Fig. 6 abgebildeten Exemplare, das wir gleichfalls zu derselben Species rechnen; ein Vergleich dieses sehr kleinen Knochens, mit dem von os pteryg. des Dipt. Murch. Fig. 3 und tuberculatus Fig. 7 und endlich init dem von Dipt. platycephahus Tab. 3 Fig. $12 \mathrm{Nr} .14$ wird die Uebereinstimmung deutlicher auseinandersetzen.

Zu derselben Species rechnen wir noch den auf Tab. כ̈ Fig, 10 abgebildeten conrexen Zahn des Unterkiefers. Zahl der Rippen, geringe Divergenz derselben und die Gestalt der kleinen Zähnehen stimmen mit den oben beschriebenen völlig uiberein. Wir fanden diese letztere Zahnplatte auf einem knöchernen Fragmente aufsitzend, welches mit geringer Gewalt unversehrt von ersterem abgelöst werden konnte und offenbar dem Aste des Unterkiefers angehören musste.

\section{DIPTERUS KEYSERLINGII.}

Tab. 7 Fig. 1.

Ein sehr schön erhaltener Gaumenzahn noch festsitzend auf dem os pterygoideum. Yon dem abgerundeten, hinteren inneren Winkel strahlen, auf fünf sehr schwach nach vorn und aussen divergirenden Reihen, kleine abgerundete Tuberkel aus, von denen nur drei bis vier an dem äusseren Rande stehende, unversehrt sich über die Fläche erheben. Hinter diesen erblickt man nur Spuren ehemaliger Tuberkel, die jetzt ganz abgerieben sind, wo nach hinten die Convexität der Zahnplatte zunimmut, rerschwinden auch diese und man liann nur mit grosser Mühe in der geglätteten hohlen Fläche die Linien verfolgen, die früher die Zälınchen einnahmen. Dürfen wir nach diesem Exemplare urtheilen, so würde die eigentliche Kaufläche nur in dem hinteren concaren Theile, in welchem die convexe des Unterkieferzahnes einpasst, zu suchen sein, während die Zähne, die nach vorn und aussen herrorragen, durch Zerreiben der Nahrungsmittel nicht abgenutzt, zum Ergreifen und Zerreissen derselben thätig bleiben. - Orel.

\section{Mikroskopisehe structur.}

Der zusammengesetzte Bau der Zahnplatten ron Dipterus lässt schon vermuthen, dass ilıre Structur verwickelter sein wird, als man bei einfachen Zähnen zu finden gewohnt ist. Abgesehen von der Verschiedenheit zwischen der Basis und den hervorragenden Spitzen der Kaufläche, von denen dia erstere aus Knochen besteht, die letzteren aus wirklicher Zahnsubstanz gebildet werden, zeigt sich noch an einigen Gegenden der Platte wahre Schuppensubstanz, die mit der, die äussere harte Hautbedeckung der Thiere bildende, ganz identisch ist. Wir unterscheiden daher fürs erste diese drei von einander. Yom hinteren inneren Winkel werden die in regelnässigen Reihen gestellten zihntragenden Rippen, bis zum vorderen und äusseren Rande, ihrer ganzen Länge nach, von einem, hinten und vorn 


\section{$-26$}

blind endigenden Canal, dem Pulpkanal durchbohrt und dieser trennt die untere Knochensubstanz, von der oberen Dentine, Tab. 5 Fig. 6, 7, 12, 13 d. Die innere glatte glänzende emailartige Lamelle der Gaumenzähne, die in der Mittellinie der Schädelbasis ihrer ganzen Läuge nach, nit der entgegengesetzten in Berührung tritt, gewöhnlich einfach ist, zuweilen aber, wie bei Dipt. Verneuillii aus mehreren einzelnen Platten besteht, ist eine wahre Schuppe. In Fig. 9 ist ein verticaler Durchschnitt derselben, neben einem ähnlichen vom Körper Fig. 17 gegeben. Lian wird an beiden die untere Knochenschicht von der mittleren, durch die netzartig unter einander verbundenen und durch häufige, in horizontaler Ricltung, anastomosirende Gefässkanäle unterscheiden, von denen, die gegen die Oberfläche vertical aufsteigenden Kanäle, sich erheben und in dieser, durch Auflösung in die feinen ausstrahlenden Röhrchen, das Kosmin bilden ').

Betrachten wir die Zahnplatte mit ihrer Basis als ein zusammenhängendes Ganzes, so können wir vier auf einer folgende rerschiedene Substanzen unterscheiden, die unterste mit grossen Gefässkanälen, die in allen möglichen, aber vorherrschenden horizontalen Richtungen verlaufen und durch eine Grundinasse voller strahligen Knochenzellen von einander geschieden werden, auf diese fo!gt eine durch das netzartige Gewebe der Medullarkanäle ihr sehr ähnliche, allein mit Knochenzellen in àer Grundmasse, die keine Ausstrahlungen besitzen; höher hinauf verlieren sich auch diese letzteren und die Grundmasse ist ganz homogen, obgleich der Verlauf der Gefïsskanäle noch fast immer derseibe bleibt, und endlich die wahre Zahnsubstanz, in welcher die Gefässkanäle einen verticalen Verlauf annelmıen, nach allen Seiten die feinen Tubuli von ihnen ausstrahlen und gegen die Peripherie des Zalines an Lumen abnelımen. Aeusserst selten kann man an einem vertiealen Durchschnitte einer einzigen Zahnplatte diese vier verschiedenen Substanzen zugleich beobachten; es finden hier bei den verschiedenen Species nicht nur, sondern bei derselben Art an rerschiedenen Stellen, Abänderungen in den Verhältnissen der einen Substanz zur anderen, Statt, indem oft eine gänzlich fehlt. So sehen wir in den beiden verticalen Durchschnitten, die wir von Dipterus Verneuillii gemacht haben, dass an den äusseren grösseren Zähnen, Tab. ̈ Fig. 6, die mit strahligen Knochenzellen versehene Sủbstanz sich uninitte.'oar an die anschliesst, die wir als die dritte bezeichnet haben, während am inneren hinteren Winkel, Fig. 7 , alle vier Substanzen regelmässig auf einander ruhen. Selten sind diese verschiedenen Substanzen ron einander scharf geschieden, die Gefässe stehen alle in einem steten Zusammenhange, die obəren sind nur Fortsetzungen der unteren und der ganze Unterschied beruht nur auf der Richtung der IlecullarKanäle, auf der Veringerung ihrer Lumina nnd der Modification der Grundsubstanz.

Leider war es nicht möglich, die durch und durch ron Betumen durchdrungene und brïchige

1) Der verticale Schnitt, Fig. 9, stammt vom inneren Rande der Platte her und man sieht in demselben nicht die auf der Oberfläche sich öfnenden Mündungen der grösseren Gefässe, wie sie in der 17 ten Figur dargestellt sind; allein eine schwache Loupe reicht schon hin, sich von der Anwesenheit derselben, an wol erhaltenen Exemplaren zu überzeugen. 
Substanz der Zahuplatten schottischer Exemplare, der mikroskopischen Untersuchung zu unterwerfen. Wir mussten unsere Zuflucht zu den russischen wol crhaltenen und wenig veränderten Exemplaren und hauptsiichlich denen aus dem Orelschen Gouvernement nehmen.

\section{DIPTERUS VERNEUILLII. \\ Tab. 5 Fig. $1-9$.}

Auf der Tab. $ّ$ ist in Fig. $\breve{~ e i n ~ v e r t i c a l e r ~ S c h n i t t ~ e i n e s ~ e i n z e l n e n ~ Z a h n e s, ~ a u f ~ d e r ~ B a s i s ~ r u h e n d, ~}$ unter der Loupe dargestellt, in Fig. 6 ist derselbe, sehr fein geschliffen, unter dem Mikroskop betrachtet. Die eigentliche Zahnsubstanz, aus vertical aufsteigenden, sich sparsan verïstelnden Gefïsskanälen gebildet, deren Aeste gleichfalls bald nach ihrem Ursprunge gegen die obere Spitze des Zihnes gerichtet sind, nimmt für sich allein nur die oberste Spitze in Anspruch; sie wird, ausser von allen Seiten, von derjenigen Substanz umgeben, die wir als die dritte angegeben haben und "die aus netzartig unter einander verbundenen Gefässen bestelıt. Noch besser sieht man diese Ungebung der Dentine von dieser Substanz in einem horizontalen Durchschnitte Fig. $S$, der von der oberen Hälfte des Zahnes gemacht wurde. Die Gefässe der Dentine entspringen grösstentheils aus dem Kanale d, welcher der Pulphöhle entspricht, zum Theil aber auch aus den Gefässen der dritten, die eigentliche Dentine umgebenden Substanz. Der Zahn ruht auf der untersten knöchernen Substanz init strahligen Knochenzellen und nur in seiner Mitte trennt die Pulphöhle oder der Pulpkanal denselben von seiner Unterlage.

Mlacht man einen schrägen Querschnitt von zwei Zähnen der beiden hintersten Rippen und schleift diesen von der hinteren und äusseren Fläche wenig ab, so bleibt bei deın einen Zalın der vorn blind endigende Kanal d' unversehrt, wïhrend dessen äussere Wand bein anderen abgeschliffen wird. Man sieht l̦ier wie nach linten die Platte aus den vier angegebenen Substanzen besteht, indem hier zu der früher betrachteten, noch die knöcherne Basis e hinzukommt.

Macht man einen verticalen Schnitt der inneren Lamelle Fig. 1 a, b so sieht man deutlich die Schuppenuatur derselben, wie schon früher angegeben ist, Fig. 9.

\section{DIPTERUS MARGINALIS.}

Tab. 5 Fig. $10-14$.

Beim ersten Anblick köunte es scheinen, als wenn in der Structur dieser Zähne eine bedeutende Verschiedenheit von Dipterus Verneuillii Statt fände, indern die, die Dentine umgebende Substanz gänzlich fehlt und nicht nur die oberen Spitzen der Zähnchen aus der vierten Substanz bestehen, sondern auch diese in die Tiefe dringt, die Zähne deswegen ein zusaminenhängendes Ganzes bilden und unmittelbar auf der Basis nit strahligen Knochenzellen ruhen Fig. 12. So abweichend dieser Bau ist, so wird er durch die Structur des Dipterus serratus Eichw. (Cten. Feyserlingii Ag.), von der uns leider nur eine einzige zahntragende Rippe zur Untersuchung zu Gebote stand, rermittelt; bei dieser Species sind die hinteren Zühne auf dieselbe Weise gebildet, wie die von Dipterus marginalis, wäh- 


\section{$-\quad 28$}

rend die vorderen, die Structur von Dipterus Vernewillii besitzen und die imnere Dentine von der vasculösen umgeben wird. Ein verticaler Schliff in der Richtung c d Fig. 11 genommen, quer über den hinteren Theil der Zahnplatte Fig. 13, zeigt den Ursprung der etwas gewundenen Medullarkantile aus ihren entsprechenden Pulpkanälen. Ein anderer Schliff in der Richtung a b mehr nach rorn Fig. 12, giebt uns ein deutliches Bild von dem fast verticalen Verlanfe der Ned. Kanäle und ihrer Entstehung aus einer offenen Spalte, so dass wir vermuthen, die Pulpkianile, die am hinteren Ende getrennt von einander verliefen und von denen jeder einer zahntragenden Rippe der Kauflieche entsprach, haben sich nach vorn rereinigt und bilden eine gemeinschaftliche Höhle, zwischen der oberen Zilhn- und untern Knochenschicht. Es sind hier also nur zwei Substanzen rorhanden, eine knöcherne Basis und eine sehr entwickelte Dentine aus vertical aufstegenden Iled. Kanälen gebildet. Diese Med. Kimäle, mit ihren nach allen Seitex ausstrahlenden kleinen Röhrehen, werden durch bestimmte Contouren bezeichnet und von den benachbarten, ihnen angrenzenden geschieden, wie dies in einem horizontalen Schnitte sehr deutlich zu sehen ist. Diese Abgeschiedenheit der einzehnen Systeme, die schon in dem horizontalen Durchschnitte vom Zahne des Diplerus Verneuillii, in geringerem Crade, zu bemerken war, erinnert an eine ähnliche Bildung bei den Ziihnen von Myliobates und der Chimneren.

\section{DIPTERUS KEYSERLINGII.}

Tab. 7 Fig. $1 \mathrm{~d}$.

Eiı durch die Feinheit seiner kleinen Röhrchen ausgezeichneter Zahn.

Ein verticaler Durchschnitt durch zwei zusammenhaingende Zähnchen mit ihrer Basis ist Tab. 7 Fig. $1 \mathrm{c}$ und Fig. $1 \mathrm{~d}$ abgebildet. Han sicht wie die eigentliche Dentine, die von vertical aufsteigenden Medullarkanälen durchbohrt wird, die Zahınplatte, wie bei Dipt.marginalis, ganz allein für sich bildet und durch den Pulpkanal von der knöchernen Unterlage gesehiedeıl ist. Die Medullarkanäle der Dentine entspringen alle aus diesem Pulpkanal, geben im Hinaufsteigen sehr sparsane Seitenäste ab und sendẹı gewöhnlich unnittelbar von ihren Stïmmen die kleinen Röhrchen, unter sehr spitzen Winkeln ab. Diese feinen Röbrehen rerzweigen sich sehr bald in kleinere, so dass der helle Raum um die Can. med. herum, einen sehr geringen Durchmesser hat und spalten sich unaufhörlich in ihrem geschlängelten Verlaufe. Auf diese Weise sehen wir in einem horizontalen Durchschnitte, fast nur die dicht an einander gedrïngten Lumina derselben, welche selbst beim feinsten Schliffe der Oberlläche ein trübes Ansehen gewähren.

Höchst merkwürdig und so viel uns bekannt ist, noch bei keinem Zahne beobachtet, ist eine scheinbar schichtenartige schr regelmässige Aufeinanderlagerung verschiedener Substanzen der Dentine, die schon dem unbewaffneten Auge Fig. 1 c deutlich ist. Erst durch sehr feine Schliffe überzeugt man sich davon, dass die Dentine aus einer und derselben Substanz besteht und dass die dunkeleren Sehichten sich von den helleren und durch eine grosse Inlı̈̈ufung der feinen Röhrehen, die in den 
helleren sparsamer auftreten, unterscheiden. Die untersten, dem Pulpkanale am nächsten liegenden, bei den dunkelen Schichten ahmen in ihrer Contour die Gestalt der Pulpe nach, sind im Terhailtnisse sehr schmal, während die höher gelegenen breiterer und dunkler sind. Zwischen den wellenförmigen Biegungen treten die Ned. Kan. hinauf. Wir können diese merkwürdige Bildung nicht anders, als dureh die Annahme gewisser Ruhepunkte in der Entwickelung, erklïren.

\section{DIPTERUS GLABER.}

\section{Tab. 7 Fig. 10.}

Beim Schlusse dieser Arbeit erhiclt ich von IIerrn Obristlieutenant Jerofejew einen Zahn, den er im Verlaufe des vergangenen Sommers an den Ufern des Scias in den devonischen Schichten gefunden hatte. Dieser Zahn bietet so viel Interess:ntes in Bezug auf die Bildung der oberen Platte dar, diss ich dessen Beschreibung unmöglich hier ïbergehen kann. Seine convexe Ober- und concave Unterflïche, sein innerer hinterer stark abgestumpfter Winkel lassen auf den ersten Blick einen Unterkieferzahn von der rechten Seite erkennen. Vier scharf herrorragende Rippen, an Höho und Läinge nach aussen und hinten abnehmend, strilhlen divergirend rom limteren inneren Rande nach dem vorderen äusseren. Beide Seitenflächen der Rippen fallen steil ab und so, dass die innerste fist vertical bis zur Basis hinuntersteigt. Hiedurch, so wie durch die scharfe zum Verkleinern der Nahrungsmittel bestimmte Kante der Rippen, unterscheiden sich diese Ziihne von dem Dipterus Murchisoni, bei welehen die innerste Rippe abgeflacht mil einer flaclen etwas concaven Ebene auf der Basis rullt. Wodurch aber dieser Zahn einen so grossen Werth für uns erhtïlt, ist die schöne Erhaltung seines vorderen und iiusseren Randes. Bei allen bis jetzt beobachteten Exemplaren endigen die Rippen nach aussen ganz abgestutzt, mit senkrechten Wänden; bei Dipt.glaber aber ist die Entwickelung des Zahnes noch nicht beendigt und man sieht die kleinen emailartig glänzenden Zilhnchen noch im Wachshume begriffen, mehr oder weniger über die Flïche erhahen, den ganzen äusseren Rand bis zur Basis besetzend. Tor den Rippen stehen diese kleinen Zihnchen zu zwei, auf der himtersten drei hinter cinander, als stumpfe Höcker hervor; in den tiefen Zwischenrïumen erscheinen, dem Anscheine nach, ans einer ithnlichen Substunz gebildete flache Platten, die ihnen ein runzliches Ansehen gewiihren und man iiberz'ugt siè hiedurch schon, bei oberflizellicher Ausicht diron, dass die Rippen aus dem Zusammenfluss solchar kleiner, 'ursprïnglich isolirt gebildeten Zähnehen, entstinden sind. Bei Diplerus Vernevillii zeigte sich an der inneren Platte der Gaumenzïhne Tab. 3 Fig. 1 und 3 elwas Aehnliches, denn auch hier bestand die gewöhnliche platte Fläche aus einzelnen kleinen nebeneinanderliegenden und getrennten Liamelien. Siehe Fig. $10 \mathrm{C}$ in natiurticher Grösse und Fig. 10 D vergrössert.

Um die fortschreitende Bildung der Zihnrippen und ihre Entwickelung aus den jungen Ziihnchen zu beobachten, wurde ein verticiler Luingsschliff ron dur dritten Rippe ed so gemirht, dass derselbe gerade durch die Mitte der Rippe bis zur Basis der Zahnplatte ging, also sowol einen Theil der 
schon ausgebildeten Zahnsubstanz, als auch die auf verschiedener Stufe der Entwickelung stehenden kleinen Zähnehen durehsehnitt. Dieser Durehschnitt ist auf Tab. 7 Fig. 10 E unter dem Mikroskop im verkleinerten Naassstabe gezeichnet. Die Basis der Zahnplatte besteht aus vertical aufsteigenden Ilarkkanälen, welche parallel und schr gedrängt an einander, vertical hinaufsteigen und Queräste fast unter rechten Winkeln absenden, durch welche sie rerbunden werden. Der Verlauf dieser Gefässe ist auffallend dem ähnlich, wie er bei Cheirodus beschricben ist, nur fehlen hier die grossen Kanäle, die die kleinen Zähnchen bei jenen bildeten. Aus diesen Kanälen, die in einer homogenen Grundsubstanz mit kleinen Zellen ohne Ausläufer eingebettet sind, steigen unnittelbar die, der Dentine gegen die Oberfläche hinauf, und der Unterschied zwischen den Gefässen der Basis und der Spitze des Zahns, besteht hauptsächlich in der Art, wie sie mit einander anastomosiren und in der verschiedenen Richtung, die sie gegen die Oberfläche annelımen. Je weiter hinauf desto spitzer werden die Winkel zwischen ihren gespaltenen Aesten und die durch sie gebildeten Haschen werden mehr in die Länge gezogen. In der Nähe der Oberfläche hören die Anastomosen. ganz auf, alle Aeste und die von ihnen ausgehenden Zweige nehmen, ein wenig geschlïngelt, eine rerticale Richtung an und vermindern durch das wiederholte Zertheilen ihr Lumen, so dass sie nur als sehr feine Kaniäle endigen. Mit diesem Hinaufsehreiten der Gefïsskanäle hält eine Veränderung in der homogenen Grundmasse gleichen Schritt, die Anzalıl der Zellen in derselben nimunt nach oben allnälig ab und in der Gegend, wo die Gefïsse anfangen längere Maschen zu bilden, verlieren sie sich gänzlich, um eimer anderen Bildung Platz zu machen. Hier entspringen von den Medullarkanälen, die man von hicr aus als Kanäle der Dentine betrachten kann, die feinen Zahnröhrchen, die nach allen Seiten von ihnen aus divergiren, nach oben sich sehr vervielfältigen, aber immer kurz und nur in der Nachbarschaft der Gefässe, ron denen sie abgehen, bleiben, ohne weit in die homogene Grundsubstanz einzudringen.

Ilan kann nun sehr schön am ganzen vorderen äusseren Rande der Zahnplatte, von oben bis unten das stufenweise Fortschreiten der Dentine aus der Substanz der Basis verfolgen; die beiden, der Rippe der Oberfläche zunächst, aber schon am äusseren Rande unter einander liegenden abgeflachten Platten e und f, die bald hinaufrücken müssen, sind in ihrer Structur schon so weit vorgeschritten, dass diese schon ganz das Ansehen der Zahnsubstanz besitzt, die Nedullargefässe haben einen langgestreckten Verlauf angenonmen, die Zellen der Basis fehlen gänzlich und die kleinen Zahnröhrchen sind deutlich zu erkennen. Bei den drei folgenden $\mathrm{g}$, h und i findet dasselbe, aber in riel geringerem Grade Statt, die Substanz der Basis durch ihre kurzen Maschen und die Anwesenheit der Zellen leicht zu erkennen, gelıt sehr weit in die Höcker hinein, aber man erkennt doch noch immer die, in die Länge gezogenen Kaniile von feinen Zahnröhrchen umgeben; bei dem letzten Tuberkel k, welcher an dem vorderen unteren Rande der Basis der Zahnplatte ganz nach aussen hervorragt, fehlen die Zahnrölırchen gänzlich und die Nlarkkanäle, obgleich schon gegen die Oberfläche etwas verlängert, behalten deswegen àas Anselien und die Natur der Basis bei. 
Wir müssen aufrichtig gestehen, dass eine Zahnbildung, wie wir sie eben beschrieben hilben etwas so Befremdendes hat, dass wir lange in Zweifel dariber waren, wie diese Platte zu betrachten sei. Sollte es möglich sein, dass nämlich ein Zahn durch Herauswachsen der Dentine aus dem unterliegenden Knochen am äusseren und vorderen Rande desselben sich vergrössern könnte, da wir doch bei allen älnlichen Bildungen erkannt haben, dass von hinten und innen sich immer neue Schichten ansetzen und dass die vorderen immer weiter hinausgeschoben und gänzlich abgenutzt werden. Können wir uns vorstellen, dass die feinen Zahnröhrchen, die bei allen bekannten Zahnbildungen, an den äusseren Rändern des Zahnsäckchens zuerst verhärten und dass die Pulphöhle oder die Iledullarkanäle, die ihre Stelle ersetzen, erst später nach der angefangenen Bildung der kleinen Tubuli und vielleichı häufig nur durch diese, mit harten Wänden eingefasst werden, hier dann erst ersclieinen, wenn die Markkanäle, schon fertig ausgebildet, vorhanden sind?

Wenn nun bei den Zälmen von Dipt.glaber, die Bildung am äusseren und vorderen Rande beginnt, so müssen sie am hinteren inneren Winkel immer zuerst abgenutzt werden und die Zähne werden, ganz entgegengesetzt von denen der übrigen, ron vorn und aussen, nach innen und hinten geschoben, so dass nur der hintere Theil derselben, die eigentliche Kiuflïche wäre. Vergleichen wir die Zahnplatten des Gaumens von Dipt.platycephalus, mit denen vom Unterkiefer, so sehen wir, dass die ersteren so flach concar sind, dass ron den stark convexen der letzteren nur der hintere Theil miit ihnen bein Kauen in Berührung komınen, und dass der vordere und äussere stark abfallende Rand an der Verkleinerung der Nahrungsmittel nicht Theil nehmen konnte.

Un cimen sicheren Aufschluss dariber zu erhalten, welcher Theil der Zahnplatte, der vordere gerippte oder der hintere glatte convexe, die eigentliche Kaufläche sei, welcher Theil des Zalmes also durch stärkere Abnutzung schon lïnger im Gebrauch gewesen war, wurde ein verticaler Schmitt vom hinteren inneren Winkel der Platte gemacht und aus dieser zeigte sich unter dem Mhkroskop, dass diese Gegend am meisten abgerieben und abgenutzt war, während die Rippen nach rorn noch ganz unberührt erschienen. In dem hinteren Durehschnitt zeigte sich die Dentine sehr dünn, die Geffisse derselben mündeten mit grösseren Oeffnungen auf der Oberfläche und anastomosirten häufiger mit einander, so dass, wenn wir die Zahnsubstanz der Rippe, mit dem hinteren Theil der Gaumenplatte rergleichen würden, letzterer nur bis zu der Höhe die in Fig. 10 E mit I bezeichnet ist, erreichen würde, während die in der Rippe selbst sich bis d hinauferstreckte. Ein offenbarer Beweis, dass nur der hintere Theil der Zahnplatte in Thätigkeit gewesen war, und die Reihe an den vorderen gerippten und tuberculirten erst nach der Zerstörung des ersteren kommen würde.

\section{DIPTERUS TUBERCULATJS.}

Tab. 5 Fig. 20—22.

In Rücksicht der mikroskopischen Structur weicht dieser Zahn bedeutend von allen übrigen ab; 
die unterste knöcherne Substanz mit strahligen Knochenzellen fehlt und die Basis der Zahnplatte Fig. 21 bei a besteht aus derjenigen, die wir als die zweite bezeichnet haben, in welcher die Zellen ohne Ausliufer rorkommen, Fig. 22 in einem horizontalen Schnitte. Aus ihr besteht die ganze Platte, die Zähruchen sind in dieselbe eingesetzt, und sie drängt sich in die Zwischenräume hinein, Fig. 21. Auf gleiche Weise fehlen die so charackteristisch langen, sich sparsam verzweigenden vertical aufsteigenden Medullarkanäle der übrigen Arten von Dipterus, und die Dentine besteht gleichsam aus derjenigen Substanz, die wir als die dritte angegeben haben, in welcher die Med. Kan. netzförmige Maschen bilden. Man kömnte, ihrer mikroskopischen Structur nach, diese Zähnchen mit denen einiger Squaliden, wie Odontaspis, Lamna u.s. w. vergleichen und es ist höchst wahrscheinlich, dass sie einem anderen Genus als Dipterus in Zukunft zugetheilt werden müssen. Die Zahnkanäle entspringen sowol aus dem Pulpkanale, wie unmittelbar aus der unteren zelligen Substanz. 


\section{CHEIRODUS. \\ Conchodus? $\mathrm{M}^{\prime}$ Coy, Chirodius? $\mathrm{II}^{\prime}$ Coy.}

Das Geschlecht Ceratodus schliesst sich durch den Bau semer Zähne, den einzigen Ueberresten, die wir bis jetzt von demselben besitzen, so ('ng an Dipterus an, dass Herr Profissor Bejrich ') nur eine grössere, etwa doppelte Zilhl der Falten, als das einzig wesentlich abweichende Herkmal der letzteren betrachtet; man kann diaher mit ziemlicher Sicherheit annehmen, dass nicht nur die Stellung der Zilhne in Gilumen und Unterkiefer, sondern auch ihıre Zahl bei beiden Geschlechtorn iibereinstimmen wird und dass wol auch die Knochen, die ihn''n zur Stiitze und Anheftung dienten, nicht sehr verschirden von einander sein werden. Agassiz hilt ohne Kenntniss von den Gaumenknochen dieser Fische, ohne je ilhen Unterkiefer gesehen zu haben, die Stellung und geringe Ziahl dieser Zilhne im Rachen sehr richtig aufgefasst, indem er sagt ${ }^{2}$ ): "Je crois plutôt que chacune de ces dents occupait un côlé des màchoires et qu'elles éla e:ıl. rapprochées l'une de l'autre sur lia ligne médiane, par l'un de leurs bords, probablement par le bord croitn. Nach seiner Ansicht war der gefiltete Rand der ïussere, der gerade der innere, welcher an den gleichnamigen der anderen Srite anstiess, und die Richtung der Falten nach rorn gewendet. Plieninger ${ }^{3}$ ) meinte, dass nicht die obere gegen den Aussenrand hin gelaltete Seite der Zahnkrone, sondern vietmehr die entgrgengesetzte unterhalb der Hörner, der durch Kiluen sich abnutzende Theil des Zihnes sei, eine Annahme die schon von Beyrich, in der erwihnten Abhandlung, als irrig dargestellt wurde. Herr Beyrich glaubt durch Vergleichungen mit anderen Zälınen, denselben eine von der Agassiz'schen versehiedene Stellung geben zu miissen und stellt sie so, dass nach vorn hin die engeren und weniger tiefen Buchten der Hörner des Aussenrandes zu stehen kommen, unterseheidet statt eines inneren und hinteren Randes, einen vurderen und hinteren Seitenrand und betrachtet die innere Ecke, in welcher die Seitenwäinde zusammenstossen, als denjenigen Punkt, in welchem die Kronen zweien, als rechten und linken zu rinander gehörenden Ziihne derselben Kinnlade, sich anı meisten nilherten. Die Verschiedenheit dies'r Ansichten liegt in der Voraussetzung, dass beide, die oberen und unteren Zïhne, wie es ge-

1) Zeitschrift der deutschen geologischen Gesellschaft. 1850. Tom. 2. Heft 2. pag. 154.

2) Recherches sur les poiss. foss. Tom. 3. pag. 129.

3) H. von Meyer und Plieninger, Beiträge zur Palaeontologie Würtembergs, pag. 85. 
wöhnlich der Fall ist, in gleichen Entfernungen von einander den Kinnladen aulliegend, entgegengeselzt, gleichgestaltet sein und daher ihre Rïnder mit einander übereinstiunmen mïssten. Die Keuntniss, die wir von der Lage und Stellung der Zähne von Diptenus erlangt laben, lässl wol keinen Zweifel über die von Ceratodus und den mit diesen so nahe verwandten Geschlechtern mehr iibrig. Wir sehen aus diesen, dass sie einen geraden Innenrand besassen, mit welchem die des Gaumens in der Mittellinie zusammenstiessen, die des Unterkiefers aber, je nach der Richtung seiner Seitenäste, von eirander entfernt blieben. Wir sehen, dass die Zähne des Gaumens eine ganz andere Gestalt, als die der Unterkinnlade latten, dass die Zu- und Abnahıme der Grosse der Kaulläche, abgesehen von ihrer Gestalt, bei beiden immer in gleichen Verhältnisse steht, dass die lïngsten und höchsten Rippen, so wie die zwischen ihnen liegenden Buchten und Vertiefungen nach vorn, die kiirzesten und flachsten, nach hinten gerichtet sind; wir unterscheiden die Kauflächen an ihrer Oberfliche, die bei den Gaumenfliichen eben, häufig concar ausgehöhlt, bei denen der Unterkiunlade gewöhnlich melır oder weniger convex gestaltet sind, und bei ersteren init abgeflachten hinteren und inneren Räindern den Gaumenknochen aufliegen, bei ersteren mit stark convexen, oft vertical abfallenden Rändern und concaver Unterfläche, die Unterkiefer umhüllen.

Zwischen denen mit stark herrorragenden glatten IIöckern besetzten Zïhnen von Ceratodus aus dem Jura und der Trias, und den mit fächerförmig ausstrahlenden und gezähnten Kielen versehenen der Clenodipteren, die dem devonischen Systeme und Bergkillke eigentliümlich zu sein scheinen, stehen andere, die durch ihre glatte Kaufläche und flachen, von dieser gegen den äusstren Rand, verlaufenden sparsamen Rippen sich ersteren, durch die ficherförmige Ausbreitung derselben, letzteren enger anschliessen, von beiden aber durch ihre mikroskopische Structur verschieden sind.

Man unterscheidet an diesen Ziilınen, wie an allen ähnlichen und verwandten, die obere Zahnplatte und die untere Basis, erstere ist gewöhnlich schwarz gefärbt, letztere hellgelb, beide werden von einander durch eine sehwache Einschnürung getrennt. Die Basis ragt nach hinten und aussen in der Fläche hervor und steigt nach inıen schräg hinab. Die Kaufliche ist bei den Gaumenzilhnen Tab. 6 Fig. 15 concav, bei denen des Unterkiefers Fig. 18 convex, nach hinten glatt, nach vorn und aussen in fingerförmig sich ausbreitende flache, abgestumpfte, divergirende Rippen gespalten. Die Rippen nebmen in ihreen Verlaufe gegen den vorderen und äusseren Rand wenig an Breite zu, die zwischen ihnen liegenden, sie trennenden Vertiefungen werden dagegen immer breiter. Bei den Gaumenzähnen ist der innere Rand, der wahrscheinlich wie bei Diplerus mit dem gleichnamigen der anderen Seite in Berührung stand, grade, der hintere geht vom hinteren inneren Winkel etwas schrïg nach aussen, der äussere Rand wird nach hinten, wie der vorige, nur von der Basis gebildet, ist etwas concav und geht unit einein convexen Bogen in den vorderen gerippten über. Herr $\mathrm{M}^{\prime} \mathrm{C}_{0} \mathrm{y}^{\prime}$ hat aus einem ähnlich gestalteten, aber mit noch stïrker ausgehöhlter Kauflïche sein Genus Conchodus ${ }^{1}$ ) gestiftet und wahr-

1) Ann. and mag of Nat. History $2^{\mathrm{e}}$ series 1848 pag. 311. 
scheinlich aus dem ihm im Unterkiefer entgegengesetzten, aber im Bergkalke gefundenen Zalıne das Genus Chirodus ${ }^{1}$ ). Als Charakter dieses letzteren Geschlechts giebt er an, dass vom inneren graden Rande eine kleine daumenartige Fortsetzung unter rechten Winkel, von der Mitte der Länge des Zahnes abgeht, so dass hiedurch die beiden neben einander liegeıden, in der Mittellinie von einander getrennt wurden. Aehnliche ges'altete Zïlıne kommen auch in Russland vor, gehören aber nicht den Gaumenknochen, sondern dem Unterkiefer an und berühren sich daher nie mit ilıren inneren Rïndern. Wir kennen von diesen beiden eben genannten Geschlechtern nicht die mikroskopische Structur; nach unseren Untersuchungen, an solchen dem Ceratodıs :̈hnlichen Formen, haben wir nur die gefunden, die von $A$ gassiz ats dem Ceratodus eigenthümlich beschrieben ist, doch können wir hierüber nicht genügend entscheiden.

Die mikroskopische Structur der Zïlne von Cheirodus ist in mancher Hinsicht sehr ausgezeichnet, der Uebergang wahrer Knochensubstanz mit strahlenden Knochenzellen in Zalınsubstanz, das Hineindringen der ersteren in die letzteren und gleichsan kleine einzelne Zälnchen, aus denen die ganze Masse der Zathnplatte besteht, von einander trennend, ist wol etwas sehr Abweichendes. Bei Diplerus konnte man noch einen Pulpkanal eskennen, der zwichen Dentine und Knochen die beiden Substanzen von einander sehied, efwas Aehnliches scheint nach den Zeichnungen von Agassiz ${ }^{2}$ ) auch bei Ceralodus vorzukommien, fehlt aber bei Cheirodus gänzlich. Bei Diplerus sehen wir schon die einzelnen Erhabenheiten der Kaufläche als für sich bestehende Zähne an, die vollständig von einander getrennt waren; bei Cheirodus sind sie alle zusammengeschmolzen und bilden eime zusammenhängende Masse durch Anastomosiren ihrer Markkinäle.

Niacht man aus der Mitte des Zahn''s, seiner Länge nach, dem hinteren Rande näher als dem vorderen, ungefiihr in der Gegend von g Fig. 1̈̈, Tab. 6, also dort, wo die Giumenplatte eine glatte Ebene besitzt, einen verticalen Schnitt, schleift diesen so weit von beiden Seiten ab, dass er ron der Jicke ciner dümnen Pappe, nur durchscheinend wird, so unterscheidet man schon unter der Loupe die knöcherne Substanz der unteren Basis, von der oberen Zalinplatte und sieht wie erstere in regelmässigen bestimmten Entfernungen in die obere hellere glasartige Substanz der Krone hinaufsteigt und letztere sich in die Zwischenräume der ersteren linuntersenkt, ja man kann schon bei geringer Vergrösserung die einzelnen Ziihnchen von eillander unterscheiden. Wird das Abschleifen so weit fortgesetzt, dass der Durchschnitt hinreichend dünn ist, unı unter dem Nikroskop betrachtet werden zu können, Fig. 19 , so tritt die Verschiedenheit der beiden Structuren noch deutlicher hervor, und man verfolgt die strahligen Knochenzelten der Basis, bis zu einer gewissen Höhe, die Zwischenräume zwischen den kleinen Zähnchen einnehnend. Die Basis besteht aus einem äusserst regelı̈ässigen Gewebe von Markkanälen,

1) Ann. and mag of Nat. History $2^{e}$ series 1848 Tom. 2 pag. 130.

2) Recherches Tom. 3 Tab. M. Fig. 1 und 2. 
dirse steigen von der unteren Fläche vertical in die Höhe und bilden, inden sie sich, durch fast unter rechten Winkeln von ihnen ausgehende Querästen mit einander verbinden, ein Netz aus viereckigen Maschen. Diese Hurizontalität der Seitenäste bedingt oder ist die Folge, wie man will, einer horizontalen Schichtung der, die hoinogene Grundsubstanz bildenden Schichten und in Folge dessen der parallelen Laigerung der Kuochenzellen, wie man sie im Isopedin zu sehen gewolnt ist, wo fast nur verticale Markkanäle ohne seitliche Aeste die Lamellen durchziehen. Hier tritt aber diese Schichtung der Knochenzellen nur im senkrechten Durchschnitte hervor, denn macht man einen horizontalen Schnitt ron einein ähnlichen Bruchstück, wie er in Fig. 22 dargestellt ist, so erkennt man deutlich, dass die Knochenzellen hier den Biegungen und Windungen der horizontal verlaufenden Markkanäle, wie in vollständigen Knochen, folgen In diesem quadratischen Gewebe des unteren Theils der Basis zeigen sich, bei sehr günstig ausgefallenen Durchschnitten, die die kleinen Zühnchen gerade in ihrer Mitte treffen, in gewissen Entfernungen ron einander, grosse rertikal aufsteigende Markkaniile, Fig. 19 und nur von diesen strahlen die Aeste und Zweige aus, die die eigentliche Zahnsubstanz bilden. Sie steigen von unten ohne ihr Lumen zu verringern, bis zu einer gewissen vorgeschriebenen Höhe hinauf und von hier aus beginnt ihre Zerspaltung in Aeste, die unter spitzeren Winkeln von ihnen abgehen. Anfangs behalten sie durch die vielfältigen Anastomosen der Aeste unter einander, noch das Ansehen der Substanz der Basis bei, aber je näher der Oberfläche, desto mehr gehen sie in die wahre Zahnsubstanz über, die Knochenzellen verlieren sich gïnzlich und die feinen, von ihnen nach allen Seiten ausstrahlenden Zahnröhrchen, ersetzen deren Stelle in der homogenen Grundsubstanz.

Ein jedes einzelne Zähnchen, obgleich im Unkreise mehr oder weniger mit seinen, ihn ungebenden Nachbarn durch Anastomose seiner Aeste und Zweige verbunden, wird von der Substanz der Basis, d. h. durch wahre Knochensubstanz, bis auf eine gewisse Hölıe von diesen geschieden, über diese Grenze hinaus sind aber alle mit einander verbunden. Um diesèn verticalen Schnitt Fig. 19 zu vervollstïndigen und die Lage der einzelnen Zähnchen in der Platte der Krone genauer betrachten zu können, wurde aus derselben Gegend, zwischen $g$ und h Fig. 15 ein horizontaler Schnitt gemacht und dieser von beiden Flächen so weit abgeschliffen, dass der Durchschnitt ungefähr der Linie a a Fig. 19 gleich kam. Hier erscheint fast in der Mitte ein horizontal durchgeschliffenes, noch vollstiindiges Zähnchen Fig. 22, von anderen in bestimnten Ertfernungen, aber nur theihweise sichtbaren, umgeben. Man erkennt wie die Markkinäle, gleichsam aus einem Centrum dem Hauptkanale, nach allen Seiten ausstrahlen, sich mit den äussersten Verzweigungen der benachbarten durch Anastomosen vereinigen und alle noch durch Knochenmasse unter einander verbunden werden.

Während die Substanz der glatten, concaven oder convexen Kaufläche der Cheiroduszähne aus neben und hinter einander stehenden kleinen Zähnchen zusanmengesetzt ist, bestehen die ron dieser nach vorn ausstrahlenden flachen Rippen, nur aus einzelnen hinter einander liegenden Reihen dersel- 
ben, deren äusserste Ausläufer sich bis in die sie trennenden Vertiefungen hineinzichen, gegen die Oberfläche aber in eine knöcherne Structur übergehen.

Macht man einen rerliealen Querschnitt von einer der vier Rippen, wie er unter der Loupe ge sehen in Fig. 20, unter dem Mikroskop Fig, 21, abgebildet ist, so sieht man wie schon fist von der unteren Fläche der Basis von einem Mittelpunkte aus, eine nach beiden Seiten divergirende Ausstrahlung der Markkanäle Statt findet. Von diesen Nittelpunkte zielıen sich die Verästelungen anfangs sei twärts in horizortaler Richtung hin und bilden durch zihlreiche Anastomosen ein sehr zusinnmengeselztes Netz, in dessen Vaschen der Breitendurchmesser vorherrscht, etwas weiter hinauf nehmen sie eimen schrägen, sclıwach aufsteigenden Verlauf an und nur diejenigen Nedullarkanitle, welche zur Bildung des Zahnes selbst bestimmt sind, steigen vertical gegen die Oberfliiche der Rippe in die Höhe, Ireten aus dem Bereich der mit Knochenzellen angefïllten Substanz heraus und bilden mit ihren kleinen feinen ausstrahlenden Zahnröhrchen die eigentliche Dentine, wie wir sie früher beschrıeben haben. In den concaven Zwischenräumen, welche die Rippen von einander scheiden, tritt ein höchst merkwürdiges und so viel wir wissen, bis jetzt weder in Ziihnen noch Schuppen beobachtetes Verhältniss auf, ein wahres Verschmelzen der Dentine mit Knochen; die Vedullarkanäle nehmen, ehe sie die Oberllïche erreichen, rasch im Durchmesser ab und bekommen ganz dis Ansehen der Rühren der Zihnsubstanz, steigen durch die Knochenmasse durchdringend, fast vertical in die Höhe und bilden um sich einen kleinen, ihrem Verlaufe entsprechenden Hofe, von homogener durchsichtiger Substanz, welcher von allen Seiten von der mit Knochenzellen angefiillten, ungeben wird.

Will man sich diese letzten Endigungen der Markkanile gleichfalls als kleine Zïhnchen vorstellen, so muss man sich die hohlen Zwischenrïume zwischen den Rippen, als aus tausenden derselben zusaminengesetzt denken, die in Knochen eingebettet sind. 
Unter den interessanten Fragmenten, die ich der Güte des Herrn von Kiprijanow verdanke und die aus den dolomitischen Schichten des devonischen Systemes im Orelschen Gouvernement herstammen, fanden sich einPalar sehr gut erhaltene, vom Vordertheile eines Kopfes, dessen Bau, von allen bis jetzt bekannten, auffallend abweicht. Eine, in ein Stück verwachsene Schnautze von knöcherner Structur, zilhntragende Knochenplatte, dem Gaumenapparat angehörig, Zähne denen der Placoillen älnlich, haben wir schon bei den Clenodipterini kennen gelernt, aber wie bei den Gymnodonten, den ganzen Vorderrand der breiten Schnautze bildende und von dieser zu beiden Seiten nach hinten ausgehende, eine Hölle einschliessende, äussere vordere Ränder des Kopfes, aus wahrer Dentine bestehend, sind uns noch bei keinem fossilen Fische vorgekommen. Aul der 6-ten Tafel ist in der 3-ten Fig. der vordere Theil des Schädels, dessen Schnautze von i bis b vollkommen erhalten war, im Profil abgebildet, in Fig. 2 derselbe von oben und Fig. 1 von unten angesehen. Die Schautze ein zusammenhängendes Ganzes bildend, ist vorn (Fig. 1 a a) breit, oben gewölbt und läuft nach unten in einen scharfen, der Quere nach, verlaufenden Rand aus, der sich durch seine etwas hellere Farbe und schönen Glanz von dem übrigen Theile des matt aussehenden Gewölbes leicht unterscheidet. In der Mittellinie ragt dieser Rand etwas hervor, an den beiden Seiten a und a endigt er spitz, spaltet sich aber hier in zwei Aeste, einen nach hinten aufsteigenden ab, der die obere seitliche Grenze der Schnautze, und eilıen nach linten herabsteigenden a k, welcher den unteren Rand einer, durch die Entfernung der beiden Aeste von einander entstandenen, tiefen dreikantigen Grube bildet. Der vordere Rand des Kopfes, an dessen unteren Seite kleine zahnartige Tuberkel hervorragen, von denen die zwei in der Nitte gelegenen die grössten sind, biegt sich nach innen hinein und nimmt gleich vom Umschlage, eine andere knöcherne Textur und hellere matte Färbung an. In der Mittellinie der Schnautze tritt dieser Unschlag nur unbedeutend nacht innen hervor, zu den Seiten aber erstreckt er sich, immer an Breite zunehinend, nach aussen von dem lierabsteigenden Aste a $\mathrm{k}$ begrenzt, bis zu den Zahnplatten f. In den dreieckigen Raun, der durch die Divergenz der beiden Hälften dieses Umschlages entsteht, legt sich eine kleine einfache Knochenplatte, vielleicht dem vomer analog hinein, ohne den Zwischenraum ganz auszufüllen, 
aber den beiden Platten aufliegend, die unter denen der Zähne gelegen nach hinten $\mathrm{c} d$ hervorragen. Diese beiden in der Mittellinie gelegenen Knochen werden durch symplyse bis c mit einander verbunden, von hier aus aber entfernen sie sich von einander und endigen nach hinten mit ziemlich scharfen Spitzen. In der zweiten Figur sieht man diese Knochen von der oberen Seite, durch eine schwach erhabene Rippe in fast zwei gleiche Theile getheilt, einem inneren, welcher oben und unten unbedecht ist und einem äusseren, dem auf der unteren Fläche die Zahnplatte aufliegt. Man kann diese eben beschriebenen Knochen ihrer Lage und Gestalt nach, mit denselben bei Dipterus vergleichen und für zusaminengeschnnolzene ossa pterygoidea und palatina betrachten, zwischen welche sich wahrscheinlich, den leeren Raum d c d ausfüllend und nach hinten hervorragend, das os sphenoideum einschob um den Basilartheil des Schädels zu ergänzen. Die beiden Zahnplatten sind nicht wie bei Dipterus in der Mittellinie verbunden, sondern ihre parallelen inneren Ränder verlaufen von vorn nach hinten in gewissen Entfernungen von einander. Bei Dipterus nimmt die Kaufläche fast die ganze Zahnplatte ein und die Gaumenplatten liegen fast in einer Ebene, bei Holodus steigen die Dentinalplatten, je weiter sie nach den Seiten vorrücken immer mehr hinauf, bis sie am äusseren Rande eine fast verticale Stellung einnehmen und ihnen hier die Zähne eingebettet oder aufgewachsen sind, Fig. 3 f. Die Zilhnplatten stosśen nach vorn an die inneren Ränder des Umschlages der Schnaulze, nach aussen ruhen sie auf Knochen, die mit dieser zusammengewachsen sind, nach hinten waren sie leider abgebrochen. Auf dem unteren Rande der verticilen leeiste der Zahnplatte, sitzt auf jeder Seite des Schädels ein Zahn mit abgerundeter stumpfer, von den Seiten comprimirter Spitze, nach vorn ist ein kleiner gleichgestalteter und wahrscheinlich auch ein ähnlicher, aber abgebrochener nach hinten angefügt. An diesem Zahne unterscheidet man auf seiner inneren, dem Rachen zugekehrten Fläche, die stumpfe ganz schwarze Spitze und eine hellbraune, durch eine hórizontale Furche von ihm getrennte Lamelle, welche allmälig in die hellgelbe Dentinalplatte übergeht, Fig. כ̈. Die äussere Fläche ist von der inneren sehr verschieden. Nan erkenst eine dunkelgefärbte Spitze und eine hellbraune Basis, und unter dieser, ron ihr, durch eine der Länge nach, verlaulende tiefe Rinne geschieden, eine Reihe kleiner flacher hellbrauner Platten mit spiegelglatten, emaillartigen Glanze, dem des Zahnes selbst gleich, Fig. 6.

Die höcht nnerkwürdige Zusammensetzung des vorderen Theiles des Schädeldaches von Holodus, eines Geschlechtes, das wahrscheinlich in späterer Zeit den Typus einer eigenen Familie bilden wird, erregt durch die Untersuchung der mikroskopischen Structur der einzelnen ihn constituirenden Theile, noch mehr Interesse.

Fangen wir mit der Substanz der äusseren Kopfbedeckungen an, so zeigen sich auf ihrer matten, ungefähr einer Linie dicken oberflächlichen Schicht, kleine und grössere Oell’nungen nach aussen ganz unregelmässig geordnet, bald einander mehr gen:ihert, bald in grösseren Entfernungen von einander Fig. 7. Wird diese Oberfläche eswas abgeschliffen, so erkennt man, dass diese Poren die Mündungen grösserer vertical absteigender Kanäle sind, welche in die knöcherne Masse des Kopfes lineindringen 
und dass, die sie einschliessenden äusseren Wände aus der homogenen Grundsubstanz bestehen, die, an der unteren Fläche Fig. 10 a, mannigfaltig gewunden und geschlängelt, Höhlen von versehiedener Gestalt und Grösse einschliessen, die, jetzt mit weissen kristallinischen Kalksteine angefüllt, in lebendigen Zustande aber wahrscheinlich Knorpelnasse cingeschlossen enthielten. Die Wände dieser Poren Fig. 13 und ihre Fortsetzungen ins Innere Fig. 10 a bestehen aus einfachen, homogenen, concentrischen, durchsichtigen Lamellen, ohne die geringste Spur von Gefïssen und Zellen.

Bei weitem höher ausgebildet als die Wände dieser Kanäle ist die Substanz, welche die Zwischenräune zwischen ilınen einnimmt. Bei b Fig. 10 erblickt man die mittiere Schicht, welche aus gewundenen anastomosirenden Yarkkanälen besteht, die durch eine homogene Grundsubstanz mit länglichen Zellen ohne strahlige Ausläufur von einander geschieden werden: nach oben e verlieren sich die 'Zellen und die gröberen Iledullarkanäle, gehen in feine vertieal aufstẹgende sich verästelnde Rölırchen, deren feinste Zweige nach allen Seiten divergiren und gegen die Oberfläche sich senkrecht hinaufbegeben, äber. Dieser Bau erinnert sehr an eicen ïhnlichen dèr Schuppen von Osteolepis, Megalichthys, Diplopterus und Dipterus und der Hauptuntersehied, zwisehen diesen und Iolodus, besteht nur in der Bildung der Wände der grossen Poren. Eine gamz ähnliche Struetur, nur durch den Mangel der grossen Poren von der Substanz des eigentlichen Schiideldaches unterschieden, zeigt sich an den, vom vorderen Rande der Schnautze, nach hinten auslaufenden Seitenästen Fig. 1 und Fig. 3 ab und ak, deren äusseres glattes polirtes Ansehen, ron ciem matten des Kopfes so auffallend verschieden ist. Hier sind Fig. 11 die feinc n, aus den gröberen Mledullarkanälen entspringenden Rölırchen bedeuten 1 länger, ihre Veriistelungen häufiger und ilıre Verzweigungen mannigfaltiger. Nur noch einen Schritt weiter und wir haben eine völlig ausgebildete Dentine, die ohne Pulphöhe und olıne Pulpe gebildet ist, vor uns. Eine solche Bildung finden wir in dem ganzen vorderen Rande der Schnautze. Schon das äussere Ansehen zeigte eine grosse Verschiedenheit, zwischen der Substanz di'ses schmalen Randes und dem Schädeldache, und die mikroskopische Untersuchung bestätigt dieselbe. Un die Verbindung des vorderen Randes der Schnautze init den Knochen des vorderen Theiles des Kopfes deutlich zu zcigen, wurde letzterer in der Nitte und an mehreren Stellen der liange nach durchgesägt und ein solcher Durchschnitt, wic er unter ver Loupe erscheint, in Fig. 4 abgebildet. Hier unterscheidet inan zwei, schon dem äusseren Ansehen nach, von einander verschiẹdene Substauzen, und namentlich den Zilhnrand, von dem eigentlichen Kopfknochen durch ganz andere Färbung; man glaubt sogar die Grenzen zwischen beiden genau angeben zu liönnen; nacht man aber ron diesen Präparate einen feinen Schliff Fig. \$, so zeigt sich der allmälige Uebergang der Knoclınsubstanz in Dentine sehr deutlich und die ganz übereinstimmende Bildung der Knochen und Zahnsubstanz, sowol der Hauttheile des Sehädeddaches als des Randzahnes, nur in verschiedenen Verhältnissen, bei letzteren mit überwiegender Ausbildung der Dentine, tritt klar hervor. Aus dem Netze von Gefässkinälen, aus welchem die mittlere Schicht der Schiidellinochen besteht, treten, wie bei diesen, die feineren Kan̈̈lchen heraus, nehmen einen 
langgestreckten und fast parallelen Verlauf an, verzweigen sich unter sehr spitzen Winkeln mehrere Male, steigen verlical gegen die vordere Spitze hinauf und geben nach allen Seiten divergirende feine Röhrchen ab. Wir haben hier also einen wahren Zahn, sowohl in Rücksicht seiner Function als der mikroskopischen Struetur nach zu urtheilen, welcher den ganzen vorderen Rand der breiten Schnautze einnimmt und wahrscheinlich ohne Pulpe entstanden, nicht dem, den gewölmlichen Ziilmen der Fïsche eigenen Wechsel unterworfen gewesen ist.

Vollkommen übereinstimmend in der Structur mit der Zalınleiste am vorderen Rande der Sclinautze nur als gesonderte Theile, den wahren Zähnen, den übrigen Fischen sowol ihrer Lage als Bildung nach entsprechend, sind die Zähne, welche den auf den Gaumenknochen liegenden Dentinalplatten all-

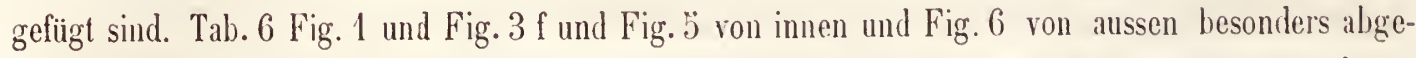
bildet. Sie gehen auf ihrer inneren Fläche, ohne alle Unterbrechung nach unten in die Zalmplatten büber und unterscheiden sich von letzteren nur durch rerschiedene Färbung; an der nach ilussen gewandten Fläche ist durch eine Einschnürung eine Trennung zu Stande gekommen, wie man sie häufig zwischen Basis und Spitze bei vielen Placoiden und namentlich den IIybodonten antrifft, ohne diss hier eine Yeränderung in der Structur zu beobachten ist. Kleine undentliche Poren erscheinen auf der Oberfläche und zeigen an, dass die feinen Kanäle siclı auf dieser öffneten.

Schleift man den Zahn von aussen und innen so weit ab, dass man eine Ansicht von einem rerticalen Lïngsdurchschnitte in seiner Mitte erliailt, so erscheint dieser wie in Tab. 6 Fig. 9 dargestellt ist und die Aehnlichkeit mit der Lciste der Schnautze ist augenscheinlich. Am unteren Rinde erblickt man noch einige Maschen, die in dic Knochensubstanz der Dentinalplatten übergehen, von diesen aus aber verlaufen die, durch ziemlich breite Zwischenrïumen der homogenen Grundsubstinz, geschiedenen Medullarkanäle in die Hölıe, spalten sich im Aufsteigen unter spitzen Winkeln melırere Male, an:stomosiren öfter durch flache bogenförmige Seitenäste mit einander und geben nach allen Seiten ausstrahlende feine Röhrchen ab.

Die einzige wahıe Knochensubstanz mit gewundenen Nedullarkanälen und strahligen Knocheızellen, die in concentrischen Kreisen erstere ungeben, fanden wir nur in der Substanz der Gaumenknochen und haben sie in Fig. 14 abgebildet.

Will man es versuchen unter den jetzt noch lebenden Geschöpfen ein Analogon für das Geschlechit Holodus ausfindig zu machen, und nicht allein dem äusseren Ansehen nach die Zahuplatten der Gymnodonten und der Chimaeren, mit denen der Schnautze von Holodus vergleichen, sondern eine Ueberstimmung in der Grösse, der Art der Anheftung und besonders der mikroskopischen Structur aufsuchen, so ist wol kein anderes Thier dazu passender als der Lepidosiren, dessen schneidende Zahnplatten ${ }^{1}$ ) die dem Alreolarrande der oberen und unteren Kinnlade ankylosirt sind, fast eine ähnliche Construction besitzen.

1) Owen. Odorlographie pag. 168 Tab. 59 Fig. 4 
Nachdeın die so eben gegebene Beschreibung vom Kopfe des Iolodus beendigt war, erhielt ieh von Herrn Taratschkoff eine Sendung von Fischiblerresten aus den Steinbrüchen von Orel, und unter vielen interessanten Fragmenten von Chelyophorus auch ein Paal Stuicke, die nir neu zu sein schienen, deren braune Farbe und äusseres Ansehen aber sehr an Holodus erinnerten. Beide Stiicke waren nicht ınehr ganz vollständig, an beiden war ein Rand rerletzt, die allgemeine Gestalt aber doch linreichend zu erkeunen. Das eine ist auf Tab. 7 in Fig. 13 abgebildet, das andere wurde zur mikroskopischen Untersuchung verwendet. Betrachtet man diese convexen, ovalen Platten ron oben, so ist die Achnlichkeit mit den Zïhnen von Holodus nicht zu verkemnen, gleiche Gestalt, gleicher Glanz und gleiche Vertheilung der Poren auf der Oberfläche, in regelı̈ässigen Eintfernungen von einander, nahe an cinander geriickt und alle von gleicher Grösse. Hierin zeigte sich ein bedeutender Unterschied voin Schädeldache des Holodus, dessen matte Oberfläche mit Poren von ungleicher Grösse, höchst unregelmässig gestellt, in grösseren Entfernungen von einander liegen und doch stimm die mikroskopische Structur fast vollkommen mit der seinigen überein. Wir wissen wirklich nicht wohin wir diese beiden Fragmente bringen sollen, obgleich an Gestalt, Zïhnen gleich, dürfen wir sie ihrer Structur nach nicht zu ilınen rechnen und müssen sie fürs erste als Sclıuppen von Holodus, entweder des Kopfes oder des Körpers, wahırscheinlich dem letzteren angehörıg betrachteı. Zn dieser Annahıne berechtigen uns zwei Gründe, 1) sehen wir, dass auf ähnliche Weise, wie an den vorderen Kopfende von Holodus, so wie auf der Schnautze und den meisten Kopfsehuppen ron Dipterus platycephahıs Porenmündungen von sehr verschiedener Grösse vorkommen, während die Oeffnungen der Medularkan̈ïle auf der Oberfläche der Schuppen desselben Fisches, wie das auch hier der Fall ist, alle von gleicher Grösse und in gleichweiten Entfernungen von einander stehen; 2) weil die in die Tiefe dringenden und geschlossenen llölılen, bildenden Fortsetzungen der unteren knöchernen lamellenartigen Schicht an Kopfe von Holodus oline Knochenzellen sind und ihre Anwesenheit in der ovalen Platte hiedurch schon limlänglich beweist, dass diese von anderen Stellen des Körpers herstammen müssen. Macht man einen verticalen Quer- oder Längsschnitt durch diese Platten, so erhält man von diesem unter dem Mikroskop ein Bild wie es Tab. 7 Fig. 13 c d gezeichnet ist, und die Aelnnlichkeit mit dem anf Tab. 6 Fig. 10 rom Schädeldache des Holodus dargestellten, ist einleuchtend, bei letzterem fehlen nur die grossen Oeffnungen der Poren, die unser Schnitt danals niclit traf, deren Anwesenheit aber durch einen Vergleich der beiden horizontalen Schnitte Tab. 7 Fig. 13 b und Tab. 6 Fig. 7 klar werden.

In diesem Durchschnitte Tab. 7 Fig. 13 c sieht man unten in der Basis die grossen, jetzt mit Gestein angefüllten Höhlen, die von dünnen gewundenen Platten mit Knochenzellen, an denen wir keine strahligen Ausliufer entdecken komnten, eingefasst werden; höher hinauf zeigen sich die Harkkamäle, vielfich anastomosirend, ein feines Netz bildend. Man kann den Uebergang der Gefiisskanäle in die unteren Hölılen deutlich verfolgen und es wäre daher wol möglich, dass letztere, statt wie wir anfings glaubten, mit Knorpelmasse im lebenden Zustande ausgefüllt zu sein, grössere Sinus darstell- 
ten. Von diesen beiden unteren Schichten sind die oberen durch einen helleren Streifen gesehieden, dessen Structur eigentlich von der der übrigen Substanz nicht abweicht, dessen Vorhandensein aber sehr deullich ist und vielleicht darauf hindeuten könnte, dass hier zwei verschicdene, an anderen Stellen des Körpers einzelne entwickelte Substanzen, mit einander vereinigt seien. In den Kopfknochen von Osteolopis und bei den Flossenstrahlen mancher Fische zeigt sich eine ähnliche Linie, die die untere knöcherne Schicht von der oberen schuppigen scheidet. Dieser, öfter durch den Verlauf der heraufsteigenden Gefässe unterbrochene, helle Streifen bildet die untere Grenze grosser Erweiterungen der Gefässkanäle, die sich auf der Oberlläche öffnen. Die platten Zwischenrïume zwischen den Poren der Markkanïle bestehen ganz aus Kosmin, wie am Schädeldache des Iolodus Tab. 6 Fig. 10. Ueber diesen Kosmin ist eine dünne Platte vollkommen durchsichtigen Ganoins ausgebreitet, welches sich, sobald es die Ränder der heraufsteigenden Kanäle erreicht, mit abgerundeten Bogen in diese hineinbegiebt und die Wände derselben bildet. Wir konnten dasselbe nicht weiter in die Tiefe verfolgen, als in der Fig. $13 \mathrm{~d}$ dargestellt ist. Wird ein horizontaler Schnitt von demselben Fragmente angefertigt und derselbe schräge geschliffen, in der Richtung a b Fig. 13 c, unı alle die verschiedenen Schichten von oben anzusehen, so kann man noch besser wie früher, den Uebergang der Markkanäle in die unteren Sinus und die Wände der grossen Poren erkennen. 
An die im Vorigen beschriebenen ausgestorbenen Geschlechter deronischer Fische reihen wir noch zwei aus demselben Systeme an, von denen bis jetzt nur einzelne Zähne aufgefunden sind, das eine nur dem devonischen Systeme angehörig und zwar seinen mittleren Kalkschichten und nicht über diese hinausgehend, das andere zuerst in den obersten auftretend, aber noch in die Formation des Bergkalkes übergehend.

Obgleich diese beiden Geschlechter nicht nur von einander in der mikroskopischen Structur ihrer Zähne verschieden sind, nach dem jetzigen Stande der Wissenschaft auch besonderen Familien angehören, und von Dipterus, Cheirodus und Holodus sehr abweichen, so ist doch in ihrem Zahnbaue Mlanche's, das gegen eine so scharfe Trennung derselben von diesen sprechen dürfte. Eine Bestätigung unserer Ansicht finden wir in einer Bemerkung des Capitain Jones '), nach welcher Helodus planus in Cochliodus magnus übergeht, und das letztere Geschlecht ist doch gewiss mit Dipterus nalie verwandt. Wir glauben daher nicht Unrecht zu haben, wenn wir sie hier anschliessen, inden sie den so eben genannten Geschlechtern, von allen denen, die wir noch zu beschreiben die Absicht haben, am nächsten stehen.

Herr $\mathrm{Agassiz}$ hat und Herr 0 wen ist ihn darin gefolgt, eine bedeutende Anzahl ausgestorbener Geschlechter der Fische, die grösstentheils nur durch den verschiedenen Bau ihrer Zähne, den bisher einzigen Ueberresten derselben, charakterisirt sind, in eine Familie zusammengestellt. Die Gründe zu dieser Zusammenstellung liegen hauptsäehlich in der Aehnlichkeit der mikroskopischen Structur dieser Zähne und da an einem lebenden Squaliden, dem Cestracion Philippi, ein in vieler Hinsicht ähılicher Zahnbau beobachtet war, so war es ganz natürlich diese Geschlechter mit einander in eine Familie, die den Namen der Cestracionten erhielt, zu vereinigen. Beigenaueren Betrachtung zeigte es sich aber, dass die Grenzen dieser Familie zu weit gesteckt waren, denn es kamen Genera zusammen, deren Zahınoberflächen sowol mit einer emailartigen harten Schicht bedeckt waren, wie dies bei Cestracion der Fall ist, als auch andere an denen diese obere Schicht fehlte und die Medullarkanäle sich auf der Oberfliiche öffneten, wie bei den Chimaeren. Herr Agassiz sah sich daher

1) Report on the Geolngy of the County of Londonderry and of parts of Tyrone and Fermanagh 1843 pag. 462. Ithink J am enabled to show that, howeven distinct and well marked the extremes may be, yet IJelodus planus passes into Cochliodus magnus. 
später veranlasst, das eine der letzteren Geschlechter Ceratodus, aus der Familie der Cestracionten zu streichen und in die der Chimaeren aufzunehmen '). Auf ähnliche Weise zeigt auch schon Herr 0 wen, dass Cochliodus eine Uebergangsform zwischen Cestracion und Callorhynchus sein möchte ${ }^{2}$. Ain dreistesten ging aber Herr Quenstedt zu Werke, welcher, da er die Unmöglichkeit einsah, dass so verschiedene Geschlechter in einer Familie vereinigt bleiben konnten, alle diejenigen, die mit den der Oberfläche sich öffnenden P.oren, den Mündungen der vertical aufsteigenden Medullarkanäle, besetzt waren zu den Chimaerinen rechnete und sie nach einer, von Agassiz einem einzigen Geschlechte zugetheilten Benennung, unter dem gemeinschaftlichen der Psammodonten aufnahm.

Das eine der beiden jetzt zu beschreibenden Geschlechter gehört zu den Psammodonten Quenstedt's und schliesst sich der Gestalt seiner Zähne nach zu urtheilen, am nächsten an Melodus Ag. an, unter welchem Namen wir dasselbe auch jetzt aufführen werden. In der Structur seiner Zahnplatten ist eine Annäherung an Ceratodus, Cheirodus und selbst an Dipterus nicht zu verkennen, das andere Ptyctodus ist in vieler Hinsicht gleichfalls dem vorigen ähnlich, seine Structur aber so charakteristisch, dass man wirklich glauben sollte, eine neue Species von Callorhynchus gefunden zu haben.

1) Tableau général des Poissons fossiles, recherches Tom. 1 pag. 37, 39 und 49.

2) Odontage pag. 65 Anmerkung. The Genus Cochliodus appears to have been on extinct transitional form between Cestracion and Callorhynchus. 


\section{HELODUS Agass.}

Obgleich die Zähne die wir hier unter dem Namen Helodus Tab. 7 Fig. 12 abgebildet haben, ihrer Gestalt nach nicht die eigentlichen von $\mathrm{Agassiz}$ angegebenen Geschlechtscharaktere besitzen, so glauben wir doch sie diesem Genus anschliessen zu können, da sie bei weitem gewölbter als die eigentlichen Psammoduszälne sind, und der Uebergang einer convexen Oberflïche in einen über dieselbe hervorragenden Höcker, bei denen in Bergkalke rorkommenden, zu häufig ist, un letzteren als das Bestimnende bei der Classification zu gebrauchen. Die Zithne, von denen wir nur drei aus den oberen devonischen Schichten des Tulaschen Gouvernements besitzen, haben vier Ecken, von dene॥ die eine so ahgerundet ist, dass die beiden Rände, die wir für die vorderen und äusseren halten, bogenförınig mit einander verbunden sind, der innere Rand, wenn man nämlich diesen aus der Analogie mit Dipterus für einen solchen halten kann, ist vertical abgestuzt, der hintere allıälig abfallend. Die grösste Höhe erreicht der Zahn in der Mitte der Kaufläché, die sich nach rorn und aussen allmälich hinuntersenkt. Die braune sehr dünne Basis ist etwas, aber wenig concav. Die schneeweisse Oberflïche ist mit deutlichen runden Poren, den Oeffnungen der, schon dem unbewaffneten Augen sichtbaren, Medullarkanäle, die ohne bestimmte Ordnung gestellt sind, besetzt, die hintere Fläche hat grössere sehr unregelnässige, ungleich gestaltete Oeffnungen.

Macht man cinen rerticalen Sclmitt durch die ganze Länge oder Breite des Zahnes, so zeigt sich, dass der Unterschied zwischen Basis und Krone nur in den verschiedenen Verlaufe der Medullarkanäle besteht, die in ersterem einen inehr horizontalen Verlauf haben, bei Beibehaltung desselben Lumens häufig unit einander anastomosiren und netzartig verbunden sind, während letztere aus ihnen vertical in die Höhe steigen, äusserst selten dichotomiren und sich nie mit einander verbinden. Die feinen Zahunröhrchen entspringen sowol aus den Kanälen der Wurzel wie aus der Krone, sind aber bei denen der ersteren bedeutend lïnger.

Wird ein horizontaler Schnitt von der etwas abgeschliffenen Oberfläche angefertigt, so zeigen sich die Oeffingen der Nedullarkanäle, ron feinen Röhrcheu ringsun umgeben. In der unmittelbaren Nähe der Gefïsswände sind diese von einem helleren Kreise eingefasst, indem von ihnen nur grössere Aeste 
entspringen und die zwischenliegende Grundsubstanz daher hell erscheint, sobald aber die Verästelung und Verzweigung derselben beginnt, wird diese dunkeler und trüber, und diese Trübung nimmt bis zum Ende der letzten feinsten Zweige, die einen runden Kreis um den Nedullarkanal bilden, zu, wodurch gleichsiın das zu einem Gefässe gehörende System der feinen Röhrchen seine Grenze erreicht und von den benachbarten durch einen helleren engen Raum geschieden wird. Bicse Abgeschiedenheit der einzelnen Medullarkanäle mit den ihnen zugehörigen feinen Zahnnöhrchen, von den benachbarten sie ungebenden, betrachtete Agassiz schon als einen Charakter, der den Cestracionten nicht zukömmnt, der nur den Zähnen der Chimaeren und mehreren Rochen eigenthiïmlich isı, und durch welchen man die einen, von den anderen unterscheiden konnte. 


\section{P TYCTODUS.}

Von allen bisher beschriebenen Geschlechtern der älteren Periode der Erde, weicht das Genus Ptyctodus durch die lamellenartige Bildung seiner Zähne, durch die Regelmässigkeit und Anordnung der Poren, sowol auf der oberen als unteren Fläche, wie auch durch seine Gestalt ab. Bei yorwaltendem Längendurchmesser ist die Höhe der Zähne gewöhnlich ihrer Breite gleich, die obere Fläche meistens eben, selten schwach concav, die untere entweder flach concar ausgehöhlt, eben oder flach conlvex; sie werden nach hinten von einem abgerundeten Rande begrenzt, nach vorn gehen sie in eine mehr oder weniger scharfe, nach einer Seite gewandte Spitze oder einem hervorstehenden Höcker ïber, und werden von fast parallelen Seitenwänden, die eine Fortsetzung der hinteren abschüssigen Wand sind, eingefasst. An beiden entgegengesetzten Flächen, sowol der Kau- als Unterflïche, sieht man quer über dieselben, unter einander parallel verlaufend, aus einer dichten Masse gebildete Lamellen hinüberziehın, welche durch ähnliche, aus an einander gereihten Poren bestehende, getrennt werden. An den beiden Seitenwänden kann man den Verlauf der Lamellen von oben bis unten verfolgen. Von der hinteren abschüssigen Wand der Zähne steigen sie mehr oder weniger vertical herab, nehmen nach vorn cine schrägere absteigende Richtung an und gehen gegen den vorderen Rand in eine horizontale Lage über, wodurch eine regelmïssige horizontale Schichtung entsteht. Diese Schichtung wird noch deutlicher an den äusseren und inneren Seitenränder, wenn die, die Lamellen trennenden Porenschichten verwittert sind und leere Räume hinterlassen haben. Bei vollständig erhaltenen Zähnen, Tab. 8Fig. 4, 10 und 12 sind die Seitenwände, so wie der hintere von glatten, dem Anscheine nach homogenen emailartigen Platten eingefasst, die die Porenöffnungen verdecken, die sich aber nie über die Unterflïche der Basis und die Oberfläche der Krone erstrecken.

Schleift man die Seitenwände ein wenig ab, Fig. 19 und 20, so erkennt mall schon mit der Loupe, dass die Poren der beiden entgegengesetzten Flächen, die Oeffnungen mit einander communicirenden Kanäle sind, die je nach der Stelle, von welcher der Schliff gemacht ist, mehr oder weniger vertical oder horizontal verlaufen. Versucht man es die Scliliffe in der Richtung der Lamellen, parallel mit ihnen anzufertigen, um den Verlauf der Gefässkanäle zu beobachten, so erscheinen diese wie in Fig. 16 und 22 urter 
schwacher Vergrösserung gezeigt ist; werden aber die Durchschnitte an der hinteren Wand vertical genommen, so entsteht Fig. 14 und Fig. 17 ein Netz von Maschen, welches die Verbindungen der Kauäle unter einander d. h. Anastomosen deutlich angiebt. In allen diesen Durchschnillen waren die angefertigten Platten noch von bedeutender Dicke, nur zur Beobachtung mit der Loupe bestimmit und daher erblickt man, wie z. B. in Fig. 17, mehrere hinter einander liegende Laigen der Gefïsskanäle. Werden nun die Schliffe so fein angefertigt, dass sie unter den Mikroskop gesehen werden können, so erseheinen die dichten Lamellen aus wahrer Dentine gebildet. Ohngeachtet der Uebereinstimmung in der Anordnung der neben einander in regelmïssigen Reihen geordneter Poren der oberen und unteren Fläche der Zähne, ohngeachtet ihres Zusammenhanges, indeın die der letzteren mur Fortsetzungen der ersteren sind, findet doch in der Structur beider eine grosse Verschiedenheit und uamentlich in dem Verlaufe der Markkanïle und der von ihneu ausstrahlenden feinen Zilhnröhren Statt. An der Kiufliache haben diese Kinäle einen graden senkrechten von unten nach oben aufsteigenden Verlauf, aus ilınen strahlen nach allen Seiten die Zahmröhrchen in verhältnissmïssig grossen Stämmche'n, die sich erst in gewissen Entferuungen zu verästeln anfangen, sich in weiteren Verlaufe immer inehr nach allen Seiten verzweigen und in unendlich viele und feine Zweige zerspalten, ohne dass ilhe letzten Endigungen sich mit denen von den benachbarten Medullarkanïlen, ihnen entgegen kommenden verbiuden. Auf diese Weise ist ein jedes Gefäss mit seinem Systeme von Zahnröhren von den übrigen geschieden und durch einen helleren Saum begrenzt. An der unteren Fläche, die man die Basis zu nennen plegt, nelmen die Markkanäle, sobald sie von unten in die Substanz des Zahnes eingedrungen sind, einen horizontalen Verlauf an, und bilden durch vielfache Anastomosen ein Netz mit grossen Maschen. Die kleinen Röhrchen, die ron ihnen ausstrahlen, treteı nicht in grossen Stämınen aus ihnen, sondern als feine Zweige und lösen sich in die feinsten Ausläufer auf. Iiedurch bekommt die ganze Substanz ein trübes Ansehen, das erst bei sehr starker Vergrösserung und bei äusserst feinen Schliffen entziffert werden kann. Aber nicht nur zwischen oben und unten herrscht dieser Unterschied in der Ausstrahlung und Verzweigungen der kleinen Zahnnröhrchen, dasselbe findet, durch allmäligen Uebergang vermittelt, auch zwischen vorn und hinten ganz auf dieselbe Weise Statt. Herr Agassiz hat in 3-ten Bande seiner Recherches p. $3: 3$ eine ïhnliche Bildung bei den Zähnen von Callorhynchus sehr genau beschrieben.

Die äussere, den Zilhn von den Stiten und hinten, ungebende Substanz, ist aufgleiche Weise, wie die der Zahnplatten selbst zusammengesetzt, sie besteht aus Medullarkanälen mit feinen ausstrahlenden Röhrchen, die ersteren bilden nach innen vielfach gewundene Netze, und aus ihneu divergiren die letzteren nach aussen, so dass die äussere, glatte, glänzende Schicht aus feinen Zahnröhrchen allein gebildet wird.

Ausser den so eben beschriebenen, die Zïhne von Plyclodus zusammensetzenden Grfässen verschiedener Grösse, zeigen sich noch andere, Tab. 9 Fig. 7 und 8, welche von den beiden oben angeführten, sich durch ihr Lunen und äusseres Ansehen unterscheiden und die wir bis jetzt bei keinem 
anderen Zahne angetroffen haben. Ihr, in Verlältniss zu den Hedullarkanälen, geringer, zu den Zahnröhrchen, grosser Durchmesser, ihre Klarheit und ihr geschlängelter Verlauf, zeichnen sie von den übrigen Gefüssen der Zahnsubstanz auffallend aus.

Versuchen wir jetzt das Genus Plyctodus an seine gehörige systematische Stelle zu bringen und vergleichen wir den Bau seiner Zähne mit den schon bekannten Familien, so finden wir in dem horizontalen Verlaufe der Markkanäle der Basis und im Heraufsteigen derselben gegen die Oberflïche, so wie in dem Ausstrahten der feinen Zahnröhrchen aus ihnen, und der Abgeschiedenheit der einzelnen Systeme von einander, eine grosse Uebereinstinmung mit den Zälnen von Myliobates und anderen verwandten Geschlechtern. Aber bei Ptyctodus fellt der enailartige Ueberzug der Kaufläche der Rochen und bei diesen dagegen die Lamellenbildung der Zähne von Plyctodus.

Am nächsten steht unstreitig die Familie der Chimaeren und namentlich das Geschlecht Callorhynchus. Bei beiden bestehen die Zähne, von der Basis bis zur Kaufläche, nur aus Dentine und der Unterschied liegt nur in dem mehr oder minder horizontalen oder verticalen Verlaufe der Medullarkanäle, bei beiden ist die Trennung der einzelnen Systeme deutlich zu erkeunen, der emailartige Ueberzug der Kaufläche fehlt bei beiden und endlich besitzen beide die lamellenartige Bildung, die aussen und innen von einer glatten Zahnplatte erstreckt wird.

Schwerlich wird man zwischen Zähnen aus einer so alten Periode der Erde, wie die devonisehe, und jetzt noch lebenden Organismen eine grössere Uebereinstimmung, als die eben angegebene finden und doch zeigt sich an den Zähnen von Plyctodus eine, wenn auch nur schwache Annäherung an eine andere Familie, die gleichfalls Zähne besitzt, die aus einzelnen auf einander liegenden horizontalen und schwach gebogenen Lamellen zusanmengesetzt sind, nämlich die der Gymnodonten. Der ganze Unterschied zwischen den Zähnen der Chimaeren und der Gymnodonten besteht nach Ag. ') und aus 0 wen's ${ }^{2}$ ) Beschreibung geht dasselbe hervor, uur darin, dass die feinen Zahnröhrchen, statt wie bei Callorhynchus, aus einzelnen Medullarkanälen auszustrahlen, aus Spalten austreten, die die einzelnen Zahuplatten von einander trennen, d. h. doch mit anderen Worten nichts anderes, als dass die feinen Zahnrölırchen aus Gefässen entstehen, deren Wände nicht verhärtet sind, die sich also in dieser Hinsicht zu den Zälınen der Chimaeren verhalten, wie die von Rhina zu Myliobates, oder von Lamna elegans zu denen von Galeus canis; vielleicht sogar wie Galeus canis zu Muslehs equestris, die in Systeme so nalıe an einander stehen. Vergleichen wir nur die Gestalt der Mledullarkanile,

1) Recherches. Tom. 3 pag. 272. - Il résulte de tout ceu que les dents des Gymnodontes ressamblent beaucoup à celles — des Callorliynques, - avec cette différence, quan lieu de canaux médullaires verticaux et isolés, il y des fissures longitudinales, des quelles portent les tubes calcifères. Qu’on place par exemple les canaux de la dent d'un Callorhynque en ligne droite et qu'on les réunisse par des fissures, et l'on aura la structure de la dent d'un Gymnodonte.

2) Odont. pag. 77 . 
die die dentinartigen Zahnlamellen, sowol bei Callorhynchus als bei Ptyctodus von einander scheiden, so zeigt sich hier ein grosser Unterschied, bei ersteren sind die Umrisse selarf, kreisrund wie bei allen Cestracionten, Myliobaten u. s. w., bei letzteren herrscht sonst immer der Querdurchmesser vor und der Uebergang in Querspalten mit knöcherner Structur zwischen den Zalınlanellen ist augenscheinlich. Es wäre daher wol möglich, dass Ptyctodus, die freilich in der Jetztwelt, so weit ron einander stehenden Familien der Gymnodonten und Chimaerinen durch gemeinschaftliche Characktere combiniren könnte. Kein einziges Geschlecht devonischer Fiscle hat, so weit unsere Beobachtungen reichen, eine kürzere Lebensdauer gehabt, als Ptyctodus. Obgleich seine Ueberreste in horizontaler Erstreckung sehr weit verbreitet sind und in den Ostseeprovinzen, dem Nowgorodschen und Pleskowschen Gourernements nicht selten vorkommen, so sind sie doch in verticaler Richtung nur auf die, einige Faden mächtigen, dem Alten Rothen Sandsteine eingelagerten Kalkschichten beschränkt. Weder in diesen Sandsteinen, noch in den unteren Mergeln des devonischen Systems, noch in dessen höheren Kalksteinen im Tulaschen und Kalugaschen Gourernements, in denen die übrigen organischen Ueberreste doch häufig mit denen der westlichen Provinzen Russlands übereinstimmen, ist bis jetzt die geringste Spur von ihnen aufgefunden worden. Man sollte glauben, dass mit dem Auftreten dieses Geschlechtes fast alle ïbrigen Fische jener Periode von ihın verscheucht, fernere und sichere Zufluchtsorte aufgesucht und sich vor ihm versteckt haben, denn mit dem Auftreten des an Mollusken so reichen Kalksteines und also auch des $P$ lyclodus, verschwindet die ungeheuere, dem unterliegenden Sandsteine eigenthümliche Henge von Fischen, um später während des Niederschlages, des den Kallsteinen aufgelagerten Sandsteines, von Neuem das Mleer zu beleben. Das Vorkommen von Ueberresten, der, den Saudsteinen angehörigen Fischüberreste im Kalksteine, gehört in den westlichen Provinzen Russlands zu den Seltenheiten; Kiefer von Dendrodus, Bruch-Stücke von Ruderorganen des Asterolepis, Schuppen von Osteolepis und Glyptolepis erscheinen wol noch in denselben, aber in Allgemeinen und im Verhältnisse schr sparsam, die einzigen treuen Begleiter des Ptyclodus, die aber schon lange. vor ilmm in den Sandsteinen Livlands auftreten und die man bis in die höchsten Schichten des Orelschen Gouvernements verfolgen kann, sind nur die Ctenodipterini. 


\section{Nac h s c h r if t.}

Nachdem diese Arbeit schon beendigt war und dem Drucke übergeben werden sollte, erhielt ich vom Herrn Sedgwick sein prachtvolles Werk "A Synopsis of the Classification of the Britisch Palaeozoie Rocks by the Rer. Adam Sedgwick with a Systematie Description of the Britisch Palaeozoie Fossils in the Geological Museum of the Unirersity of Cambridge by Frederic M'Coys'). Gern hatte ich aus den Beschreibungen, die Herr Ml' Coy von den Fischen giebt, die den Gegenstand dieser Abhandlung bilden, Manches schon dem Texte beigefügt, allein eine bevorstehende Reihe hindert mich daran diesen umzugestalten und ich erlaube es mir daher die abweichenden Ansichten hier am Schlusse und in Kurzem zu erwähnen, besonders da ich gar keine Veranlassung finde meine Beschreibungen zu ergänzen oder zu verändern.

Herr $\mathbf{I}^{\prime}$ Coy vereinigt pag. 590 , gestützt auf die Autorität von Hugh Miller, Polyphractus Ag. und Ctenodus Ag. ganz richtig mit Dipterus Sedg. und II urch. Er theilt unsere Ansicht über die Gestalt und Auflagerung der Schuppen, als runde sich dachziegelartig deckende und findet hierin einen hinreichenden Grund die Dipteri, von den mit rhomboidalen Schuppen besetzten Sauroiden, wie Osteolepis u. s. w. zu trennen. Er glaubt das Genus Dipterus den Coelacanthen Ag. anschliessen zu müssen, indem die Verwandtschaft mit Holoptychius, Glyptolepis etc. und namentlich zu dem letzteren Geschlechte so eng sei, dass er keinen Unterschied zwischen beiden auffinden kann. Nach der Anzahl und Stellung der Flossen, Gestalt und Oberfläche der Schuppen, so wie nach dem äusserlichen Charakter der Zähne, scheint er geneigt, die beiden Genera mit einander zu vereinigen und schlägt vor, für beide den älteren Namen Dipterus beizubehalten. Es bedarf wol jetzt keiner weiteren Auseinandersetzung, dass die scharfen, sptzen, conischen Zähne der Glyptolepiden unmöglich init de-

1) Obgleich von diesem Werke schon mehrere Exemplare in St. Petersburg vorhanden waren, so fehlten in ihnen die Beschreibungen und Abbildungen der devonischen Fische, von denen ich erst jetzt und namentlich von denen des Genus Dipterus, das nicht wie viele andere Genera des dev. Systemes und des Bergkalkes, früher von II $^{\prime}$ Coy in der $\Lambda$ mn. of Nat. History beschrieben war, Keuntniss erlangte. 
nen von Ctenodus vereinigt werden können. Was die Species anbelangt, so unterscheidet Herr $\mathbf{M}^{\prime} \mathrm{Co}$ Y auf gleiche Weise, wie de Herren Sedgw. und Murch. es gethan hatten, nach der Grösse der Schuppen und Flossen, drei Species Dipt. beochypygopterus, macropygopterus und Valenciennesii und hält die Ansicht $A$ gassiz's, nach welcher diese Verschiedenheit auf Alter und schlechtere oder bessere Erhaltung derselben beruhte, für irrig. Wir sind in dieser Abhandlung der Ansicht Agassiz's gefolgt, indem wir diese drei Species unter dem gemeinschaftlichen Namen Dipterus Valenciennesii mit einander vereinigten, können aber sehr leicht hierin Unrecht haben, wie aus Herrn $\mathbb{I}^{\prime} \mathrm{C}_{0} \mathrm{y}^{\prime}$ ' Beschreibung, der drei von Sedgw. und Murch. aufgestellten Species liervorzugehen scheint. Da wir uns jetzt nur mit dem Baue und der Organisation des ganzen Geschlechtes Diplerus beschäftigt haben, so hat diese Trennung für diesen Augenblick keinen grossen Werth für uns. Was die vierte Species Dipt.macrolepidotus Sedgw. und Murch. anbelangt so weist Herr II' Coy ganz richtig nach, dass dic Ueberreste nach welchen diese aufgestellt wurde, zu Diplopterus und namentlich Diplopt. macrolepidotus gehören. Das auf Tab. 16 Fig. 2 in der Transaction und von $\mathrm{Agass}$. Recherches Tab. 2 Fig. 4 abgebildete, als Dipterus macrolepidotus bezeichnete Exemplar, wird nirgends angefiihrt, ist aber, wie wir schon früher angegeben haben, ein Osteolepis. Was die Charackteristick des Cenus Diplerus nach Herrn $\mathbb{N}^{\prime} \mathrm{Coy}$ anbelangt "small fusiform fisches, with compressed heads, and perfectly heterocercal tails, and two dorsal fins precisely opposite two similar anal fins» etc., so können wir derselben nicht ganz beistimmen. Gegen die geringe Grösse spricht Dipt. platycephalus, der Kopf ist nicht compact, sonderu flach und stark deprimirt, der Schwanz nicht vollkommen heterocere und was die Flossen anbelangt, so ist nur eime anale vorhinden, wie wir schon früher gesehen haben. Von den Zähnen, der schon in den Annals and Nagazine of Nat. Histury 2nd series Vol. 11, beschriebenen Geschlechtern Conchodus aus dem devonischen Systeme und Chirodus aus dem Bergkalke, sind in dem oben angeführten Werke gleichfalls Abbildungen gegeben. Wenn wir nur nach den äusseren Charackteren dieser Zähne urtheilen, so scheint unser Geschlecht Chcirodus mit ersterem übereinzustimmen, indem das von I' Coy Tab. 2 C Fig. 7, als Conchodus ostraciformis abgeblddete Exemplar, durch seine starke Concavität als Gaumenzahn leicht zu erkennen ist. Hierüber muss in späterer Zeit die Untersuchung der mikroskopischen Structur genauere Auskunft geben. 


\section{Heschreibung aer trafeln.}

\section{Tafel I.}

Fig. 1. Dipterus Valenciennesï von den Seiten. Das vollständigste Exemplar, das wir je gesehen haben, die Flossen sind alle erhalten, die Brustllosse ist durch den Querbruch nach hinten und unten geschoben, die Bauchflosse über die Seite des Körpers zurück und hinaufgeschlagen; die Knochen des Kopfes, der Kiemendeckel, die Orbita, der Unterkiefer sind in ihrer natürlichen Lage, nur die Schnautze fehlt. Die Seitenlinie ist bis gegen den Schwanz zu verfolgen, ilre Fortsetzung gegen dessen oberen Rand war nicht zu erkennen, über der Seitenlinie und parallel mit ihr verlïuft ein schwarzer Streifen, den wir für einen $\Lambda$ b. druck der Wirbelsäule ansehen.

Fig. 2. Diesellue Species. Am deprimirten flachen Kopfe erkennt man die einzelnen Kopfschnppen, an der linken Seite ist der Kiemendeckel, der Rand der Orbita und ein Theil, der unter dem Schädel liegende Knochen, zu unterscheiden; auf der rechten nur die Knochenschuppen, die den oberen Rand der Orbita begremzen. In der Mitte liegt die Squama occipitalis media, die squamae occ. externae, squamae laterales etc.

Fig. 3. Diese Platte zeigt am schönsten die Brustflosse, die mit kleinen Schuppen besetzt ist und die von ihr seitwärts abgehenden Flossenstralilen.

Fig. 4. Das ausgezeichnetste Exemplar. Alle Flossen von Schuppen entblösst, sind in ilırer natürlichen Lage und Gestalt. Es ist das einzige, in welchem beide Ventralflossen zugleich siclitbar waren.

Fig. 5. Der hintere Theil mit den beiden Rücken, den After- Schwanz- und Bauchflosse von einer anderen Species, wahrscheinlich von Dipterus platycephalus, ein sehr schöner Abdruck, in welchem die Grenzen zwischen Flossenträgern und Strahlen, wie in Fig. 4 und die kurzen oberen Strahlen der Schwanzflosse, deutlich zu erkennen sind.

Fig. 6. Ein Bruchstück. Kiemendeckel und Scapula, linter ihm und hinter dieser die Brustflosse über die Schuppen des Körpers zuruckgesehlagen.

Fig. 7. Ein Fragment aus der Mitte des Körpers, mit deutlichen Brust- und Bauchflossen der rechten Seite.

Fig. 8. Gestreute Schuppen und Knochen vom Schultergelenke, von der Wirbelsäule und vom Gaumen mit einer aufsitzenden Zalıplatte von Dipterus Valenciennesii, vergrössert.

Fig. 9. Knochenschuppen die unter dem Kiemendeckelapparate zwischen den beiden Aesten der Unterkinnlade gelegen sind, 18 squamae supraorbitales, 11 squam. infraorbitales, erstere sind nach unten herumgeschlagen, 19 der Operkel, 20 der Suboperkel, 21 und 22 Knochenplatten an der Stelle der Kiemenhautstrahlen, 23 eine kleine, zwischen diesen liegende Platte, wie bei Megalichthys etc.

Fig. 10. Eine vom Email entblösste Schuppe, stark vergrössert, von oben angesehen.

Fig. 11. Eine älınliche von der Unterfläche betrachtet, aus der Seitenlinie. 
Tafel II.

Fig. 1. Eime ideelle Zeichnung von Dipterus V'alenciennesii, der Kopf ist nach dem auf Tab. I Fig. I abgebildeten Exemplare genommen, daher fehlt sein vorderer Theil, die Schnautze. In zweifacher Grösse.

Fig. 2. Das hintere Ende von Dipterus platycephalus, w Bauchllosse, y Afterllosse, z Schwanzllosse.

Fig. 3. Ein sehr verschobenes Exemplar, vorn gegen den Kopf zu ist die Brustflosse noch mit emaillirten kleinen Schuppen besetzt sehr deutlich, nach hinten scheint aber der ganze Körper ungekehrt zu sein, denn $w$ hat das Ansehen der vorderen und $x$ das der hinteren Dorsalflosse, $y$ die Anal- und z die zerbrochene und ganz verschobene Schwanzflosse.

Fïg. 4 und Fig. 5 sind zwei Platten, auf welchen runde Schuppen von Dipterus zerstreut in Gemeinschaft mit anderen Knochen herumliegen. Aus diesem Grunde glauben wir berechtigtzu sein, die übrigen Knochen demselben Geschlechte zutheilen zu können; die zum Bogensystem der Wrirbelsäule gehörigen processus liegen noch ziemlich regelmässig an einander gereiht, die Wirbelkörper selbst fehten aber.

Fig. 6. Das hinterste Ende vom Körper des Dipterus Valenciennesii. Die himtere Dorsit-, die Anal- und ein Theil der Schwanzflosse ist sichtbar und zwischen ihmen ein Abdruck, ein aus kleinen Kuöchek hen bestehender, an einander gereihten perlschnurartiger Streifeı, vielleicht die Körper der W'irbelsäule, vergrössert.

Fig. 7. Ein ähnliches Stück, um den Verlauf der Seitenlinie zn zeigen.

Fig. 8. Eine einzelne Schuppe von der unteren Fläche, gut erhalten, um die concentrischen Kreise derselben zu zeigen.

Fị. 9. Eine ideelle Zeichnung von der Unterkinnlade im Profil, in natürlicher Grösse von Dipterus platycephahus.

Tafel III.

Fig 1. Eine ideelle Zeichung von der Oberläche des Kopfes nach den Originalen, die in Fïg. 2-9 abgebildet sind, zusammengesetzt, 1. Squama occipitalis media, 2. Squamae parzetales, 3. eine einfache, häufig in der Mittellinie von der benachbarten getrennte Schuppe, oft sehr unsymmetrisch, oft mit denen Nr. 2 zusanimengewachsen, 4. Squamae frontales, 5. Squamae occipitales externae, 6. Squamae occipitales arteriores, 7. Hautknochen, 8. Squamae supraorbitales. Vor diesen Scluppen des Schädeldaches liegt die Schnautze, die aus einem Stück zu bestehen scheint, aber doch manchmal Spuren von Näthen aa zeigı, die einen mittleren 9. von zwei seitlichen 10. scheidet, 11. ein Fortsatz der Schnautze nach hinten, der sich unter der Orbita mit den Squamae infraorbitales verbindet.

Fig. 10. Eine squama occipitalis media von einem Kopfe, dessen glänzende äussere emailartige Schicht zerstört war. Selbst in diesen Schuppen ist eine gewisse Asymmetrie nicht zu rerkennen und auch in ihr befinden sich Poren des Seitenkanalsystemes.

Fig. 11. Basis des Schädels und Gaumenapparates mit denselben anheftenden Zälınen, Nr. 12 os sphenoideum basilare, Nr. 13 und 14 stellen das os palatinum und os pterygoideum internum dar, sie scheinen in manchen Exemplaren von einander getrennt zu sein, in anderen aus einer einzigen Platte zu bestehen. In ersterem Falle entspricht Nr. 13 den in der Nitteltinie des Rachens sich berühreuden ossa palatina, Nr. 14. den pterygoidea interna, Nr. 15 das os pterygoideum extermum, Nr. 16 os quadratojugale, Nr. 17 die Gaumenzïhne, Nr. 18 die in der Mitte sich durch ilıren inneren Rand berülıenden Zahnplatten. Diese Nummern sind in allen folgenden Abbildungen mit gleicher Bezeichnung beibehalten. Eine ideelle Zeichnung. 
Fig. 12. Das Originalexemplar, welches uns zuerst von dem Zusanmenhange der Zähne mit dem Kople überzeugte. Die vordere Schnautze ist gut erhalten, aber über die Nitte hinaus sind die Schuppen und Knochen des Schädels zerstört und die Basis desselben mit dem Gaumenapparate ist von der oberen Seite sichtbar. Die Zahnplatte ist nur im Abdrucke sichtbar und die Abbildung nicht ganz richtig, da es den $\Lambda$ nschein hat als ob die Zähnchen hervorständen, wälrend man nur die leeren Räume sieht, die sie hinterlassen liaben.

Fig. 13. Eiı ähnliches Stïck, an welchem die Schuppen des Schädeldaches erhalten, aber zerbrochen und verschoben wareı, von der unteren liläche dargestellt.

Fig. 14. Ein Bruchstück vom Gaumenapparat, in welchem die inneren sich in der Mittellinie berührenden Iamellen der Zahnplatten sehr breit und die Kauflächeu der Zïhne weiter als gewöhnlich von einander entfernt waren.

Fig. 15. Ein Fragment des Gaumenapparates, in welchem das os palatum und pterygoideum durch eine Sutur von einander geschieden waren.

Fig 16. Unterkiefer von Dipterus platycephalus in zweifacher Grösse, um das Verhïltniss desselben zu der ideetlen Zeichnung Fig. 1 zu zeigen, I processus posticus, II Fovea glenoidalis, III processus coronoideus etwas zerbrochen und nach aussen gekrümmt, IV vorderes breites Einde. der Gestalt der Sclnautze entsprechend, V convexe Zahuplatten, den Seitenästen des Unterkiefers aufliegend.

Fig. 17. Der Unterkiefer von der unteren Seite. Nr. 22 die beiden, der Lage nach den Kiemenhautstrahlen anderer Fische entsprechende Platten, Nr. 19 der Operkel.

\section{Tafel IV.}

Fig. 1-19. Verschiedene W'irbel aus den devonischen Schichten Russlands.

Fig. 1. Ein kleiner Wirbel von den Ufern des Scias in natïrlicher Grösse. Schwach concar mit geriugen Andeutungen kleiner Grübrhen zur Insertion der processus spin. Auf der einen Fläche $b$ ist die grösste Ti̊fe durch eine Grube, die sich gerade in der Mitte des Wirbelkörpers befindet, zu welcher von einem Rande eine schwache Furche verläuft, angedeutet, auf der entgegengesetzten $a$ ist dieses tiefe Grübchen excentrisch und steht dem einen Rande viel näher, als deın anderen. Wir sind immer noch ungewiss, ob dieser Wirbel aus dem devonischen oder silurischen Systeme herstammt, da wir ihn erst nach dem Zerschlagen eines röthlichen Kalksteines mit Illaenus crassicauda bemerkten, ohıe früher uns daron überzeugt zu habell, ob er diesem Stïcke nur auflag oder aus ihm herausfiel. Das Gestein, das an demselben aber jetzt noch anhängt, gleicht sehr dem mit silurischen Ueberresten angefüllten.

Fig. 2. Ein Wirhel den Herr von Helmersen in den devonischen Schichten des Nowgorodschen Gouvernements gefurden lat, ebenfalls concav coneav, im Verhältnisse flach mit deutlicheren Anzeigen der Insertion der proc. spin. ill natürlicher Grösse abgebildet. Von diesen beiden Wirbelkörpern konnten wir leider nicht die mikroskopische Structur untersuchen; was die nun folgenden aber anbelangt, so sind sie sich alle in dieser Hinsicht selır ähnlich, stammen alle aus einer blauen Thonschicht. sind schneeweiss und bestehen aus einer homogenen Grundsubstanz mit runden und länglichen, denen des Knorpels ähnlichen Zellen, ohne strahlige Ausläufer; von grossen, schon bei schwacher Vergrösserung sichtbaren Medularkanälen durchzogen. Sie sind alle in vergrössertem Maassstabe dargestellt, indem sie höchstens die Grösse eines groben Stecknadelkopfes erreichen. 
Fig. 3 und Fig. 4. Eine der regelmässigsten Gestalten, die entgegengesetzten Flächen beide concav. In der einen eine mittlere kleine tiefe Grube sichtbar, in der anderen felitt diese. Die Poren, die Oeffnungen der' Kanäle deutlich unter der Loupe sichtbar. Der Läinge nach rerläuft ein flacher Kanal, wahrscheinlich oben, welchem das Rückenmark auflag.

Fig. 5. Dem vorigen an Gestalt älınlich, unterscheidet er sich nur von ilım durch den im Mittelpunkte des Wir. belkörpers durehgehenden feinen Kanal.

Fig. 6. Concav convex, und bei weitem kürzer im Längenmesser, als die beiden vorhergehenden. Auf der einen Fläche ist eine tiefe Grube im Centrum, auf der anderen ist diese einem Rande mehr gentïhert.

Fig. 7. Eine Fläche eben, die andere convex.

Fig. 8. Concav concav mit excentrischen tiefen Gruben und hervorstehendem Rande, über oder unter derselben.

Fig. 9. Concav convex mit einer convexen Fläche, die den concaven im Unfange nicht ganz entspricht, s. Fig. 9 c.

Fig. 10. Concav convex. Die convexe Fläche regelmässig an den Aussenrändern abgerundet, in ihrer Mitte flach.

Fig. 11. Sehr kurz im Verlältnisse. Umriss nicht ganz kreisrund, älınlich Fig. 8, aber mit centralen tiefen Gruben.

Fig. 12. Concav convex. Zur Bildung der convexen Fläche neigen sich die Seitenwände, gleich voın äusseren Rande der concaven Fläche gegen einander und bilden auf der Spitze der convexen Fläche eine kleine Erhabenlıeit.

Fig. 13. Eine ähnliche Form nur mit einem, einen kleinen durch den Wirbel durchgehenden, Centralkanal.

Fig. 14. Dem vorigen ähnlich mit einem grossen Centralkanal versehen.

Fig. 15. Ist ein den Vorigen an Gestalt ähnlicher Wirbelkörper, dessen convexe Fläclie mit einer hervorragenden Platte geschlossen wird, statt einen Kanal zu besitzen.

Fig. 16. Concav convex, die ganz convexe Fläche läuft in eine mittlere Spitze aus.

Fig. 17. Die Centralröhre selır gross, so dass die Knochenmasse wie ein schmaler Ring dieselbe ungiebt.

Fig. 18. Aehnlich in Rücksicht der Centralröhre dem Wirbelkörper in Fig. 14, aber mit entgegengesetzten Flächen, die fast einen gleichen Durchınesser haben.

Fig. 19. Oberfläche eines in der Quere durchschnittenen Wirbels, um die Mündungen der Kanäle zu zeigen; unter der Loupe gesehen.

Fig. 20. Eine isolirte Schuppe von einer Flosse, deren obere Schicht zerstört und daher die Poren sichtbar sind; unter der Loupe gesehen.

Fig. 21. Vier ähnliche Schuppen vom Körper in ihrer natürlichen Lage, an welchen die oberen Sclichten zerstört sind, die Poren und deren Stellung in regelmässigen Reihen, die man an der äusseren Fläche nicht so genau beobachten kann, sichtbar; vergrössert.

Fig. 22. Mehrere Reihen Schuppen aus der Gegend der Seitenlinie des Körpers in ihrer natürlichen Lage, ohne emailartigen Ueberzug; vergrössert.

Fig. 23. Kiemendeckel von Dipterus platycephalus.

Fig. 24 und 25. Zwei Platten die zum Kiemendeckelapparat gehören, von denen eine der Suboperkel, der andere der Interoperkel sein mag.

Fig. 26. Dieselben Knochen noch so ziemlich in ihrer natürlichen Lage.

Fig. 27. Knochen des Schultergelenkes von Dipterus platycephalus. 
Fig. 28. Stellt die äussersten Endigungen der paarigen Flosseu dar, an denen die Flossenträger mit Schuppen, denen des Körpers ähnlich, bedeckt sind. Fig. 28 a in vollkommneren Zustande. Schuppen der Träger und Strahlen der Flossen, mit der emailartigen oberen Sehicht bedecht. Fig. 28 b von dieser entblösst.

Fig. 29. Die vordere Rïckenflosse. Die Träger werden gegen ihr äusseres Ende durch Längsfurchen in mehrere dünıere Stäbe getheilt, an welche die sich spaltenden Strahlen ansetzen.

Fig. 30. Eine ähnliche Zeichnung vom unteren Theile des Schwanzes.

Tafel V. Zähne und Schuppen von Dipterus.

Fig. 1-9. Dipterus Verneuillii.

Fig. 1. Ansicht der Zahnplatte von oben in natürlicher Grösse, Gaumenzahn der linken Seite.

Fig. 2. Dieselbe Zahnplatte im Profil, vom äusseren Rande gesehen.

Fig. 3. Die innerste Reihe Zähnchen mit der inneren Lamelle, die bei dieser Species aus einzehnen kleinen Platten zusammengeselzt ist; vergrössert.

Fig. 4. Die zweite Zahnreilıe derselben Zahnplatte; vergrössert.

Fig. 5. Querdurchschnitt eines einzelnen Zahnes, unter der Loupe betrachtet, stark vergrössert. a. Die knöcherne Basis oder Wurzel. b. Die Spitze oder Krone und zwischen ihnen der querdurchschnittene, dunkel angegebene Pulpkanal, der, der ganzen Länge nach, unter den Zahnrippen verläuft.

Fig. 6. Derselbe Durchschnitt sehr fein geschliffen und unter dem Mikroskop betrach tet. a. Die knöcherne Basis mit Markkanälen und strahligen Knochenzellen. b. Die die Basis der Zahıkrone in Umfange einfassende knochenähnliche Substanz ohne Zellen. c. I)ie Spitze des Zahnes, die aus der, dieser Species eigenen, Dentine besteht. d. Der durchschnittene Pulpkanal, aus welcheu die Nedullarkanäle der Dentine mit ihren kurzen feinen Zahnrölırchen in die Höhe steigen.

Fig. 7. Ein schräg angefartigter Querdurchschnitt von zwei vorderen Zähnen der hinteren äusseren Reihe derselben Zahnplatte, an dem die obersten Spitzen der Zähnchen abgesclliffen sind, a. die knöcherue Basis mit Zellen, b. die die Dentine umgebende, zwischen Zahn und Knochen in der Mitte stehende Substanz, c. die Krone des einen Zahnes aus Dentine gebildet, d. der durchschnittene Längskanal des rechten Zälınchens, $d^{\prime}$. derselbe von dem linken, kurz vor seiıer blinden Endigung am vorderen Rande. e. die unterste knochenartige Schicht der Zalmwurzel aus horizontal über einander gelagerten Lamellen bestehend, zwischen denen die Gefïsse einen horizontalen Verlauf haben, so dass man grösstentheils die querdurchschnittenen Oeffnungen derselben erblickt.

Fig. 8. Horizontaler Durchschnitt eines einzehnen Zähnchens von Dipterus Verneuillii, ohngeführ von dem vierten Theile seiner Ilöhe. Im Centrum erscheint die Dentine, aus vertical aufsteigenden Medullarkanälen gebildet, ungeben von der knochenähnlichen Substanz ohne Knochenzellen, in welcher die Markkanälen, d. h. hïufiges Anastomosiren, ein Netz von regelmässigen Maschen bilden. Gegen die Peripherie zeigt sich das schönste Kosmin, in welchem dic Gefässlianäle sich in feine Aeste zerspalten und aus diesen die noch feineren Rölırchen, strahlenförmig dichotomirend und sich verzweigend, in die äusserste Schicht hineindringen. Es scheint wirklich als ob hier die Zahnsubstanz eine Schuppenbedeckung erhalten hat, denn die beiden äusseren, die Dentine ungebenden Schichten, entsprechen in jeder Hinsicht den oberen Schichten der Schuppeı. Den Uebergang von Zähnen zur Schuppe finden wir in der folgenden Abbildung Fig. 9 noch deutlicher. Diese Figur stellt einen verticalen Längsdurchsehnitt der inneren Lamelle der Zilhn- 
platte Fig. 1 ab dar. a. Substanz der Basis mit netzartig verbundenen Medullarkanälen und Zellen. b. eine der vorigen ähnliche Schicht, aber durch stärkeres Anastomosiren der Gefïsskanäle unter einander von ihr unterschieden, c. die obere Kosminschicht.

Fig. 10-14. Dipterus marginalis Agassiz.

Fig. 10. Drei verschiedene Ansichten desselben Zahnes: a. ron oben, b. von unten, c. im Profil.

Fig. 11. Lmriss desselben Zahnes, um die uun folgenden Durchschnitte genauer anzugeben.

Fig. 12. Ein verticaler Querdurchschnitt der Zahuplatte von Dipterus marginalis. In der Riehtung von a nach b Fig. 11 wurde ein Durchschnitt von der oberen Flïche durch die Wurzel gemacht, auf diese Weise fiinf Rippen abgesondert und fein geschliffen; von diesen fiinf sind nur drei gezeichnet. a. die knöcherue Basis mit anastomosirenden Markkanälen und Zellen, c. die drei kleinen Zïlnchen, die ans reiner Dentine bestehen, d. die canalartige Spalte, die der Sitz der Pulpa war. Vielleicht sind in diesem Schliffe die Wäıde. die die einzelnen unter den Rippen verlaufenden Kanïle von einander tremen, zerstört worden, vielleicht erstreckt sich die Pulpa als cine zusammenhängende Höhle unter der ganzen Kauplatte bei dieser Species, nach hinten sind die Kanäle bestimmt von einauder gesondert, wie wir in

Fig. 13 sehen. Verticaler Durchschnitt gleich dem Vorigen, aber am hinteren Rande derselben Zahuplatte in der Richtung von e nach d. a. Knochenartige Basis mit Markkanälen und Zellen. c. Dentine, die aber noch nicht das Ansehen der dieser Species eigenthïmlichen Zahnsubstanz lat und sich zu dieser verhält, wie die in Fig. 7 gleichfalls rom linteren Rande des Dipterus Vernevillii abgebildeten, zu der in Fig. 6 dargestellten. d d d. Querdurchschnitte der drei Längskanäle, die unter den drei Rippen verlanfen.

Fig. 14. Horizontaler Selnitt des Knochens, auf welchem die Zahnplatte von Dipterus marginalis aufsitzend gefunden wurde, welche den unter denselben liegenden Aesten des Unterkiefers angehörte.

Fig. 15-19. Schuppen von Dipterus platycephahus.

Fig. 15. Ein Stück einer Schädelschuppe von den Ufern des Wolchow.

Fig. 16. Eine Schuppe vom Schädel desselben Fisches von Kokenhusen, beide in gleicheın Maassstabe vergrössert.

Fig. 17. Ein verticaler Schnitt dureh dic ganze Schuppe, die vom Wolchow herstannte. a. Isopedin aus horizontalen parallelen über einander gelagerten Lamellen gebildet, mit Knochenzellen die eine älınliche Schichtung zeigen, von vertical aufsteigenden Markkanälen durclızogen. b. Mittlere Schicht, aus anastomosirenden netzartigen Maschen bildenden Gefässen bestehend. c. die oberste Schicht, in welcher die heraufsteigenden Markkanäle d auf der Oberfläche ausmünden, und dic Zwischenräume zwischen diesen Poren durch Kosmin d. h. durch eine Auflösung der grösseren Gefïsse in Aeste und Zweige gebildet werden.

Fig. 18. Ein dünner Schliff unmittelbar unter dem Kosmin, mit der äusseren Oberlläche fast parallel angefertigt, um das Gefässnetz, die zweite Schicht deutlich zu zeigen.

Fig. 19. Ansicht von der Oberlläche selbst, nachdem die unteren Schichten abgesehliffen waren, um die Oeffnungen der Poren zu zeigen.

Fig. 20-22. Dipterus tuberculatus.

Fig. 20. Obere Ansicht von der Zahnplatte von Dipterus tuberculatus, a. natürliche Grösse, b. vergrössert, c. eine einzelne Zahureihe um die Stellung der kleinen Zähnchen zu einander darzustellen.

Fig. 21. Verticaler Durchschnitt von zwei neben einander stehenden Zïlhnchen auf ihrer Basis ruhend, a. die knöcherne Basis, die in den Zwischenraum zwischen den beiden Zähnen hinaufgeht und sie bei b von 


\section{$-60-$}

einander trennt. c. Dentine, aus grossen sich verästelnden und anastomosirenden, lange Maschen bildenden, Markkanälen gebildet, die im Innern und gegen die Peripherie in feine Aeste und Zweige sich spalten. Die Zahnsubstanz von Dipteris tuberculatus ist zun Verwechseln derjenigen ähnlich, der die innere Dentine bei Dipt. Verneuilii (vergleiche Fig. 6 und 8) umgiebt und hat ganz die Structur der oberen Schichten einer Schuppe. Die Zïhne von Dipt.tuberc. sind nichts anderes, als hervorragende Spitzen der Schuppen desselben Thieres, ohne Porenöfnungen auf der Oberfläche.

Fig. 22. Forizontaler Schnitt der knöchernen Basis, aus der Milte genommen.

Fig. 1-14. Holodus Kiprïanowi.

Tafel VI.

Fig. 1. Der vordere Theil des Schädels von Holodus Kiprijanowi von unten betrachtet. a a. Der vordere glïnzende emailartige Rand der Sclnautze, welcher von den Seiten derselben sich in zwei Aeste ab und ak, die nach hinten divergirend aus einander gelien, spattet. $\mathrm{c} d \mathrm{~d}$. Die hinteren Ränder der Gaumenknochen, die unter die Zahnplatten sich fortsetzen und von ilmen auf der unteren Fläche bedeckt werden. e. Die Zahnplatten, auf welchen zu beiden Seiten der Zahn f vertical aufruht. g. Der nach innen unả hinten umgebogene Theil des vorderen Endes der Schnautze, am vorderen Rande mit kleinen Tuberkeln besetzt. Zwischen den beiden divergirenden Sclienkeln dieses Uinschlages fügt sich eine kleine Platte hinein, die man als dem Vomer analog betrachten kann. i. Eine kleine nach vorn hervorragende Spitze des Schnautzenrandes. Natürliche Grösse. Orel.

Fig. 2. Derselbe Kopf von oben angesehen, der hiutere Theil ist abgebrochen, so dass die Gaumenknochen von ihrer oberen Fläche sichthar werden.

Fig. 3. Derselbe Kopf im Profil, die Buchstaben wie oben. In dieser Richtung sieht man den Zahn $f$ in seiner verticaten Stellung.

Fig. 4. Längsdurchschnitt desselben Kopfes in der Mitte, un die Verschiedenheit zwischen den Knochen und dem vorderen Zahnrande, so wie dessen Ankylose zu zeigen, vergrïssert. In der Substanz, der zu einem einzigen Stück zusammengewachsenen Kopfknochen, zeigen sich schon in diesem Durchsclnitte die grossen, jetzt mit Kalksteinen, im frischen Zustande wahrscheinlich mit Knorpel, angefüllten grossen Räume, von Knochenlamellen eingefasst.

Fig. 5. Zahn mit Zahuplatte von innen gesehen, a. natürliche Grösse, b. vergrössert, f. ein kleiner Nebenzalın, m. Zahnplatte.

Fig. 6. Derselbe Zahn von aussen angesehen, a. nat. Grösse, b. vergrössert, m. die Zahnplatte, 1. kleine Platten, die die Basis von aussen umgeben, f. Basis des Zahnes.

Fig. 7. Ein Stück des Schädeldaches unter der Loupe vergrössert, um die Poren seiner Oberfläche, die von sehr verschiedener Grösse und sehr unregelmässig gestellt sind, zu zeigen.

Fig. 8. Längsdurchschnitt des vorderen Kieferrandes der Schnautze mit dem ihn einfassenden Knochen. a. Die knochenarlige Substanz des Schädełdaches, die aus einem Netz von Gefässen und Zellen bestelı, b. die deı Kieferzahn umgebende, der vorigen ähnliche Substanz, aber ohne Zellen, c. die Dentine aus vertical aufsteigenden feinell, unter spitzen Winkeln dichotomirenden Markkanälen gebildet, von denen die feinen Zalnnröhrchen nach alleı Seiten ausstrahlen.

Fig. 9. Ein Lïngsdurchschnitt durch die Mitte der Krone des Zahnes Fig. 3 f.

Fig. 10. Verticaler Durehschnitt der kı̈̈chernen Substanz des Schädeldacles. Leider hat dieser Durchschnitt 
keinen von den Poren des Kopfes berihrt und ihr Bau ist daher in dieser Zeichnung nicht angegeben worden. Wir müssen deshalb auf Fig. 13 diesər Tafel und auf eine folgende Tafel rerweisen. a. die in die Tiefe dringenden Fortsetzungen der Kıochensubstanz, nur aus über einander liegenden durchsichtigen Lamellen bestehend, ohne Knochenzellen. Die dünnen Wïnde, vielfach gewunden und geschlïngelt, bilden geschlossene Höhlen, die jetzt mit Kalkstein angefïlt sind. b. Die mittlere Kunochensubstanz mit länglichen, nach allen Richtungen unregehmässig gestellten Zellen, ohne strahlige Ausläufer. c. Die obere Kosminschicht.

Fig. 11. Vertlcaler Durchschnitt des, den oberen Rand der seitlichen Grube ron oben begrenzenden Fortsatzes ab, des vorderen Schnautzenrandes a a. - Die feinen Röhrchen strahlen bündelförmig aus den Verïstelungen der Medullarkanäle gegen die Oberlläche limauf und bilden ein wahres Kosmin.

Fig. 12. Horizontaler Schnitt der mittleren knochenartigen Substanz des Schädeldaches, in der Gegend von b Fig. 10 genommen.

Fig.13. Ein horizontaler Schliff der oberflächlichen Schicht des Schädeldaches, in der Gegend von c Fig. 10 genommen. a. Die Oeffnungen der Kanïle, die auf der Oberflïche erscheinen und in die Substanz des Knochens, bis zu einer gewissen Tiefe, eindringen. Sie werden von besonderen hellgelben kreisrunden Wänden eingefasst.

Fig. 14. Horizontaler sehr feiner Schliff rom Gáumenknochen, der aus wirklichem Kinochen bestehı, die grösseren und feineren Gefässkanäle sind horizontal und schräg durchschnitten und werden von concentrischen Lamellen umgeben, deren Richtung die Knochenzellen mit ihren strahligen Ausläufern folgeo.

Fig. 15-22. Cheirodus Jerofejewi.

Fig. 15. Ansicht des Gaumenzahmes der ersten Seite von Cheirodus Jerofejewi von oben, von a nach vorn der innere, bd der äussere, ab der hintere, de der vordere äussere Rand. Voin hinteren, längst dem inneren Rande, zieht sich naclı vorn eine abgestumpfte erhabene Fläche hin und von dieser aus bildet die Platte nach aussen und vorn eine concave Kaufläche. Von Herru Oberstlieutnant Jerofejew am Wolchow gefunden.

Fig. 16. Derselbe Zahı von der unteren Fläche.

Fig. 17. Derselbe Zahn im Profil, von aussen angesehen.

Fig. 18. Ein Zahn des Unterkiefers von derselben Species vom Scias. mit convexer Oberfläche von der linken Seite.

Fig. 19. Ein verticaler Längsdurchschnitt in der Nähe des immeren Randes, aus der Gegend von g Fig. 15 genommen. In der knöchernen Substanz der Basis erschemen unter den vertical hinaufsteigenden, durch lırizontale Queräste mit einander verbundenen, gedrüngt an einander stehenden Markkanälen, einzelne grössere, in regelmässigen Entfernungen, die als die eigentlichen Hauptkanäle der Zähne, aus denen die obere Zahnplatte besteht, zu betrachten sind. Ihre dentinische Spaltung in einer gewissen vorgeschriebenen Höhe a a, ihr netzartiges Gewebe mit langgezogenen Maschen und ihre feineren Verästelungen gegen die Oberlläche, so wie das Ausstrahlen der feinen Zahnröhrchen aus ihnen, ist deutlich. Sie werden von einander durch eine der Basis ähnliche, mit Knochenzellen versehene Substanz, bis zu einer gewissen Höhe getrennt.

Fig. 20. Ein verticaler Querschnitt durch eine Rippe der Zahnplatte an ihrem vorderen Rande. In der Mitte der Zeichnung ragt die Rippe lıervor und von ihr aus neigt sich die Oberlläche zu den anliegenden Vertiefungen hinab. Unter der Loupe gesehen.

Fig. 21. Dasselbe Prïparat fein geschliffen, unter dem Mikroskop betrachtet. Aus einem, der unteren Fläche 
der Basis nälıer gerücktem Centrum, strahlen die Mlarkkanäle nach allen Seiten, obgleich durch häufige Anastomosen unter einander verbunden, und gegen die Oberfläche der Rippe aus, und gehen in letzteren, in die eigentliche Dentine über; lier rerlieren sich die Knochenzellen gänzlich und die Markkanäle mehmen einen langgestreckterr, verticalen Verlauf an Nach den Seiten, d. h. gegen die Vertiefungen der Buchten der Kaufläche behält die Substanz, die der Basis bei, die Knochenzellen erstrecken sich bis zur oberen Fläche und schliessen die letzten feinen Endigungen der Markkanäle, die von einem helleren Hof, einer homogenen Grundsubstanz umgeben werden, von allen Seiten ein. Man sieht hier im Kleinen eine Wiederholung der Zahnbildung im Grossen und kann jedes kleine Aestchen, als einen besonderen Zahn von Knochensubstanz eingefasst, betrachten. Wem nicht sur die hervorstehenden Rippen, sondern auch die sie von einander trennenden Buchten bei Cheirodus zur Verkleinerung der genossenen Nalırungsmittel angewandt werden, so gesclieht dieses durch wirkliche Kinochen mit Knochenzellen.

Fig. 22. Ein horizontaler feiner Schliff von dem linteren Theile der Zahnplatte, ohngefähr von derselben Stelle, voll wo der Schnitt Fig. 19 gemacht wurde, so dass die einzelnen Zähnchen in der Quere von a a Fig. 19 durchschnitten und daher noch von Knochensubstanz umgeben sind. Ein fast in der Mitte der abgeschliffenen Lamelle sich befindender Zahn, wird ron allen Seiten vou ähnlichen umgeben.

\section{Tafel VII.}

Fig. 1. a. Concave Zahinplatte von der rechten Seite des Gaumens mit dem unterliegenden Gaumenknochen von Dipterus kieyserlingii. Orel. Nat. Gr. b. Seitliche Ansicht einer zalıntragenden Rippe, vergrössert. c. Ein verticaler Durchschnitt zweier neberreinander stehenden Zahnrippen von demselben, unter der Loupe gesehen. d. Derselbe Durchschnill sehr fein geschliffen, unter dem Mlikroskop betrachtet, aa die durchschnittenen Kanäle, b b b die knöcherne Substanz der Basis. c c die kleinen Zähnchen. e. Ein horizontaler Durchschnitt eimes kleinen Zühnchens von derselben Zahnplatte, man sieht hier das so äusserst feine Gewebe der Zahnröhrchen, die fast alle durchschuitten sind.

Fig. 2. Convexe Zahnplatte der linken Seite des Unterkiefers von Dipterus Murchisoni, ein junges Individuum. Optucha. Nat.Gr. a vorr vorn, b. von oben, c. in Profil von binten. d. ein lorizontaler Schnitt eines kleirren Zähnchens, in welchem die einzelnen Systeme der liarkkanäle von den benachbarten getrennt, deullich zu sehen sind.

Fig. 3. Convexer Lnterkieferıahn der rechten Seite von Dipterus Murchisoni, ein älteres Individuun Orel. Nat. Gr. a. von vorn, b. von oben, c. im Profil von hinten gesehen.

Fig. 4. Gaumenknochen mit Zähnen ron Dipterus Murchisoni. a. die nebeneinander liegenden Zahnplatten. b. die ossa palatino-pterygoidea, zwei längliche vertical stehende Knochenplatten, dem os sphenoideum entsprechend, zwei in der Mittellinie sich berülrende kleine Knocheuplatten, durch tiefe Furchen von den übrigen Kinochen gesclieden. Orel. Nat. Gr.

Fig. 5. Ein Abdruck eines os sphenoideum des Dipterus platycephalus aus der Schiefern von Pomona. Nat. Gr. Fig 6. Dipterus marginalis Ag. mit einem Fragmente vom Gaumenknochen von der rechten Seite. Orel. a. $\Lambda$ usicht ron oben, nat. Gr., b. rergrössert, c. Seitenansicht einer zahntragenden Rippe.

Fig. 7. Eïi anderes Exemplar derselben Species rom Gaumenknochen der linken Seite, mit den linteren concentrischen Furchen, welche nach Agassiz den Charakter der Species bilden sollten. Orel. a. Ansicht 
von oben in natürlicher Grösse, b. vergrössert. Der entgegengesetzte Zahn vom Unterkiefer ist aul Tab. 5 Fig. 10 und 11 abgebildet und dessen mikroskopische Structur in Fig. 12-14.

Fig. 8. Gaumenzahnplatte der rechten Seite ron Dipterus radiatus Eichw. (Ctenod. Mörthii Agass.). Marin: bei Zarskoje Celo. a. Ansicht von oben in natürlicher Grösse, b. vergrössert, c. Seitenansicht einer zalıntragenden Rippe.

Fig. 9. Unterkieferzahn derselben Species von der rechten Seite. a. Ansicht von vorn. Nat. Gr. b. vergrössert. Marina.

Fig. 10. Dipterus glaber. A. Ansicht von oben, B. von der inneren Seite, C. Ansicht von vorn, D. dieselbe vergrössert, von den Lfern des Wolchow. E. Ein verticaler Durehschnitt in der Richtung von d bis e Fig. D. d. Spitze der zahntragenden Rippe aus Dentine gebildet, in welcher die heraufsteigenden, mit feinen Zahnröhrchen umgebenen Markkanäle erseheinen; von e bis $\mathrm{K}$ die am Vorderrande der Zahnplatte hervorstehenden kleinen Tuberkel, die zu Zähnchen nmgewandelt werden, un später sich an die sehoı fertig ausgebildeten Rippen anzuschliessen, in verschiedenem Grade der Entwichelung.

Fig. 11. Seitenansicht einer zahntragenden Rippe von Dipterus platycephalus. Gaunenzalın. Selotland.

Fig. 12. Ein Zahn von Helodus (Psammodus) aus den devonischen Schichten des Tulaschen Gouvernements. at. von oben, b. von unten, c. im Profil, d und e. Oberflächenansicht von zwei solchen Zähnen, die sich durch die Zahl und Stellung der Oeffnungen der Medullarkanäle auf der Oberllïche unterscheiden, vergrössert. f. Ansicht von der unteren Fläiche, vergrössert. g. Fin verticaler Durchschnitt desselben Zahues. h. Ein horizontaler, in welehem die einzeluen von einander getrenuten Systeme der Mledullarkan̈̈le sichıbar sind. Fig. 13. Eine Platte oder äusserer linochen von IJolodus. Orel. a. Ansicht von oben. Nat. Gr. b. ein Stïck vou der Oberfläche, vergrösselt. c. ein verticaler Durchschnitt. d. ein einzelner Kanal vergrössert, 'un die Hincinsenkung des Ganoins in denselben zu zeigen. e. ein horizontal etwas schräg geschliffener Durchschnitt.

\section{Tafel VIII.}

Fig. 1-13. Verschiedene Ansichten von den Zähnen des Ptyctodus.

Fig. 14-22. Versehiedene Durehschnitte desselben Zahns, uuter der Loupe gesehen.

Auf dieser Tafel sind eine grosse Anzahl Zïlhe von den Oberflïchen und den Seiten abgebildet; bei den meisten waren die seitlichen Wände zerstört und man kann daher die Lamellen, aus denen die Zähne bestehen, vom hinteren bis zum vorderen Rande verfolgen, wic namentlich in Fig. 1 c, Fig. 2 c, Fig. II b und $d$ und an besten in den vergösserten Ansichten, Fig. 11 h und Fig. 13. Nehrere waren indessen ganz vollstïndig erhalten und die Lamellen-Schichtung durch eine, die äusseren Wände bildende glatte glïnzende Platte, verdeckt, wie bei Fig. $4 \mathrm{c}$ und d, Fig. 12 a und b. In Fig. $10 \mathrm{c}$ ist ein Theil der äusseren Wand zerstört und man erkennt die lamellen unten und hinter der wolerlaltenen Platte. In den Ansichten von oben und unten, wie in Fig. 1 a und b, noch deutlicher in Fig. 4 a und b, Fig. 7 a und c, von oben in der vergrösserten Zeichnung Fig. $11 \mathrm{~g}$ u. s. w. sieht man die Querreihen der Poren, den Oeffnungen der Medullarkanäle, welche die harten Lamellen von einander scheiden, nur bei dem einzigen ziemlich gut erlaaltenen Exemplare, das in Fig. 10 abgebildet ist, erscheinen die Poren auf der Fläche der Basis nicht, sondern eine glatte concave Platte verdeckt sie, und es wäre thaher wol möglich, dass diese bei allen übrigen zerstört wäre.

Obgleich in den auf dieser Tafel abgebildeten Exemplaren eine grosse Verschiedenheit in der Gestalt nicht zu verkennen ist und nicht nur die verschiedenen Dnrchmesser der Zähme variiren, sondern auch ihre äussere 
Gestalt manchen Veränderungen unterworfen ist, bei manchen die Oberflïche mehr oder weniger convex, bei anderen schwach concav ist, diese bald eine ebene Fläche darbietet, bald nach forn in einen hervorragenden Höcker übergeht, so ist es doch sehr schwer nach ilınen die Species zu bestimmen, denen sie angehörten, wenn wirklich davon mehrere vorhanden waren Wir wissen nicht einmal ob der Rachen des Thieres, wie bei den Chimaeren und Gymnodonten nur mit einer geringen Anzahl solcher Zahuplatten besetzt war oder ob mehrere Reihen derselben pflasterartig neben einander lagen. Die Kauflächen, wie die der Basis geben zu geringe Unterschiede und die mikroskopische Structur gar keine an, um die verschiedenen Species genau von einander zu trennen. Wir können indessen doch zwei Formen mit grosser Wahrscheinlichkeit von einander trenren.

Plyctodus obliquus. Zähne schmal nach hinten breiter, nach vorn spitzer zulaufend und die vorderste Spitze nach unten und gegen eine Seite gewandt. Zu dieser Form nehmen wir alle Abbildungen, ausgenommen Fig. 10 und Fig. 12, bei denen letzteren die Seitenwände mehr parallel unter einander verlaufen und die vordere Spitze statt hinuntergebogen, hakenartig hinaufsteigt und dalıer Ptyctodus ancinnatus heissen mag.

Die grosse Anzahl von Abbildungen, die wir von einzelnen Theilen dieser Zïhne, sowol unter der Loupe betrachtet, als unter deın Mikroskope, nach feinen Schliffen gegeben haben, sollen dazu dienen, an den geringsten Bruchstücken dies Genus wieder zu erkennen. Das plötzliche Auftreten, wie das plötzliche Verschwinden dieses Geschlechtes, wodurch die Wichtigkeit der genauen Kenntniss desselben in geognostischer Hiusicht, als ein wahrer Leiter für die mittlere Kalkschichten des devonischen Systemes in Russland herrorleuchtet, ist äusserst merkwürdig. Sein ephemeres Erscheinen in einer so frühen Periode erregt gleichfills in zoologischer Hinsicht ein grọsses Interesse, da, allem Anscheine nach, noch jetzt lebende Wesen sich ihm anzuschliessen scheinen, was wol bei dem grössten Theil seiner Zeitgenossen schwerlich der Fall sein möchte.

Auf Taf. 8 sind in den Fig. $14-22$ verschiedene Durchschnitte abgebildet, wie sie unter der Loupe erscheinen. Fig. 14 und Fig. 17. Senkrechte Querdurchschnitte am hinteren Ende des Zahnes.

Fig. 15 und 16. Aehnliche Durchschnitte der Mitte und dem vorderen Rande nälıer gemacht.

Fig 18. Ein verticaler Durchschnitt in der Ebene der Lamellen.

Fig. 19-21. Längsschnitte in der Mitte und am äusseren Rande.

Fig. 22. Ein horizontaler Querdurchschnitt.

\section{Tafel IX.}

Fig. 1. Vergrösserte Seitenansicht vom hinteren Theile.

Fig. 2. Ansicht voll unten ron demselben Stücke.

Fig. 3. Dasselbe Stiick ganz im Profil.

Fig. 4. Querschnift rom linteren abschüssigen Rande.

Fig. 5. Derselbe, fein geschliffen, unter dem Mikroskope gesehen.

Fig. 6-14. Verschiedene verticale und Lorizontale Durchschnitte in sehr feinen Schliffen, unter dem Mikros-

kope, unter verschiedener Vergrösserung, gezeichnet.

Fig. 10. Ein horizontaler Schliff von der oberen Fläche.

Fig. 12. Derselbe stärker und Fïg. 11 noch stärker vergrössert.

Fig. 14. Ein ähnlicher Schliff, der Basis näher. Die einzelnen Poren gehen in Querspalten über.

Fig. 13. Ein verticaler aber schrïg geschliffener Durchschnitt

Fig. 6, 7, 8, 9. Horizontale Schliffe von verschiedenen Stellen, sehr sturk vergrössert. 


\section{D) u c la fe li l e r.}

\begin{tabular}{|c|c|c|c|c|c|c|}
\hline te & 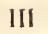 & $e$ & 1 & F. II & Tes & 1. \\
\hline ont & VII & , & 1 & จ. 0. & . & die, die die \\
\hline & VII & D & 13 & 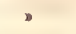 & , & Plagiostomen \\
\hline & 1 & - & 5 & v. u. & - & mehrere \\
\hline & 1 & - & 2 & $\triangleright$ & 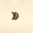 & Oolitic \\
\hline & 4 & - & 9 & , & 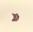 & allen \\
\hline & 5 & D & 9 & จ. 0. & , & Cephalaspiden \\
\hline & $\mathfrak{j}$ & 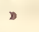 & 7 & v. 11. & , & Bezeichnungen \\
\hline & 6 & D & 14 & 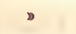 & $\bullet$ & abgestumpfi \\
\hline & 7 & " & 3 & v. 0. & 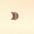 & , nehm \\
\hline D & 7 & , & 3 & 》 & 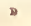 & letzterer \\
\hline 》 & 7 & • & 11 & v. u. & D & rerletzt \\
\hline , & 7 & D & 11 & 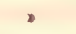 & 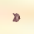 & dieselt \\
\hline 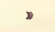 & 7 & D & 9 & D & » & den \\
\hline - & 9 & D & 3 & r. 0. & $\triangleright$ & den \\
\hline D & 9 & D & 5 & , & , & die \\
\hline » & 9 & » & 12 & • & , & Aspredo \\
\hline • & 10 & - & 12 & v. u. & , & nur \\
\hline - & 10 & - & 1 & - & , & oder \\
\hline - & 11 & & 18 & 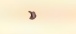 & , & dagestellt \\
\hline 》 & 12 & $\triangleright$ & 15 & • & . & Begrenzung \\
\hline 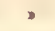 & 16 & - & 11 & $\triangleright$ & , & aber \\
\hline b & 16 & $\triangleright$ & 1 & D & - & nur \\
\hline
\end{tabular}

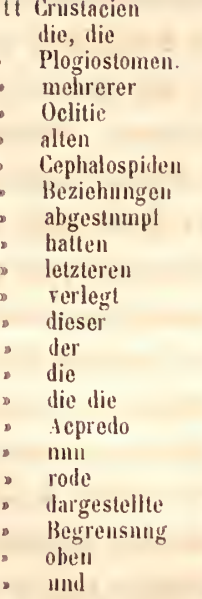

\begin{tabular}{|c|c|c|c|c|c|c|}
\hline & 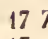 & eile $6 \mathrm{r}$. ॥ & & sto & tall & \\
\hline - & 17 & $\Rightarrow 6$. & - & rom & . & roll \\
\hline , & 19 & 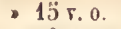 & , & den & , & der \\
\hline s & 21 & 6 г.u. & , & liegender & , & liegenden \\
\hline . & 24 & $=9$ г. 0. & , & len jiïngereı & . & der jungere \\
\hline - & 24 & $=18$ & - & d'accroissement & & d'acraissement \\
\hline - & 26 & $.13 \mathrm{~N}$ & , & rorherrschend & . & vorherrschemden \\
\hline , & 26 & $=5$ r. 1. & - & Bitumen & 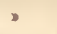 & Betımen \\
\hline . & 27 & , 3 r. 0. & , & zul denen & . & der \\
\hline . & 27 & $" 10$. & , & aussen & 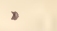 & ser \\
\hline , & 28 & - $1 \mathrm{r.} 11$. & , & nur & - & nnd \\
\hline D & 29 & $=11.0$. & - & beiden & & bei den \\
\hline 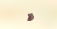 & 33 & $\Rightarrow 6 \mathrm{v} . \mathrm{u.}$ & $v$ & zweier & . & $2 W$ \\
\hline , & 34 & $\Rightarrow 3$ พ.0 & , & Bipterus & , & Diptenus \\
\hline ” & 41 & .12 & ע & über & » & briber \\
\hline , & 42 & $.22 "$ & - & geschlossene & × & geschlossenen \\
\hline , & 43 & $=40$ & . & einzelı & - & einzelne \\
\hline 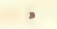 & 43 &, 10, & , & dies & - & dis \\
\hline$n$ & 48 & $\Rightarrow 8 \mathrm{r.1I}$. & , & hintere, & , & hintere \\
\hline , & 51 & $10 \mathrm{r.o}$ & , & Gonvernement & , & Gourernements \\
\hline , & 51 & .13 & , & Gourernement & D & Gouvernements \\
\hline - & 33 & $\times 3$. & - & brachypygopterus & s. & beachypggopterus \\
\hline 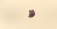 & .33 & 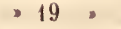 & , & comprimint & 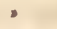 & compact \\
\hline
\end{tabular}




